\title{
A REVISION OF THE DIDELPHID MARSUPIAL GENUS MARMOSOPS, PART 1. SPECIES OF THE SUBGENUS SCIOPHANES
}

\author{
JUAN F. DÍAZ-NIETO \\ Department of Ecology, Evolution, and Behavior; and \\ J.F. Bell Museum of Natural History, \\ University of Minnesota \\ ROBERT S. VOSS \\ Division of Vertebrate Zoology (Mammalogy), \\ American Museum of Natural History
}

BULLETIN OF THE AMERICAN MUSEUM OF NATURAL HISTORY

Number 402, 70 pp., 28 figures, 11 tables

Issued May 11, 2016 


\section{CONTENTS}

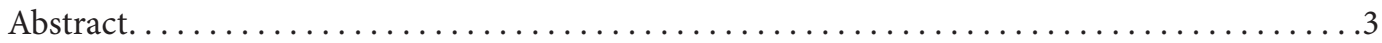

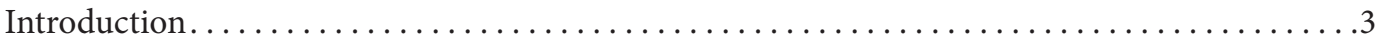

Materials and Methods ..........................................

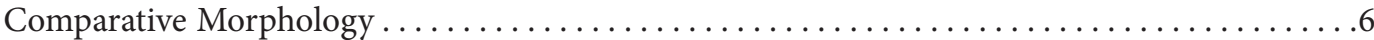

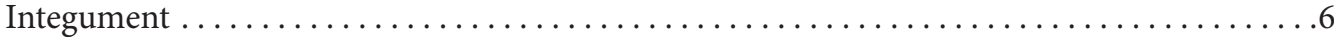

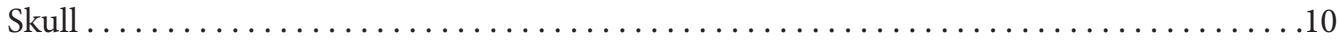

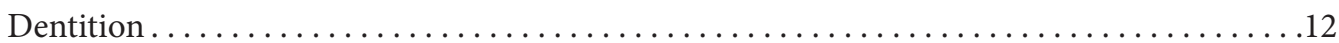

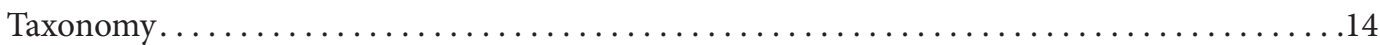

Genus Marmosops Matschie, 1916 ................................... 14

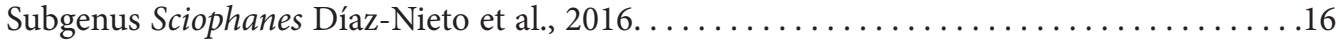

Species of the Parvidens Group...................................... 17

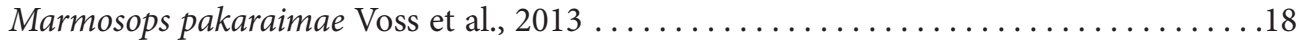

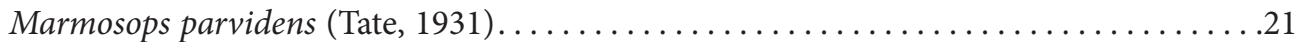

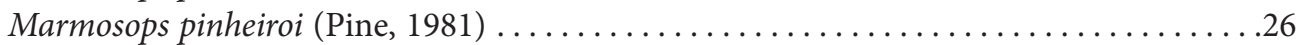

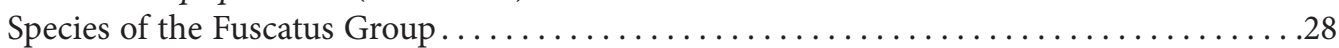

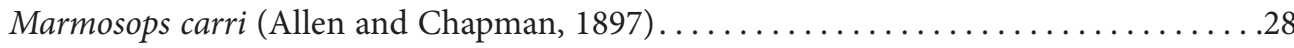

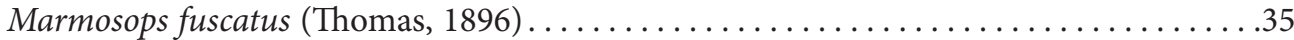

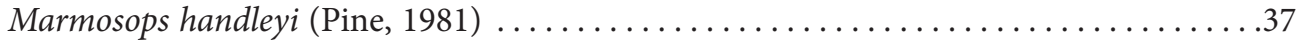

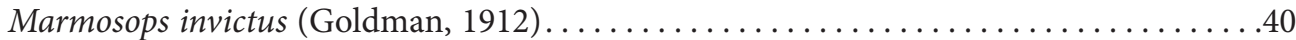

Species of the Bishopi Group ...................................... 42

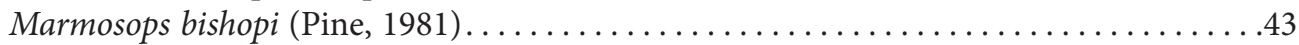

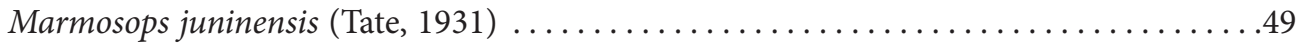

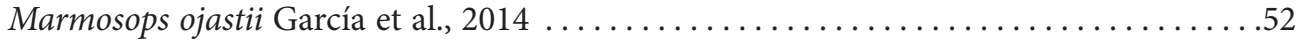

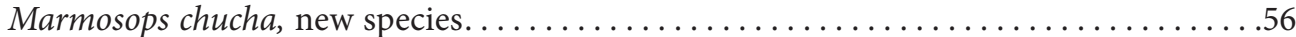

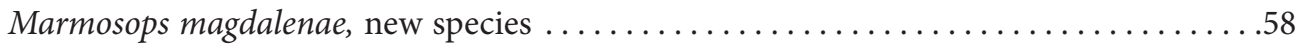

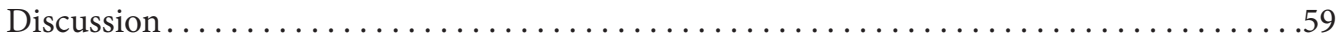

Acknowledgments . . . . . . . . . . . . . . . . . . . . . . . . . . . . . . . . 60

References ...................................................60

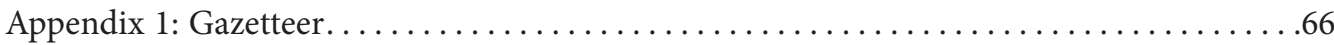




\begin{abstract}
In this report, the first installment of a comprehensive revision of the didelphid marsupial genus Marmosops, we revise the species of the subgenus Sciophanes. Based on morphological character variation among almost 300 examined specimens-which we interpret in the context of a previously published analysis of molecular sequence data-this revision recognizes 12 valid species in three monophyletic species groups: the Parvidens Group (including M. pakaraimae, M. parvidens, and M. pinheiroi), the Fuscatus Group (M. carri, M. fuscatus, M. handleyi, and M. invictus), and the Bishopi Group (M. bishopi, M. juninensis, M. ojastii, and two new species). For each species we summarize information about type material, ecogeographic distribution, and diagnostic morphological characters. Despite our diligent search for relevant material in North and South American museums, the absence of any specimens of Sciophanes from vast Amazonian and Andean landscapes with seemingly suitable habitat suggests that significant range extensions and/or new species will result from future inventory fieldwork.
\end{abstract}

\section{INTRODUCTION}

Members of the genus Marmosops are small ( $<200 \mathrm{~g}$ ) didelphid marsupials that collectively range from eastern Panama to southern Bolivia and southeastern Brazil. Black-masked, longtailed, and pouchless, they were classified for many years in the genus Marmosa along with other superficially similar taxa (e.g., by Tate, 1933; Cabrera, 1958). However, subsequent morphological and molecular research (reviewed by Voss et al., 2004; Voss and Jansa, 2003) has shown that the species referred to Marmosops by Matschie (1916), together with those later referred to the genus by Gardner and Creighton (1989), form a strongly supported monophyletic group that is not closely related to Marmosa (sensu stricto). Instead, Marmosops is now placed in the didelphine tribe Thylamyini, a clade that also includes Chacodelphys, Cryptonanus, Gracilinanus, Lestodelphys, and Thylamys (Voss and Jansa, 2009).

Unlike most other thylamyines, which occur in dry forests, savannas, grasslands, and highlatitude deserts, species of Marmosops typically inhabit humid-forest habitats. In particular, the genus is widespread-perhaps ubiquitous-in cis-Andean lowland rain forests (Mustrangi and Patton, 1997; Patton et al., 2000; Voss et al., 2001), and it also occurs in premontane and montane rain forests of the Andes, the Venezuelan coastal cordilleras, and Pantepui (Díaz-N. et al., 2011; Voss et al., 2013; García et al., 2014). Insofar as known, these are scansorial opossums that are primarily active on the ground and within a few meters of the ground in understory vegetation (Malcolm, 1991; Patton et al., 2000; Voss et al., 2001; Cunha and Vieira, 2002; Vieira and Monteirho-Filho, 2003; Loretto and Vieira, 2008), where they apparently forage for arthropods (mostly insects) and fruit (Passamani, 1995; Leiner and Silva, 2007; Lessa and Costa, 2010). At least in the Atlantic Forest of southeastern Brazil, species of Marmosops appear to be semelparous breeders that experience almost complete postreproductive mortality, such that successive adult generations are nonoverlapping (Lorini et al., 1994; Leiner et al., 2008).

The genus as a whole has never been revised, although taxonomic analyses of specimens collected in the course of regional faunal surveys have contributed numerous insights (Mustrangi and Patton, 1997; Voss et al., 2001, 2004, 2013; Díaz-Nieto et al., 2011; García et al., 2014). The current classification formally recognizes 17 valid species of Marmosops, a total that includes the 15 species recognized by Gardner and Creighton (2008) and two others subsequently described as new (Voss et al., 2013; García et al., 2014). Among 
other didelphid genera, only Monodelphis (with 22 currently recognized species; Pavan et al., 2014; Pavan, 2015) and Marmosa (with 19 species; Voss et al., 2014) are comparably diverse.

Although molecular sequence data have been analyzed in a few taxonomic studies of Marmosops (e.g., by Mustrangi and Patton, 1997; Patton et al., 2000; Voss et al., 2004, 2013), much of the current nomenclature is based exclusively on phenotypic comparisons. Unfortunately, the morphology-based primary taxonomic literature is inadequate to confidently identify several species, secondary sources (e.g., field guides and keys) that are routinely consulted for identification purposes are sometimes unreliable, and some currently accepted synonymies are not based on firsthand examination of type material. Not surprisingly, museum specimens of Marmosops are often misidentified.

This report, the first installment of a comprehensive generic revision, is based on a multiyear study of morphological specimens (including all relevant type material), the results of which we interpret in the context of a recently completed analysis of molecular sequence data (Díaz-Nieto et al., 2016a). Among the more robustly supported outcomes of that analysis was the discovery of a basal dichotomy in the genus, resulting in two clades that were formally recognized as subgenera. This report concerns the subgenus Sciophanes, which contains Marmosops parvidens (the type species), and 11 additional species, including two new species.

\section{Materials and Methods}

SPECimens: The morphological specimens we examined and others mentioned below are preserved in the following collections (listed in order of their standard institutional abbreviations): AMNH (American Museum of Natural History, New York), BMNH (Natural History Museum, London), CM (Carnegie Museum, Pittsburgh), CTUA (Colección Teriológica de la Universidad de Antioquia, Medellín), EPN (Escuela Politécnica Nacional, Ciencias Biológi- cas, Quito), FMNH (Field Museum, Chicago), ICN (Colección de Mamíferos Alberto Cadena García, Instituto de Ciencias Naturales, Bogotá), INPA (Instituto Nacional de Pesquisas da Amazônia, Manaus), ISEM (Institut des Sciences de l'Evolution de Montpellier, Montpellier), KU (University of Kansas Biodiversity Research Center, Lawrence), LACM (Los Angeles County Museum, Los Angeles), LSUMZ (Louisiana State University Museum of Zoology, Baton Rouge), MHNUC (Museo de Historia Natural, Universidad de Caldas, Manizales), MSB (Museum of Southwestern Biology, University of New Mexico, Albuquerque), MUSM (Museo de Historia Natural de la Universidad Nacional Mayor de San Marcos, Lima), MVZ (Museum of Vertebrate Zoology, University of California, Berkeley), QCAZ (Museo de Zoología, Pontificia Universidad Católica del Ecuador, Quito), ROM (Royal Ontario Museum, Toronto), UF (Florida Museum of Natural History, University of Florida, Gainesville), UMMZ (University of Michigan Museum of Zoology, Ann Arbor), and USNM (National Museum of Natural History, Washington).

Measurements: We transcribed total length (nose to fleshy tail tip, TL) and length of tail (basal flexure to fleshy tip, LT) from specimen labels, and we computed head-and-body length (HBL) by subtracting LT from TL. We also transcribed length of hind foot (heel to tip of longest claw, HF), length of ear (from notch, Ear), and weight from specimen labels or field notes, but we sometimes remeasured HF on fluid-preserved specimens to check the accuracy of values recorded by the collector, and we used our values whenever large discrepancies were found. (In a few instances we omitted problematic collectors' measurements when computing sample means and observed ranges.) All external measurements are reported to the nearest millimeter $(\mathrm{mm})$, and all weights are reported to the nearest gram $(\mathrm{g})$.

Craniodental measurements were taken with digital calipers as skulls were viewed under low $(6-12 \times)$ magnification. Measure- 

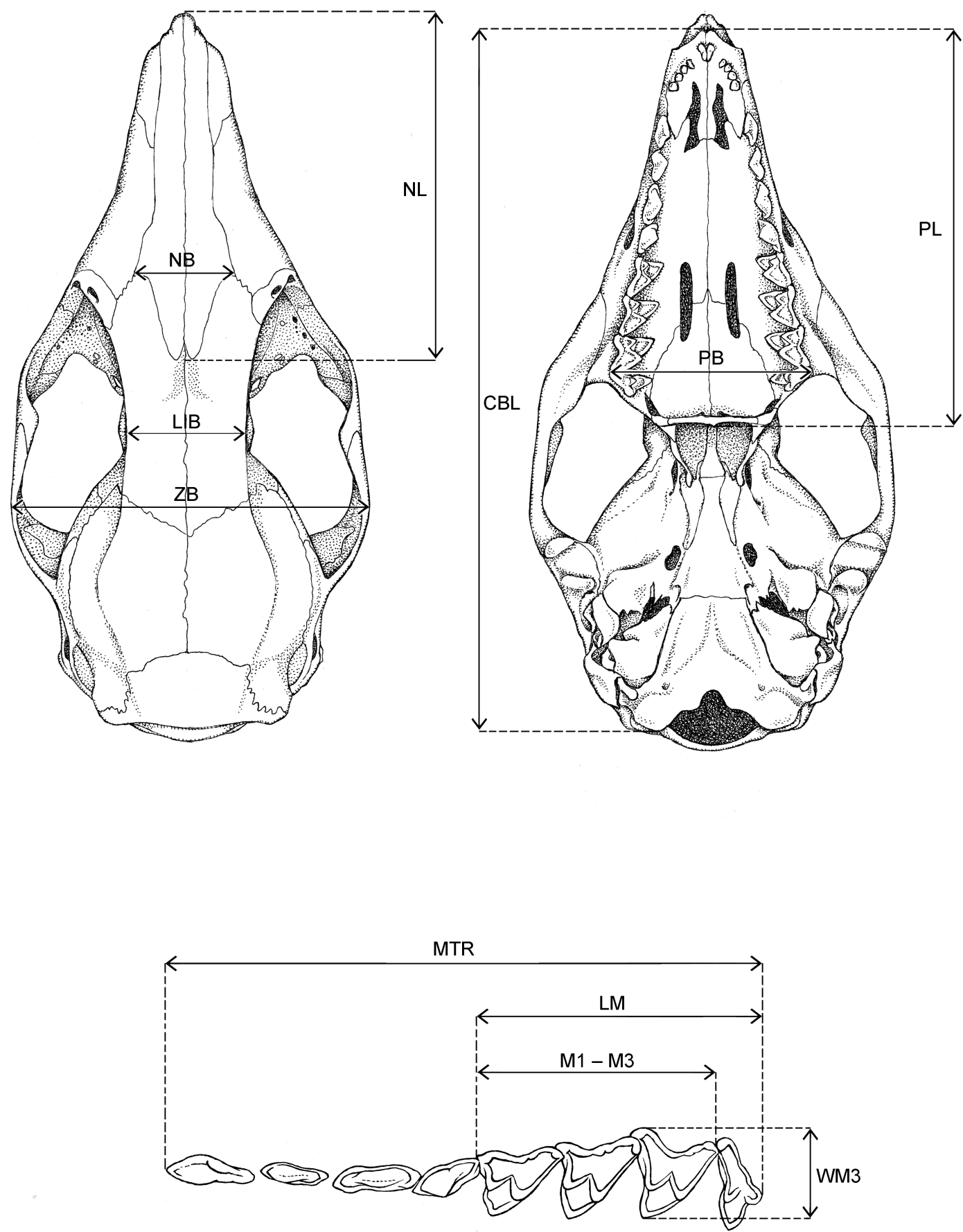

FIG. 1. Dorsal and ventral cranial views and occlusal view of the maxillary dentition of Marmosops pinheiroi, showing the anatomical limits of 11 craniodental measurements defined in the text. 
ment values were recorded to the nearest 0.01 $\mathrm{mm}$, but those reported herein are rounded to the nearest $0.1 \mathrm{~mm}$. The following dimensions were measured (fig. 1):

Condylo-basal length (CBL): measured from the occipital condyles to the anteriormost point of the premaxillae.

Nasal length (NL): the greatest anteroposterior dimension of either bone.

Nasal breadth (NB): measured between the triple-point sutures of the nasal, frontal, and maxillary bones on each side.

Least interorbital breadth (LIB): measured at the narrowest point across the frontals between the orbits, even when the postorbital constriction (between the temporal fossae) is narrower.

Zygomatic breadth (ZB): measured at the widest point across both zygomatic arches.

Palatal length (PL): measured from the anteriormost point of the premaxillae to the postpalatine torus, including the postpalatine spine (if present).

Palatal breadth $(\mathrm{PB})$ : measured across the labial margins of the M4 crowns, at or near the stylar A position.

Maxillary toothrow length (MTR): measured from the anterior margin of $\mathrm{C} 1$ to the posterior margin of M4.

Length of molars (LM): measured from the anteriormost labial margin of M1 to the posteriormost point on M4.

Length of M1-M3 (M1-M3): measured from the anteriormost labial margin of M1 to the posteriormost point on M3.

Width of M3 (WM3): measured from the labial margin of the crown at or near the stylar A position to the lingual apex of the protocone.

AgE CRITERIA: Unless otherwise noted below, we recorded measurements and scored qualitative morphological data from adult specimens only. Following Voss et al. (2001), a specimen was judged to be juvenile if $\mathrm{dP} 3$ was still in place; subadult if $\mathrm{dP} 3$ had been shed but P3 was still incompletely erupted; and adult if the permanent upper dentition (I1-I5, C1, P1-P3, M1-M4) was complete. Because dP3 is molariform, juvenile specimens have only two premolariform teeth (P1 and P2) between the upper canine and the first molariform tooth ( $\mathrm{dP} 3)$, whereas adults have three fully erupted premolariform teeth (P1, P2, and P3) between the upper canine and the first molariform tooth (M1).

\section{COMPARATIVE MORPHOLOGY}

Species of Marmosops can be distinguished from one another by qualitative differences in numerous characters of the integument, skull, and dentition. We describe and illustrate these characters in the accounts that follow, using anatomical terminology defined or referenced by Voss and Jansa $(2003,2009)$ and Díaz-N. et al. (2011). For the most part, our usage is consistent with morphological descriptors defined by Brown (1971), Brown and Yalden (1973), Bown and Kraus (1979), and Wible (2003), which should be consulted for relevant explanations and illustrations.

\section{Integument}

Dorsal PELAGe COLOR: As in many other groups of small nocturnal mammals, dorsal pelage color exhibits a limited range of variation among species of Marmosops. In general, the species treated in this report are soberly colored in various dull, substrate-matching shades of brown, but coat-color contrasts are sometimes striking (fig. 2). Ordinary color descriptors (e.g., "pale grayish brown") are sufficient for most comparative purposes, but we also cite Ridgway's (1912) terminology, which is always capitalized (e.g., Dark Umber).

Ventral PELAGe COLOR AND PATTERn: Ventral pelage hairs can be the same color from base to tip, or they can be grayish basally with paler tips. Ventral fur composed of hairs that are the same color from base to tip is said to be selfcolored (e.g., self-white, self-buffy, etc.; Tate, 1933), whereas ventral fur composed of hairs 

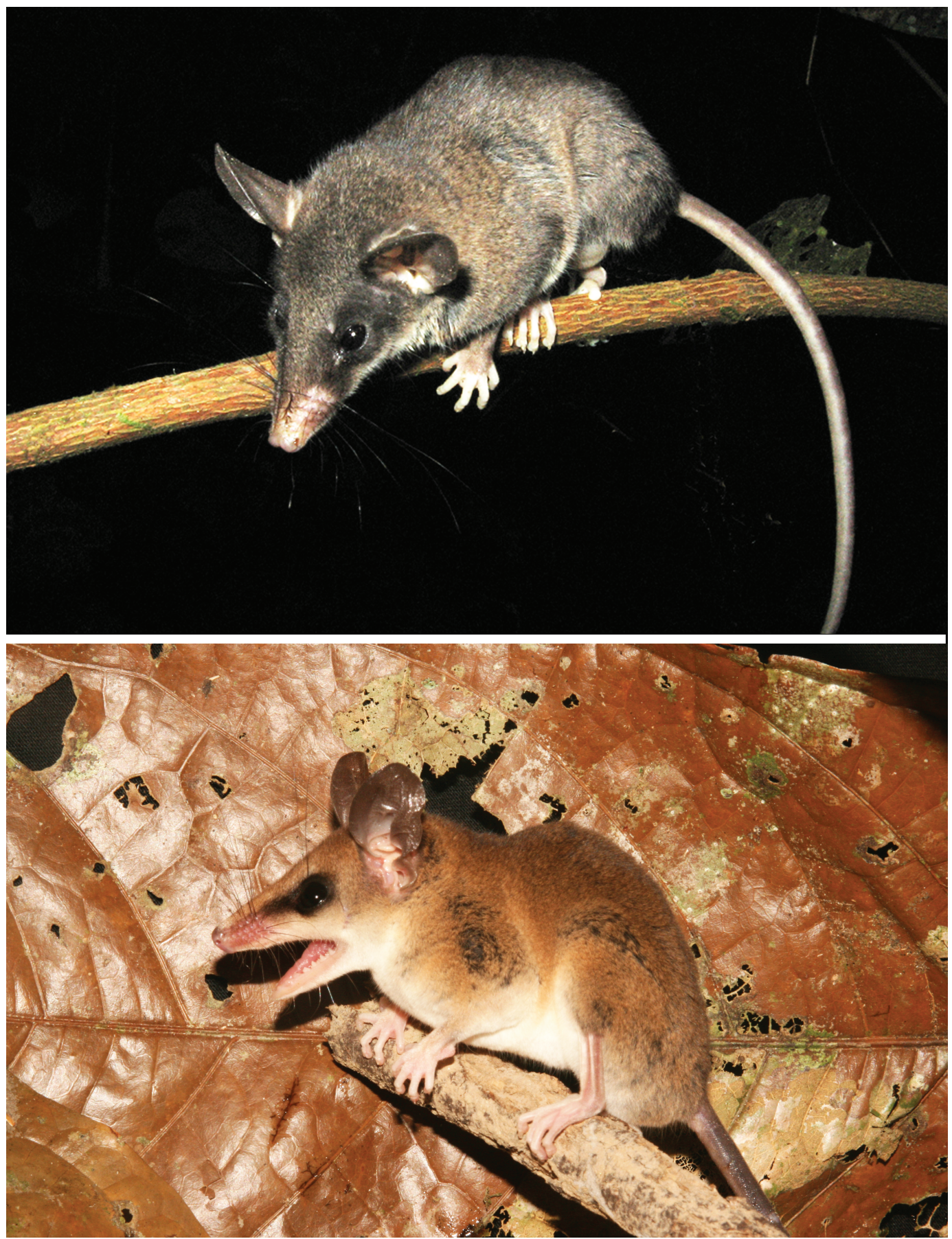

FIG. 2. Marmosops handleyi (above; photographed by J. Díaz-Nieto at Finca Costa Rica, Antioquia, Colombia) and M. parvidens (below; photographed by T. Semedo near Urucará, Amazonas, Brazil). In addition to obvious differences in body pelage color, these species differ in forefoot markings: whereas $M$. handleyi has dark metacarpal fur that contrasts with the pale fur of the manual digits, M. parvidens has all-pale forefeet. 
A

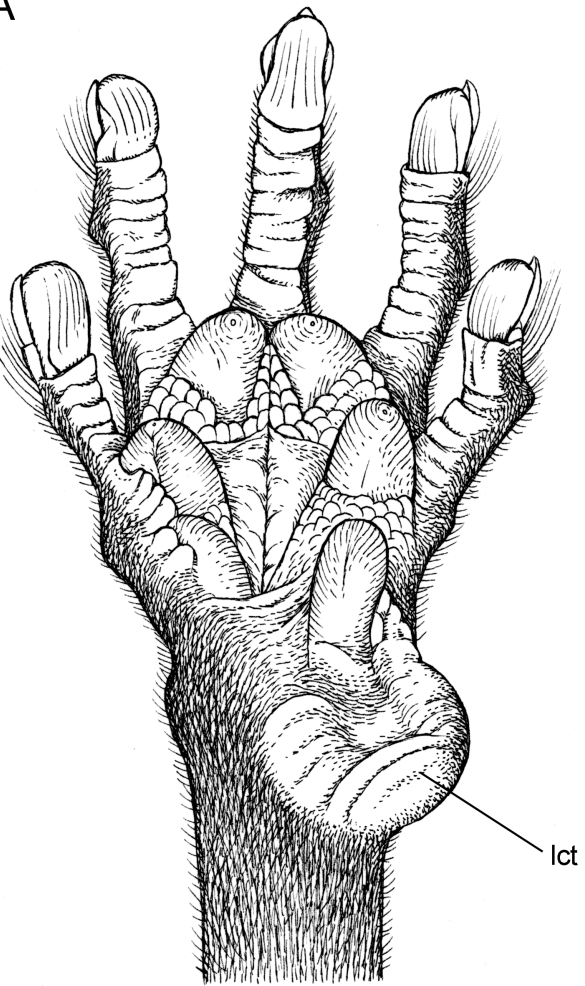

$\mathrm{B}$

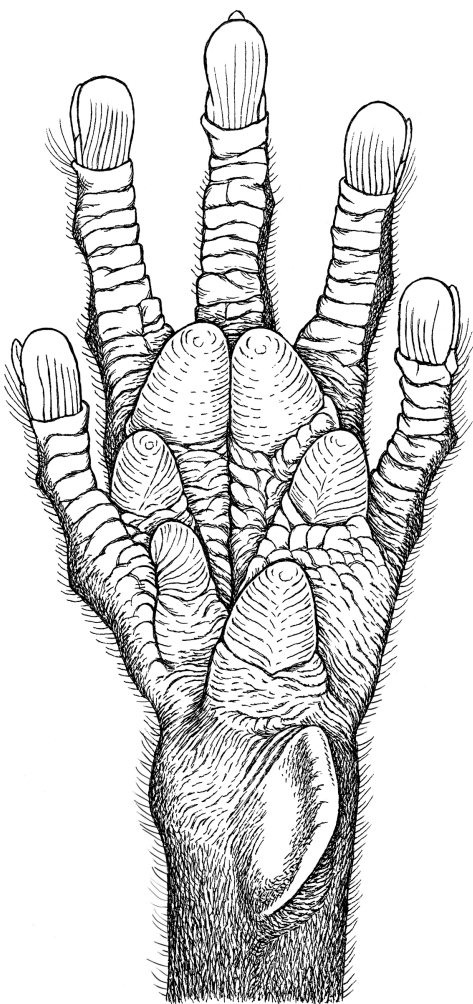

FIG. 3. Plantar views of left forefoot (manus) and wrist of Marmosops pinheiroi (A, AMNH 267346) and M. bishopi (B, MUSM 23801) illustrating different morphologies of the lateral carpal tubercle (lct), which is spoon shaped in adult males of M. pinheiroi and bladelike (laterally compressed) in adult males of M. bishopi.

with gray bases is said to be gray based. In general, the fur of the chin (including the oral margins), and groin (including the scrotum) is self-whitish in Marmosops, but the coloration of the throat, chest, abdomen, and the inside surfaces of the fore- and hind limbs is taxonomically variable. In several species of the subgenus Sciophanes, the entire ventrum (except the chin and groin) is covered with gray-based fur, but in other species there is a continuous midventral zone of self-colored fur that extends from the chin to the groin. In some species the self-whitish midventral fur is much narrowed by lateral zones of gray-based fur, and in others the selfcolored fur is reduced to a discontinuous midventral streak. The short fur surrounding the mammae of lactating adult females is sometimes reddish or brownish; within the subgenus Sciophanes we observed this trait in specimens of $M$. bishopi (e.g., TTU 101238), M. chucha (FMNH 69837), M. magdalenae (ICN 19924), and $M$. pinheiroi (USNM 393529).

Gular GLAND: Many species in the nominotypical subgenus of Marmosops have a conspicuous midventral patch of naked skin on the throat that is presumably homologous with the gular gland of other didelphids (Barnes, 1977), but species of the subgenus Sciophanes lack any external trace of glandular activity in the throat region, which is uniformly furred and unstained by cutaneous secretions.

Dorsal PElAge of MANus AND PES: The dorsal surface of the manus is covered with short hairs that are uniformly pale in some species, whose forefeet lack any pigmental contrast between the metacarpal and digital pelage. In other species, however, the metacarpals are covered with dark (brownish or grayish) hairs that 


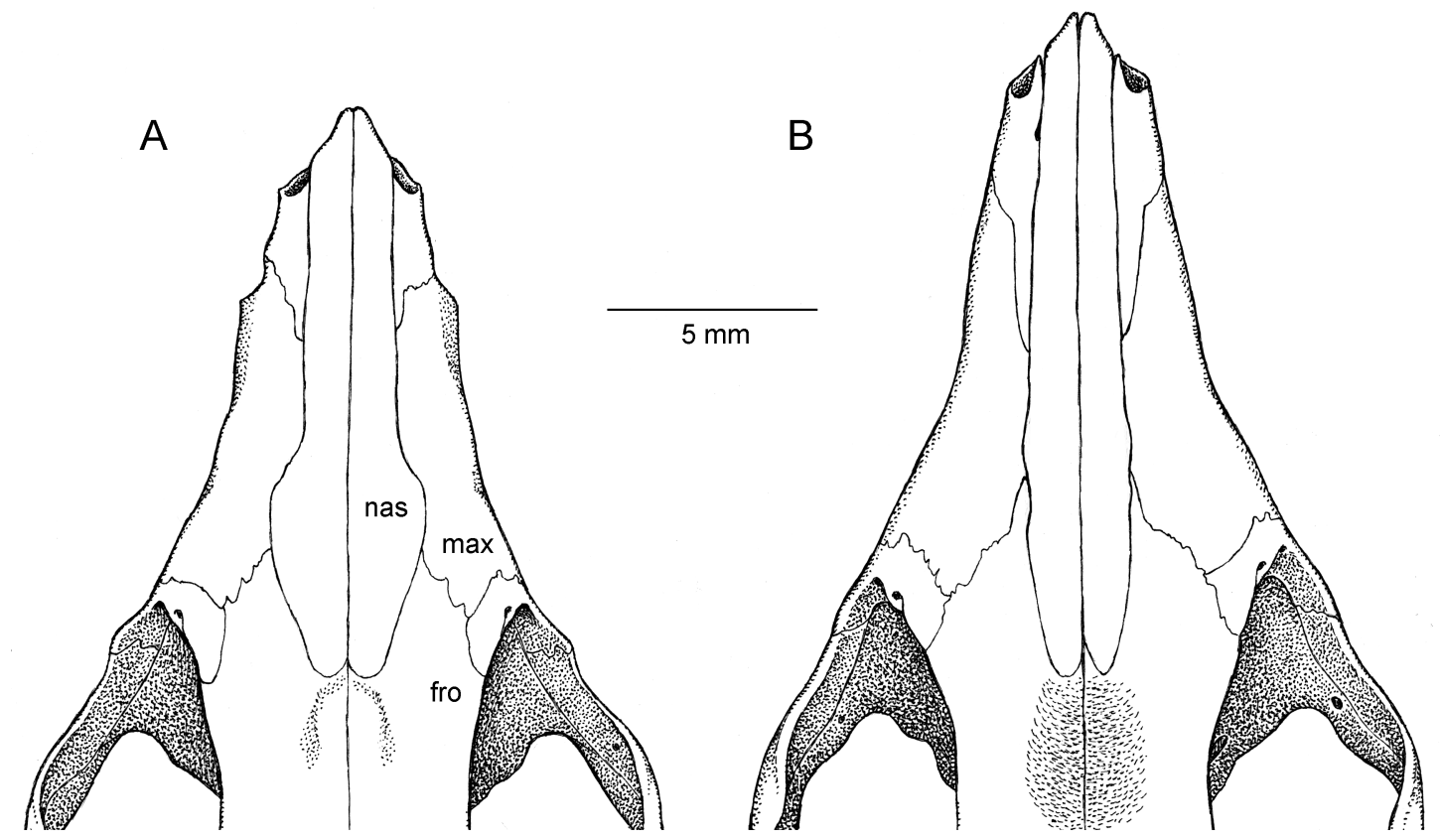

FIG. 4. Dorsal views of the rostrum of Marmosops invictus (A, USNM 306386) and M. fuscatus (B, FMNH 22174), illustrating taxonomic differences in nasal width. Abbreviations: fro, frontal; max, maxillary; nas, nasal.

contrast abruptly in color with the paler digital fur. (See fig. 2 for contrasting examples of manual pelage markings.) Hind feet exhibit similar variation in the nominotypical subgenus of Marmosops, some species of which have dark metatarsals that contrast with abruptly paler digits, but all species of the subgenus Sciophanes have uniformly pale-furred hind feet.

Carpal tubercles: Prominent carpal tubercles that are supported internally by the pisiform bone (Lunde and Schutt, 1999; Voss et al., 2001: fig. 20) are present on the lateral surface of the wrist of adult males of most species of Marmosops, but these are sexually dimorphic structures that do not occur in females, and they are often not apparent on the wrists of immature males. In the subgenus Sciophanes, carpal tubercles are taxonomically variable in shape. In some species they are spoon shaped (broadly concave anteriorly; fig. 3A), whereas in others they are bladelike (laterally flattened and aligned with the long axis of the wrist; fig. 3B).

Antebrachial vibrissae: Most didelphids, including most species of the nominotypical subgenus of Marmosops, have a single long vibrissa on the dorsolateral surface of the forearm, but species of the subgenus Sciophanes consistently have two antebrachial vibrissae (Díaz-N. et al., 2011: fig. 5). The only exceptional species known to us is M. (M.) ocellatus, of which most examined specimens appear to have two antebrachial vibrissae.

Mammae: Didelphid mammae are typically restricted to the inguinal or abdominal region, where they form a roughly circular array that often includes an unpaired median teat (Voss and Jansa, 2009: fig. 5b). We summarize mammary morphology as teat counts using the formula $\mathrm{R}-\mathrm{M}-\mathrm{L}=\mathrm{T}$ (Right-Median-Left $=$ Total). Thus, a species with three teats on the right side, one unpaired median teat, and three teats on the left side would have a mammary formula of $3-1-3=7$. In species with nine or fewer teats, all of the mammae are circularly arranged and abdominal-inguinal, but in species with 11 or more mammae-for example, Marmosops (Marmosops) ocellatus, with mammary formula 6-1-6 $=13$ (Voss et al., 2004) - one or more pairs are 
A

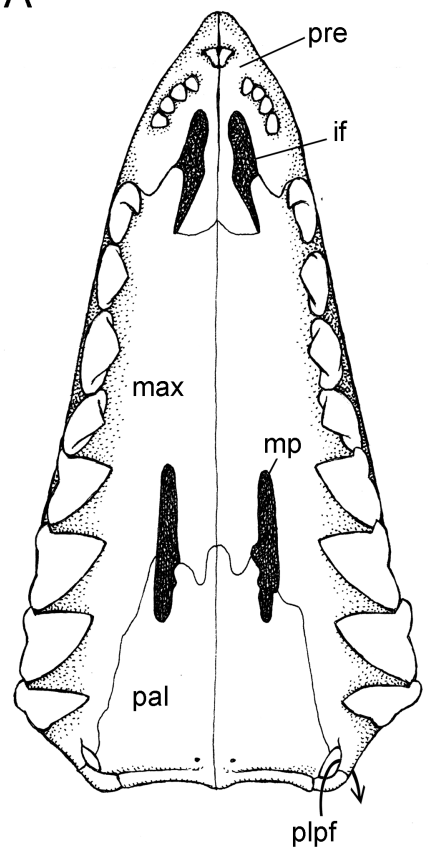

B

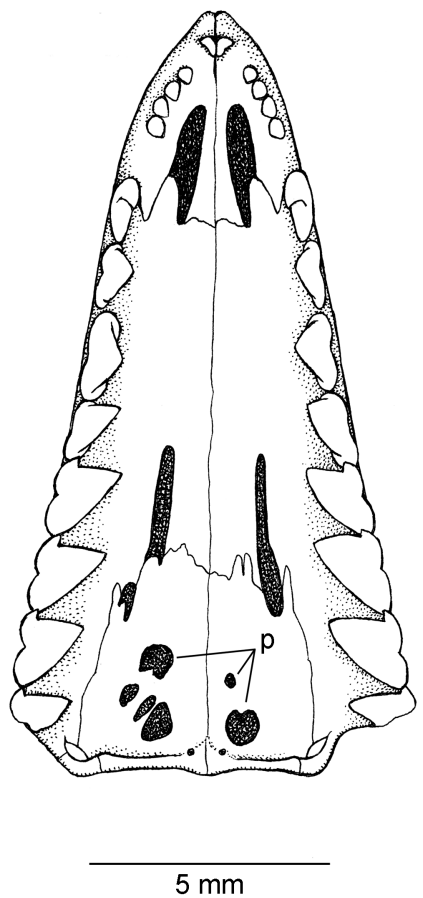

C

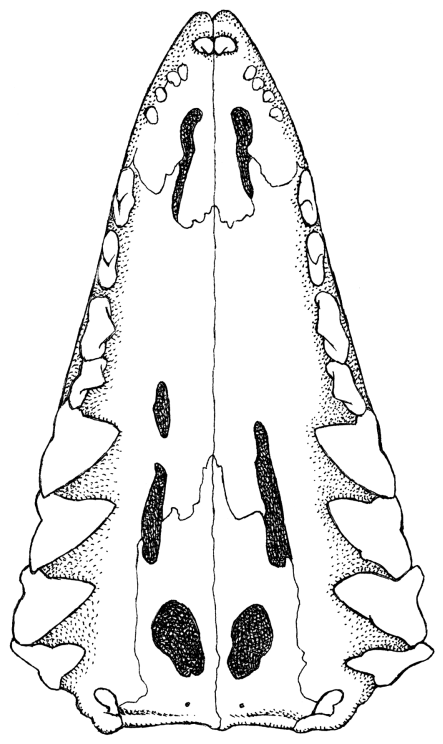

FIG. 5. Ventral views of the palates of Marmosops parvidens (A, AMNH 267359), M. juninensis (B, AMNH 230016), and M. magdalenae (C, ICN 19926) illustrating species differences in the presence, absence, and morphology of palatal fenestrae and foramina. Abbreviations: if, incisive foramen; max, maxillary bone; $\mathbf{m p}$, maxillopalatine fenestra; p, palatine fenestrae; pal, palatine bone; plpf, posterolateral palatine foramen; pre, premaxillary bone.

said to be "pectoral" (Tate, 1933) because they are positioned anterior to the circular abdominal-inguinal array, although none that we have seen actually occur on the chest. Insofar as known, species in the subgenus Sciophanes have no more than nine mammae, all of which are abdominal-inguinal.

Caudal coloration: The tail in Marmosops is furred only at the base and appears to be completely naked because the three bristlelike hairs emerging from each scale are visible only under magnification. Some species have unicolored tails that are dark from base to tip on both dorsal and ventral surfaces, but in other species the caudal integument is more heavily pigmented dorsally and/or basally than it is ventrally and/or distally. Tails that are distinctly darker dorsally than ventrally are said to be bicolored, whereas tails that are darker basally and paler near the tip are said to be particolored. No species of the subgenus Sciophanes has a distinctly particolored tail.

\section{Skull}

NASAL SHAPE: The paired nasal bones are narrow and parallel sided anteriorly, but in most species of Marmosops they are much wider posteriorly than anteriorly because they are laterally expanded at or near the frontal-maxillary suture (fig. 4A). However, in some species of the nominotypical subgenus (e.g., M. incanus) and in two species of Sciophanes (namely M. carri and M. fuscatus), the nasals are almost as narrow posteriorly as they are anteriorly, with only slight lateral expansion near the frontal-maxillary suture (fig. 4B).

LACRIMAL FORAMINA: The lacrimal foramina transmit the lacrimal canaliculi and a small 
accompanying vein through the lacrimal bone, which forms the anterodorsal margin of the didelphid orbital fossa (Wible, 2003). Most species of Marmosops have two lacrimal foramina on each side, but the position of these openings is taxonomically variable. In some species of Sciophanes the foramina (or foramen, when only one is present) are more or less concealed from lateral view inside the anterior orbital margin (fig. 14A), but in others they are laterally exposed anterior to the orbit (fig. 14B). Yet other species exhibit an intermediate morphology in which one foramen (usually the dorsalmost) is completely or partially concealed inside the orbit and the other (usually the ventralmost) is exposed on the orbital margin, and this character is sometimes quite variable even in local populations.

Squamosal-Jugal overlap: The zygomatic process of the squamosal is more or less acutely pointed and broadly overlapped dorsally by the jugal in most species of Marmosops (fig. 23A). But in M. (Sciophanes) juninensis the squamosal zygomatic process is rounded and not dorsally overlapped by the jugal, or is only shallowly overlapped by that bone (fig. 23B).

SUBSQUAMOSAL FORAMEN: The subsquamosal foramen $^{1}$ is a lateral opening in the squamosal bone that exposes the underlying petrosal just dorsal to the ear region of many marsupials. In the subgenus Sciophanes the subquamosal foramen is anteroposteriorly elongated, revealing not only the sulcus for the prootic sinus, but also a substantial strip of the relatively featureless lateral surface of the pars canalicularis behind that groove (fig. 9A). By contrast, the subsquamosal foramen in the nominotypical subgenus is shorter and does not extend posteriorly much behind the sulcus for the prootic sinus (fig. 9B).

Palatine fenestrae: The didelphid bony palate is perforated by several pairs of foramina

\footnotetext{
1 Our use of the term "subsquamosal foramen" is consistent with its original definition (Cope, 1880) and with well-established anatomical usage in the marsupial literature (e.g., Gregory, 1910; Archer, 1976), but Wible (2003: 183) referred to this opening as the "suprameatal foramen," a neologism.
}

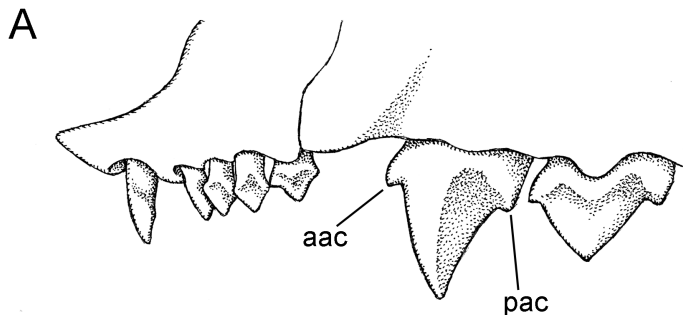

B

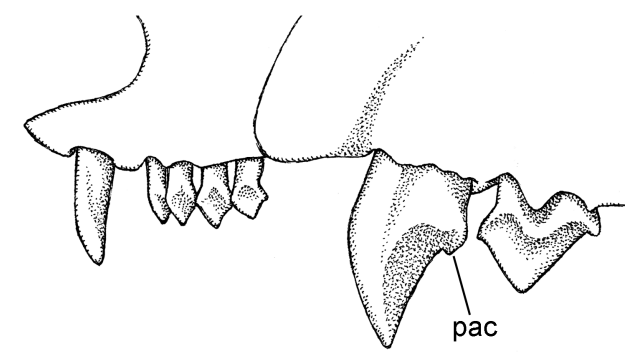

C

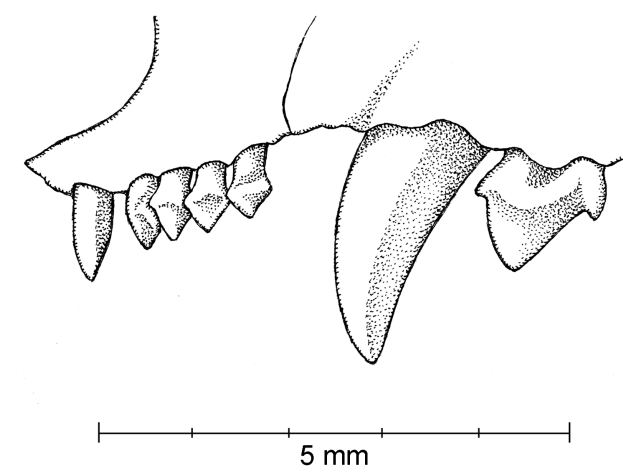

FIG. 6. Lateral view of anterior left upper dentition (I1P1) of Marmosops pinheiroi (A, AMNH 267349), M. magdalenae (B, ICN 18788), and M. carri (C, KU 120254) illustrating species differences in the presence or absence of accessory upper canine (C1) cusps. All illustrated specimens are males. Abbreviations: aac, anterior accessory cusp; pac, posterior accessory cusp. 

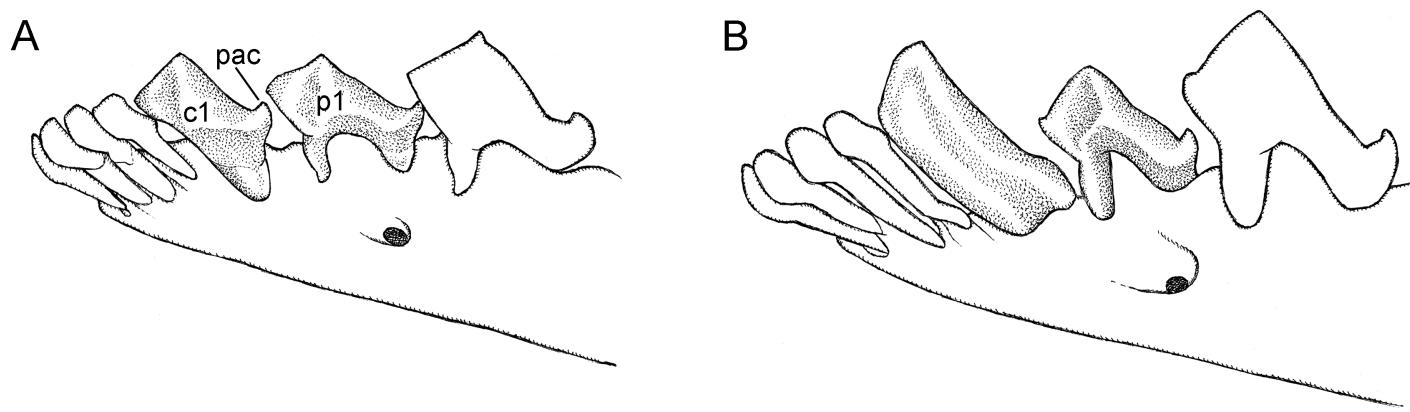

FIG. 7. Lateral view of anterior left lower dentition of Marmosops parvidens (A, AMNH 266425) and M. carri (B, KU 120254) illustrating species differences in lower canine (c1) morphology. In M. parvidens, c1 is subequal in height with the first lower premolar (p1), and it has a distinct posterior accessory cusp (pac). By contrast, $\mathrm{cl}$ in $M$. carri is distinctly taller than $\mathrm{p} 1$ and lacks a posterior accessory cusp. Both illustrated specimens are males.

(transmitting ducts, nerves, and/or blood vessels) and fenestrae (which do not transmit anything), some of which exhibit important taxonomic variation (fig. 5). All didelphids have incisive foramina, which occupy the premaxillary-maxillary suture and transmit the nasopalatine ducts between the oral and nasal cavities. In most species of Marmosops the incisive foramina extend posteriorly only between the upper canines, but in at least one species of the nominotypical subgenus they are much longer, extending posteriorly between the first upper premolars (Mustrangi and Patton, 1997: fig. 15). Most didelphids also have maxillopalatine fenestrae and posterolateral palatal foramina, both of which are in the maxillary-palatine suture, but these openings are not known to exhibit noteworthy variation among species of Marmosops. Instead, the presence or absence of palatine fenestrae-which penetrate the palatine bone just behind the maxillopalatine fenestrae-is a diagnostically useful character for species recognition in both subgenera.

Some species of the subgenus Sciophanes have completely ossified palatines that lack any trace of fenestration (fig. 5A), whereas others have large palatine fenestrae. In some species the palatine fenestrae may consist of multiple irregular openings on each side (fig. 5B), whereas other species may have a single large palatine fenestra on each side (fig. 5C). Although palatine fenes- trae sometimes vary in number, shape, and size among conspecific individuals, they tend to be consistently present or consistently absent in most species. Unfortunately, the thin bone of the posterior palate is often damaged by careless specimen preparation, so it is sometimes impossible to determine whether palatine fenestrae were present or absent.

ETHMOID FORAMEN: The didelphid ethmoid foramen is a small perforation in the medial wall of the orbit that transmits the ophthalmic artery and the ethmoidal nerve through the suture between the frontal and orbitosphenoid bones (Wible, 2003). In some species of the subgenus Sciophanes the dorsolateral margin of the foramen is consistently formed by the orbitosphenoid, whereas in others it seems to be consistently formed by the frontal. We have not surveyed variation in this character among species of the nominotypical subgenus.

\section{Dentition}

C1 ACCESSORY CUSPS: The upper canine (C1) is conventionally caniniform-a simple, recurved, unicuspid tooth-in most marsupials, including all species in the nominotypical subgenus of Marmosops. By contrast, the subgenus Sciophanes is richly endowed with unusual upper-canine phenotypes, including sexual dimorphism. In both sexes of three species of 
A

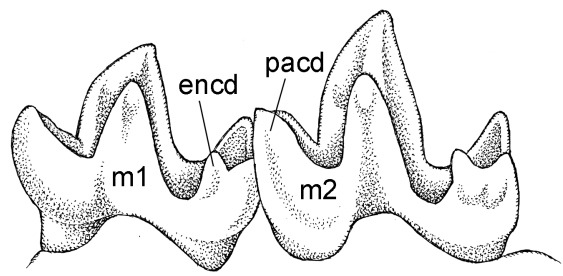

B

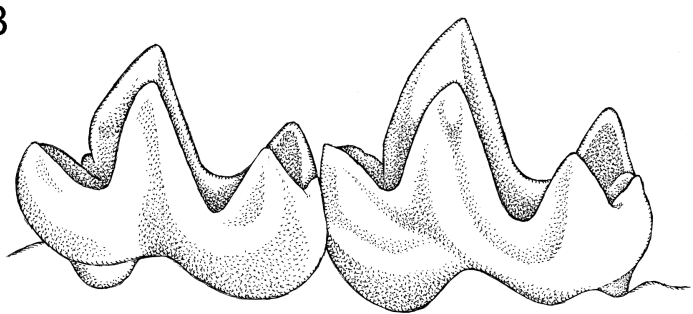

FIG. 8. Lingual view of the first two lower right molars ( $\mathbf{m} \mathbf{1}$ and $\mathbf{m} 2)$ of Marmosops bishopi (A, AMNH 276697) and M. carri (B, AMNH 234953) illustrating taxonomic differences in the cusp height. In M. bishopi the entoconid (encd) of $\mathrm{m} 1$ is shorter than the adjacent paraconid (pacd) of $\mathrm{m} 2$, whereas these cusps are subequal in height in M. carri.

Sciophanes, $\mathrm{C} 1$ is short and provided with both anterior and posterior accessory cusps (fig. 6A), resulting in a strikingly premolariform tooth. In other species of Sciophanes, however, females have both anterior and posterior $\mathrm{C} 1$ accessory cusps, whereas males have only a posterior accessory cusp (fig. 6B). In some species, both males and females usually have only posterior accessory $\mathrm{C} 1$ cusps; and in two species, females usually have only posterior $\mathrm{C} 1$ accessory cusps, whereas males have unicuspid teeth (fig. 6C).

As noted previously (Voss and Jansa, 2009: 48), some care is needed in determining $\mathrm{C} 1$ crown morphology because accessory cusps are sometimes obliterated by wear, and because false posterior accessory cusps are sometimes created when the trailing edge of $\mathrm{C} 1$ is notched by occlusion with $\mathrm{p} 1$. Therefore, $\mathrm{C} 1$ morphology is best determined from subadult or young adult specimens.

M3 ANTERIOR CINGULUM: A continuous shelf along the anterior (mesial) border of the upper molars in some didelphid species is formed by the union of the anterolabial cingulum with the preprotocrista; in other didelphids, the anterior cingulum is incomplete because the preprotocrista terminates at the base of the paracone (Voss and Jansa, 2003: fig. 13; Voss and Jansa, 2009: 52-54). Both conditions are seen in the genus Marmosops, but a complete anterior cingulum, when present, is never very wide in the subgenus Sciophanes, and careful examination of unworn teeth under relatively high magnification and good lighting is sometimes necessary to determine this character. Because this character sometimes varies along the toothrow, we scored it from the third upper molar (M3).

LOWER CANINE MORPHOLOGY: Like $\mathrm{C} 1$, the lower canine ( $\mathrm{c} 1$ ) is conventionally caniniform-a simple, recurved, more or less erect, unicuspid tooth-in most didelphids, including some species in the nominotypical subgenus of Marmosops. By contrast, in most species of the subgenus Sciophanes $\mathrm{cl}$ is strikingly premolariform: procumbent, subequal in height to the first lower premolar (p1), and with a distinct posterior accessory cusp (fig. 7A). In two species of Sciophanes, however, c1 is distinctly taller than $\mathrm{p} 1$ and lacks a distinct posterior accessory cusp (fig. 7B).

In addition to the posterior accessory cusp described above, a distinct lingual accessory cusp is present on c1 in Marmosops (Sciophanes) handleyi (see Díaz-N. et al., 2011: fig. 9B). However, this unusual structure occurs polymorphically in other species of Sciophanes, and it is sometimes difficult to decide whether it is present or absent in older specimens with worn canines.

Relative HeIghts of M1 ENTOCONID AND M2 PARACONID: The lower first molar ( $\mathrm{m} 1$ ) entoconid is conspicuously shorter than the immediately adjacent $\mathrm{m} 2$ paraconid in some species of the subgenus Sciophanes (fig. 8A), but in other species these cusps are subequal in height (fig. $8 \mathrm{~B})$. We have not surveyed this trait among members of the nominotypical subgenus of Marmosops, or among other didelphid taxa. 
TALONID ON M4: In most didelphids the talonid of each lower molar is provided with three cusps (hypoconid, entoconid, and hypoconulid), but in some species of Sciophanes the talonid of $\mathrm{m} 4$ is bicuspid, apparently because the entoconid and hypoconulid are not distinguishable as separate cusps.

\section{TAXONOMY}

\section{Genus Marmosops Matschie, 1916}

Type species: Marmosops incanus (Lund, 1840) by original designation.

CONTENTS: At least 19 species (as recognized by Voss and Jansa, 2009; Voss et al., 2013; Díaz-Nieto et al., 2016a; and this report) in two subgenera.

Description: ${ }^{2}$ Combined length of adult head and body ca. 90-195 mm; adult weight ca. 20-140 g. Rhinarium with two ventrolateral grooves on each side of median sulcus; dark circumocular mask present; pale supraocular spot absent; dark midrostral stripe absent; throat gland consistently present in adult males of some species (e.g., $M$. incanus, $M$. noctivagus) but apparently absent in others (e.g., $M$. caucae, $M$. parvidens). Dorsal pelage unpatterned, usually some shade of dull grayish brown, but distinctly redder or grayer in some species; dorsal hair bases always dark gray; dorsal guard hairs short and inconspicuous; ventral fur self-colored (whitish, buffy, or brown) or entirely or partially gray based. Manus mesaxonic (dIII > dIV); manual claws small, shorter than fleshy apical pads of digits; dermatoglyph-bearing manual plantar pads present; central palmar epithelium smooth or sparsely tuberculate; lateral carpal tubercles externally conspicuous on wrists of large adult males of most species; medial carpal tubercles absent in both sexes. Pedal digits unwebbed; dIV longer than other pedal digits; plantar surface of heel macroscopically naked (a microscopic pelage of very short hairs, not coarse fur, is usually

2 After Voss and Jansa (2009: 134-137), but including minor corrections and supplementary observations of character variation discovered in the course of this study. present). Pouch absent; mammae varying among examined species from $3-1-3=7$ to $7-1-7=15$ (anteriormost pairs "pectoral" when mammae $\geq$ 11; e.g., in M. ocellatus); cloaca present. Tail longer than combined length of head and body, slender and muscular (not incrassate), and macroscopically naked (without a conspicuously furred base); naked caudal integument uniformly dark (usually grayish), bicolored (dark above, pale below), or particolored (dark proximally, paler distally); caudal scales in spiral series, each scale with three bristlelike hairs emerging from caudal margin; median hair of each caudal-scale triplet usually much thicker and darker than lateral hairs; ventral caudal surface modified for prehension distally (with naked median groove and apical pad bearing dermatoglyphs).

Premaxillary rostral process long and well developed in some species (e.g., $M$. parvidens, $M$. pinheiroi) but short in others (e.g., M. noctivagus) and apparently absent in some (M. incanus). Nasals long, extending anteriorly beyond I1 (concealing nasal orifice in dorsal view), and conspicuously widened posteriorly near maxillary-frontal suture except in M. carri, M. fuscatus, and M. incanus (which have narrow, more or less parallelsided nasals). Maxillary turbinals (viewed through nasal orifice) elaborately branched. Lacrimal foramina usually two on each side, concealed from lateral view inside orbit (e.g., in M. parvidens) or exposed on orbital margin (e.g., in M. pinheiroi). Interorbital region without abrupt constrictions; supraorbital margins rounded in some species (e.g., M. parvidens), beaded in others (e.g., M. noctivagus); postorbital processes usually absent. Left and right frontals and parietals separated by persistent median sutures. Parietal and alisphenoid in contact on lateral braincase (no frontal-squamosal contact). Sagittal crest absent. Petrosal consistently exposed laterally through fenestra in parietal-squamosal suture in most species (but fenestra polymorphically absent in $M$. incanus and $M$. noctivagus). Parietal-mastoid contact present (interparietal does not contact squamosal).

Maxillopalatine fenestrae present; palatine fenestrae present in some species (e.g., $M$. 
creightoni), but absent in others (e.g., M. pinheiroi); maxillary fenestrae absent; posterolateral palatal foramina small, not extending anteriorly lingual to M4 protocones; posterior palate with prominent lateral corners (the choanae constricted behind). Maxillary and alisphenoid not in contact on floor of orbit (separated by palatine). Transverse canal foramen present. Alisphenoid tympanic process small, often bluntly conical or laterally compressed (never smoothly globular), always with a well-developed anteromedial process enclosing the extracranial course of mandibular nerve (secondary foramen ovale present), and not contacting rostral tympanic process of petrosal. Anterior limb of ectotympanic directly suspended from basicranium. Stapes triangular, with large obturator foramen. Fenestra cochleae exposed, not concealed by rostral and caudal tympanic processes of petrosal. Paroccipital process small, rounded, and adnate to petrosal. Dorsal margin of foramen magnum bordered by supraoccipital and exoccipitals, incisura occipitalis present.

Two mental foramina usually present on lateral surface of each hemimandible; angular process acute and strongly inflected.

Unworn crowns of I2-I5 symmetrically rhomboidal ("premolariform"), with subequal anterior and posterior cutting edges, increasing in length (mesiodistal dimension) from I 2 to I5. Upper canine $(\mathrm{C} 1)$ alveolus in premaxillarymaxillary suture; $\mathrm{C} 1$ without accessory cusps in some species (e.g., M. creightoni), or with only posterior accessory cusp (e.g., M. invictus), or with both anterior and posterior accessory cusps (e.g., M. parvidens). First upper premolar (P1) smaller than posterior premolars but well formed and not vestigial; second and third upper premolars (P2 and P3) subequal in height; P3 with posterior cutting edge only; upper milk premolar (dP3) large and molariform. Molars strongly carnassialized (postmetacristae much longer than postprotocristae); relative widths usually M1 < M2 < M3 < M4; centrocrista strongly inflected labially on M1-M3; ectoflexus shallow or indistinct on M1, shallow but usually distinct on M2, and consistently deep on M3; anterolabial cingulum and preprotocrista discontinuous (anterior cingulum incomplete) on M3 in some species (e.g., M. noctivagus), but anterolabial cingulum narrowly continuous with preprotocrista (anterior cingulum complete) in others (e.g., $M$. parvidens); postprotocrista without carnassial notch. Last upper tooth to erupt is P3.

Lower incisors (i1-i4) with distinct lingual cusps. Lower canine (c1) distinctively tall, recurved, and unicuspid in some species (e.g., M. noctivagus), but smaller and premolariform in others (e.g., M. pinheiroi). Second lower premolar (p2) subequal in height to p3 in some species (e.g., M. incanus) but distinctly taller than p3 in most others; lower milk premolar (dp3) trigonid complete. Hypoconid labially salient on $\mathrm{m} 3$; hypoconulid twinned with entoconid on m1-m3; entoconid usually taller than hypoconulid on $\mathrm{m} 1-\mathrm{m} 3$.

REMARKs: As discussed by Voss and Jansa (2009: 137-138), the monophyly of the genus Marmosops is strongly supported by phylogenetic analyses of nuclear exon sequences and by combined analyses of nuclear genes and morphological characters. In the latter analyses, several morphological traits optimized as generic synapomorphies, including (1) spirally arranged caudal scales, (2) the petiolate morphology of the central hair in each caudal-scale triplet, and (3) the presence of a distinct rostral process of the premaxillae. Generic monophyly is also supported by unique deletions at the DMP1 and BRCA1 loci (Voss and Jansa, 2009: figs. 29, 31). The monophyly of Marmosops was additionally corroborated in recent phylogenetic analyses with much denser taxon sampling by Díaz-Nieto et al. (2016a, 2016b), who sequenced several genes not included in Voss and Jansa's (2009) study. As discussed elsewhere (Voss and Jansa, 2003: 56-57), DNA-DNA hybridization results reported by Kirsch and Palma (1995) and Kirsch et al. (1997) that recovered Gracilinanus nested inside the genus Marmosops are unambiguously attributable to misidentified voucher material. Diagnostic morphological comparisons among 
Marmosops and other didelphid genera with which it was formerly confused (Gracilinanus, Marmosa, and Thylamys) were described, illustrated, and tabulated by Voss et al. (2004).

Subgenus Sciophanes Díaz-Nieto et al., 2016

Type species: Marmosops parvidens (Tate, 1931) by original designation.

Contents: Twelve species as described below.

Description: Combined length of head and body usually $<120 \mathrm{~mm}$ and adult weight usually $<30 \mathrm{~g}$ (except in Marmosops carri and M. fuscatus, both of which are substantially larger). Gular gland absent in all examined material. Lateral carpal tubercles consistently present in mature adult males; forearm with two widely separated antebrachial vibrissae. Mammae 3-1-3 = 7 or $4-1-4$ $=9$, all abdominal-inguinal (but note that mammary morphology is unknown for $M$. fuscatus, $M$. juninensis, M. ojastii, M. pakaraimae, and M. magdalenae). Scrotal integument consistently unpigmented and covered with self-whitish fur.

Nasals laterally expanded at or near maxillaryfrontal suture (except in M. carri and M. fuscatus, which have very narrow, almost parallel-sided nasals). Interorbital region with rounded or squared supraorbital margins, without distinct beading and without distinct postorbital processes. Fenestra in parietal-squamosal suture consistently present; subsquamosal foramen anteroposteriorly elongate, exposing lateral surface of petrosal pars canalicularis behind sulcus for prootic sinus. Incisive foramina short, extending posteriorly between but not behind $\mathrm{C} 1$.

Upper canine $(\mathrm{C} 1)$ with accessory cusps in one or both sexes (males of Marmosops carri and M. fuscatus lack C1 accessory cusps). Upper third molar (M3) with or without complete anterior cingulum (anterolabial cingulum and preprotocrista discontinuous in some species). Lower canine (c1) premolariform (procumbent, subequal in height to $\mathrm{p} 1$, and provided with a posterior accessory cusp) in most species (but not in males of $M$. carri and M. fuscatus, which have taller c1s that lack accessory cusps). Lower first molar ( $\mathrm{m} 1)$ entoconid and adjacent lower second molar $(\mathrm{m} 2)$ paraconid subequal in height in some species, but $\mathrm{m} 1$ entoconid shorter than $\mathrm{m} 2$ paraconid in others.

COMPARISONS WITH THE NOMINOTYPICAL SUBGENUS: As explained by Díaz-Nieto et al. (2016a), species of Sciophanes can be unambiguously distinguished from species in the subgenus Marmosops by the morphology of the subsquamosal foramen (anteroposteriorly elongate in Sciophanes, anteroposteriorly constricted in Marmosops; fig. 9), C1 accessory cusps (present in one or both sexes in Sciophanes, consistently absent in Marmosops), and number of antebrachial vibrissae (two in Sciophanes, one in most Marmosops). However, the two subgenera also differ in their modal expression of other characters. In particular, most species of Sciophanes are small (HBL usually $<120 \mathrm{~mm}$, weight usually $<30 \mathrm{~g}$ ), whereas most members of the nominotypical subgenera are substantially larger. There is some size overlap, however, because two species of Sciophanes (M. carri and M. fuscatus; see below) are large, and because some species in the nominotypical subgenus (e.g., M. ocellatus; see Voss et al., 2004) are smaller than the subgeneric average. Nevertheless, wherever the two subgenera occur together (along the Rio Juruá, for example; Patton et al., 2000), species of Sciophanes are always smaller than sympatric members of the nominotypical subgenus.

Another potentially useful character for subgeneric identification is the morphology of the lower canine (c1), which is small (subequal in height to p1) and premolariform (with a well-developed posterior accessory cusp) in both sexes of most species of Sciophanes. By contrast, c1 is a larger tooth (always distinctly taller than p1) and often lacks a distinct posterior accessory cusp in members of the nominotypical subgenus. The noteworthy exceptions in this context are male specimens of the largest species of Sciophanes (M. carri and $M$. fuscatus), in which $\mathrm{c} 1$ is taller than $\mathrm{p} 1$ and lacks a distinct posterior accessory cusp.

Among external traits that are sometimes observed in the nominotypical subgenus, no spe- 

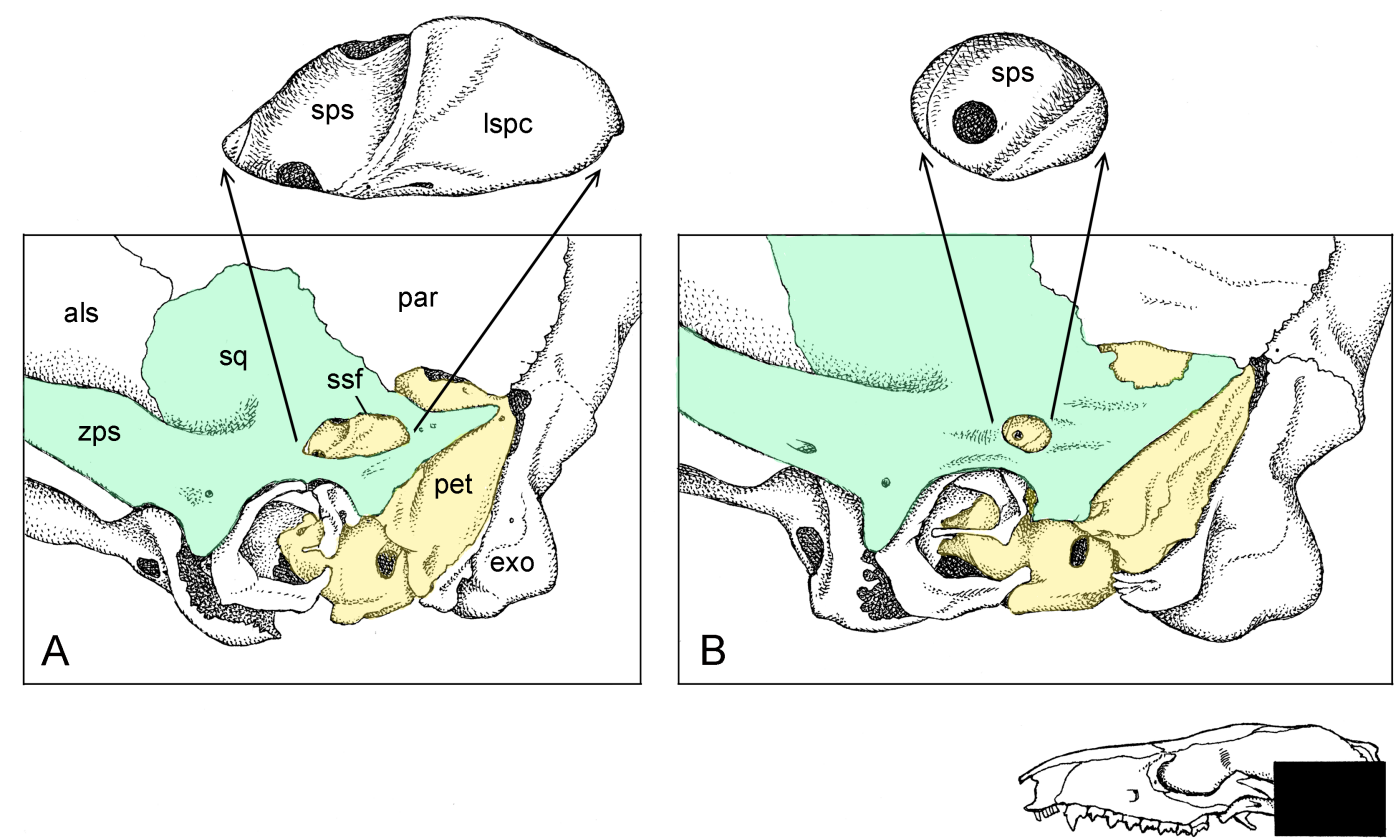

FIG. 9. Lateral view of posterior braincase of Marmosops (Sciophanes) pinheiroi (A, AMNH 267345) and M. (M.) noctivagus (B, MUSM 13288) illustrating diagnostic subgeneric morphologies of the squamosal (green) and petrosal (yellow). Abbreviations: als, alisphenoid; exo, exoccipital; lspc, lateral surface of pars canalicularis (of petrosal); par, parietal; pet, petrosal; sps, sulcus for the prootic sinus (of petrosal); sq, squamosal; ssf, subsquamosal foramen; zps, zygomatic process of the squamosal.

cies of Sciophanes has a gular gland, and none has dark-furred hind feet, "pectoral" mammae, or pigmented scrotal epithelium. Additionally, no species of Sciophanes has distinctly beaded supraorbital margins, develops postorbital processes, has long incisive foramina (extending behind the upper canines), or lacks a fenestra in the squamosal-parietal suture.

REMARKs: The monophyly of Sciophanes is strongly supported by taxon-dense phylogenetic analyses of both nuclear and mitochondrial genes (Díaz-Nieto et al., 2016a, 2016b). Unfortunately, taxon-dense phylogenetic analyses incorporating morphological characters have yet to be completed, so it is not known which (if any) of the diagnostic external and craniodental traits described above might optimize as subgeneric synapomorphies.

The same molecular analyses that provided strong support for the monophyly of Sciophanes also recovered three well-supported species groups within this subgenus. Díaz-Nieto et al. (2016a: fig. 5) referred to these groups using alphabetical labels, for which we substitute other names in this report: the Fuscatus Group (for "clade A," including Marmosops carri, $M$. fuscatus, M. handleyi, and $M$. invictus), the Bishopi Group (for “clade B," including M. bishopi, M. juninensis, M. ojastii, and two new species), and the Parvidens Group (for "clade C," including $M$. pakaraimae, $M$. parvidens, and $M$. pinheiroi). All three groups are morphologically diagnosable (table 1).

\section{Species of the Parvidens Group}

Species of the Parvidens Group are distinguished from other members of the subgenus Sciophanes by their very long tails (averaging about $150 \%$ of $\mathrm{HBL}$ ), spoon-shaped lateral carpal tubercles in adult males, consistent lack of palatine fenestrae, C1 with anterior and posterior 
TABLE 1

Diagnostic Comparisons Among Species Groups of Marmosops (Sciophanes)

\begin{tabular}{|c|c|c|c|}
\hline & Parvidens Group & Fuscatus Group & Bishopi Group \\
\hline Geographic distribution & cis-Andean & Andean \& trans-Andean & widespread \\
\hline Ventral pelage & variable $^{\mathrm{a}}$ & entirely gray-based & variable $^{\mathrm{a}}$ \\
\hline Relative tail length ${ }^{\mathrm{b}}$ & ca. $150 \%$ & $<130 \%$ & $<140 \%$ \\
\hline Lateral carpal tubercles & spoon shaped & bladelike & bladelike \\
\hline Mammae & $3-1-3$ or $4-1-4^{c}$ & $3-1-3^{\mathrm{d}}$ & $4-1-4^{e}$ \\
\hline Palatine fenestrae & absent & variable $^{\mathrm{a}}$ & variable $^{\mathrm{a}}$ \\
\hline C1 accessory cusps & present in both sexes ${ }^{c}$ & variable $^{\mathrm{a}}$ & variable $^{\mathrm{a}}$ \\
\hline M3 anterior cingulum & variable $^{\mathrm{a}}$ & variable $^{\mathrm{a}}$ & narrowly present \\
\hline $\mathrm{m} 1$ entoconid $\& \mathrm{~m} 2$ paraconid & entoconid shorter & usually subequal & entoconid shorter \\
\hline
\end{tabular}

a Varies among member species.

b Length of tail divided by length of head-and-body, expressed as a percentage.

${ }^{c}$ Females of Marmosops pakaraimae are unknown.

d This character could not be scored for Marmosops fuscatus.

e This character could not be scored for Marmosops juninensis, M. magdalenae, or M. ojastii.

accessory cusps in both sexes, and $\mathrm{c} 1$ subequal in height to $\mathrm{p} 1$ (table 1). The three recognized species are all cis-Andean: restricted to the Guianas, eastern Venezuela, and eastern Amazonian Brazil (fig. 10). The following accounts are only slightly modified from those in Voss et al. (2013) and are based on substantially the same material that we examined in that earlier study. Diagnostic quantitative and qualitative comparisons are summarized in tables $2-4$.

Marmosops pakaraimae Voss et al., 2013

\section{Figures 11-13}

Marmosops pakaraimae Voss et al., 2013: 6 (original description).

Type material: The holotype (by original designation) consists of the skin, skull, postcranial skeleton, and preserved tissues of an adult male (ROM 115129; original number F46739) collected by Burton K. Lim and Deirdre M. Jafferally on 26 February 2003 at "Second Camp" on Mount Roraima (fig. 10: locality 49), CuyuniMazaruni Region, Guyana. The other seven specimens listed below are all paratypes.

Distribution, HABITATS, AND SYMPATRY: Marmosops pakaraimae is currently known from just five localities, of which three are in the Pak- araima Highlands of western Guyana and two are in the adjacent highlands of eastern Venezuela. Recorded elevations at these localities range from $800 \mathrm{~m}$ to about $1500 \mathrm{~m}$ above sea level, and recorded habitats are premontane or lower montane rain forest (Voss et al., 2013). This species is not definitely known to occur sympatrically with any congeneric species, although it might be expected to come into contact with $M$. parvidens and/or M. pinheiroi at lower elevations in western Guyana or eastern Venezuela.

Description: Body pelage dark brown (near Dark Umber) middorsally, but indistinctly paler laterally, and about 8-9 mm long at midback; ventral pelage superficially whitish (the ventral coloration contrasting abruptly with the brownish flanks), but hairs of throat, chest, abdomen, and inner surfaces of fore- and hind limbs uniformly gray based (only the apex of the chin, the oral margins, and the scrotum have self-white fur). Manus covered dorsally with uniformly pale hairs in some specimens (e.g., ROM 114698), but metacarpals distinctly darker than digits in others (ROM 115129); lateral carpal tubercles spoon shaped in all examined adult males. Mammary formula unknown (no female specimens examined). Tail much longer than combined length of head and body 


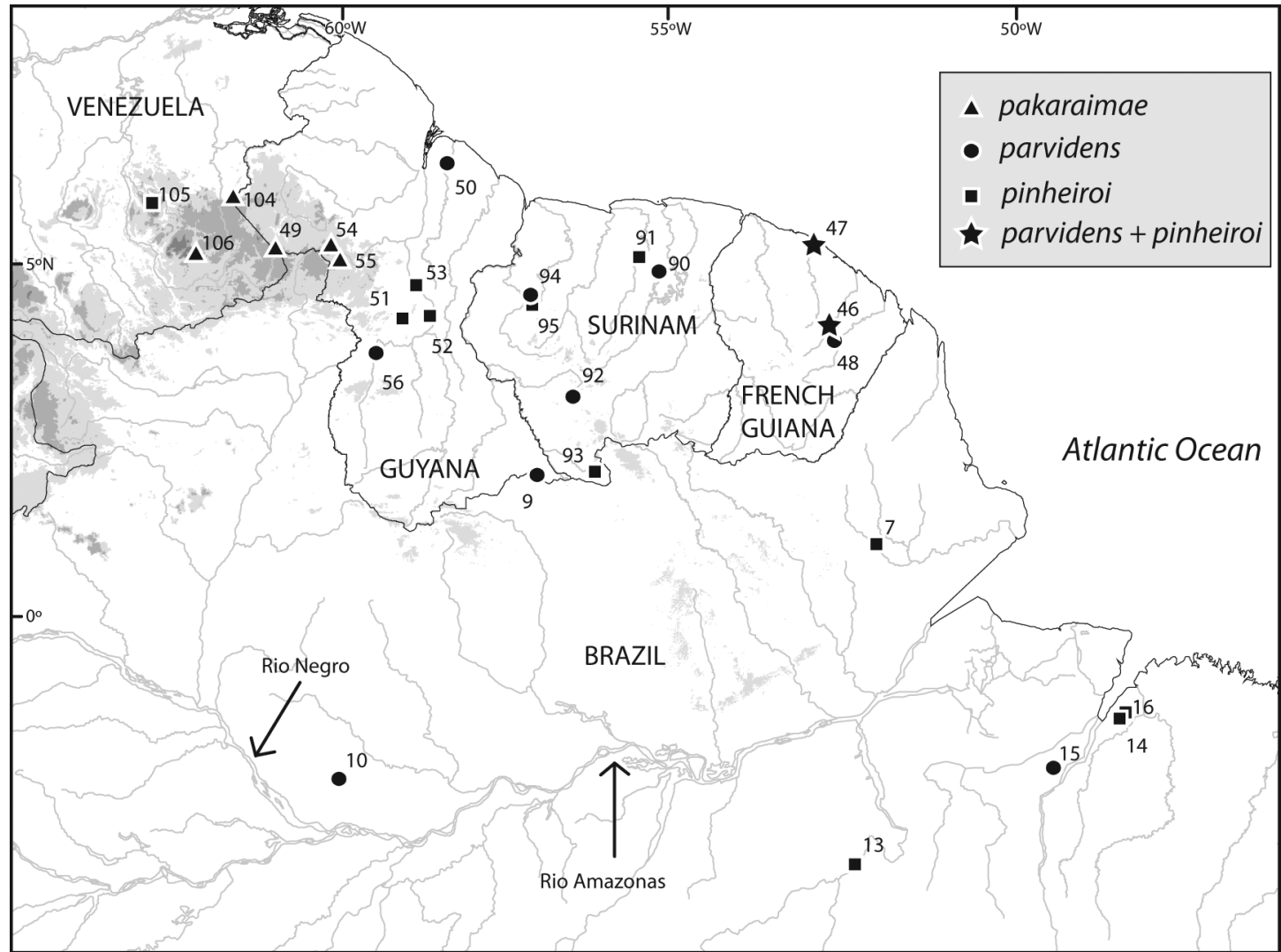

FIG. 10. Collecting localities of examined specimens of the Parvidens Group of Sciophanes. Numbers are keyed to entries in the gazetteer (appendix 1). Progressively darker shading indicates higher elevations: pale gray $\geq 500 \mathrm{~m}$, medium gray $\geq 1000 \mathrm{~m}$, dark gray $\geq 2000 \mathrm{~m}$, darkest gray $\geq 3000 \mathrm{~m}$.

$($ mean LT/HBL $\times 100=148 \%)$; dorsal caudal surface uniformly dark from base to tip, but ventral surface indistinctly paler (especially near the base of the tail).

Nasal bones long (consistently extending well behind the lacrimals) and much wider posteriorly than anteriorly (laterally expanded at the maxillary-frontal suture). Lacrimal foramina concealed from lateral view inside anterior orbital margin; zygomatic process of squamosal broadly overlapped dorsally by the jugal. Palatine fenestrae absent. Dorsolateral margin of ethmoid foramen formed by the orbitosphenoid.

Upper canine (C1) short, with anterior and posterior accessory cusps in males (female specimens are unknown). Upper third molar (M3) anterolabial cingulum narrowly continu- ous with preprotocrista (anterior cingulum complete). Lower canine (c1) premolariform (procumbent, with posterior accessory cusp) and small, subequal in height to $\mathrm{p} 1 ; \mathrm{c} 1$ anterolingual accessory cusp absent. Entoconid of $\mathrm{m} 1$ apparently subequal to adjacent $\mathrm{m} 2$ paraconid; 3 unworn $\mathrm{m} 4$ talonid with three distinct cusps.

Comparisons: Marmosops pakaraimae averages larger than $M$. parvidens in most measured external dimensions (table 2), and the two species differ strikingly in dorsal pelage coloration (dark brown in pakaraimae versus paler and distinctly reddish brown in $M$. parvidens; Voss et al., 2013: fig. 2). The difference in ventral pel-

\footnotetext{
${ }^{3}$ This character is difficult to evaluate because specimens with unworn molars (juveniles and subadults) are unavailable.
} 
TABLE 2

Measurements (mm) and Weights (g) of Adult Male Specimens of the Parvidens Group of Marmosops (Sciophanes)

\begin{tabular}{llll}
\hline \hline & M. pakaraimae $^{\mathrm{a}}$ & $M_{\text {parvidens }}^{\mathrm{b}}$ & M. pinheiroi $^{\mathrm{c}}$ \\
\hline HBL & $109(104-116) 7$ & $100(93-107) 10$ & $101(85-121) 12$ \\
LT & $161(151-169) 7$ & $150(142-160) 10$ & $150(142-160) 12$ \\
HF & $18(17-19) 7$ & $16(15-17) 10$ & $17(16-18) 12$ \\
Ear & $22(22-23) 7$ & $22(21-24) 9$ & $22(20-25) 12$ \\
CBL & $30.8(29.8-31.9) 7$ & $28.3(27.3-29.1) 9$ & $29.1(28.4-29.8) 12$ \\
NL & $14.6(14.2-15.2) 4$ & $13.7(12.7-14.4) 9$ & $14.1(13.2-14.7) 11$ \\
NB & $3.8(3.5-4.0) 7$ & $3.4(2.9-3.6) 12$ & $3.7(3.1-4.2) 12$ \\
LIB & $6.0(5.8-6.2) 7$ & $5.3(4.9-5.5) 11$ & $5.4(5.2-5.7) 12$ \\
LPB & $6.2(6.0-6.6) 7$ & $5.5(5.2-5.7) 11$ & $5.6(5.2-5.9) 11$ \\
ZB & $15.2(14.8-15.7) 7$ & $14.5(13.9-15.0) 10$ & $15.1(14.6-16.0) 12$ \\
PL & $17.3(16.5-17.9) 7$ & $16.0(15.0-16.8) 10$ & $16.3(16.0-16.7) 11$ \\
PB & $8.9(8.2-9.4) 7$ & $8.3(8.0-8.7) 12$ & $8.6(8.2-8.9) 12$ \\
MTR & $12.2(11.9-12.6) 7$ & $11.2(11.0-11.6) 11$ & $11.6(11.3-12.0) 12$ \\
LM & $6.1(6.0-6.3) 7$ & $5.5(5.3-5.7) 12$ & $5.7(5.6-5.9) 12$ \\
M1-3 & $5.2(5.2-5.4) 7$ & $4.8(4.6-5.2) 12$ & $5.0(4.8-5.2) 12$ \\
WM3 & $2.0(2.0-2.1) 7$ & $1.9(1.8-2.0) 12$ & $1.9(1.8-2.0) 12$ \\
Weight & $30(25-33) 6$ & $25(21-31) 9$ & $27(22-33) 12$ \\
\hline
\end{tabular}

a The mean, the observed range (in parentheses), and the sample size are provided for each measurement of the type series (ROM 114698, 115129, 115148, 115254, 115841, 115845; USNM 385046).

$\mathrm{b}$ The mean, the observed range (in parentheses), and the sample size are provided for each measurement of the following series: AMNH 93970, 267347, 267348, 267353, 267359, 267361; MNHN 1995-929, 1995-930, 1995-933; ROM 114144, 117348; USNM 579989.

c The mean, the observed range (in parentheses), and the sample size are provided for each measurement of the following series: AMNH 266423, 267341, 267342, 267345, 267346, 267349, 267352, 267357; CM 63506; FMNH 95320; MNHN 1995-931, 1995-932; ROM 108920, 111558, 111663; USNM 461459, 461460, 461462-461465.

age coloration (op. cit.: fig. 3) is even more striking: whereas M. pakaraimae has almost completely gray-based ventral fur, all examined specimens of $M$. parvidens have a continuous streak of self-whitish fur that extends from chin to groin. Marmosops pakaraimae is consistently larger than parvidens in all measured craniodental dimensions, especially in five variables (CBL, LIB, LPB, MTR, LM) that exhibit nonoverlapping variation between our male samples (no female specimens of $M$. pakaraimae are known). Side-by-side comparisons of representative skulls (figs. 11-13) reveal that M. pakaraimae has a visibly broader interorbital region but relatively smaller orbits than $M$. parvidens. In qualitative aspects of craniodental morphology, however, these species are notably similar, both having lacrimal foramina that are mostly concealed from lateral view inside the anterior orbital margin, upper third molars with narrowly complete anterior cingula, and consistently tricuspid $\mathrm{m} 4$ talonids.

Marmosops pakaraimae also averages larger than $M$. pinheiroi in most external dimensions, and the two species differ in dorsal pelage color (dark brown in M. pakaraimae versus paler brownish gray in $M$. pinheiroi). The ventral fur of M. pakaraimae is also more extensively gray based than the ventral fur of $M$. pinheiroi, which usually includes a narrow, discontinuous midventral streak of selfwhite hairs. Marmosops pakaraimae is also larger on average than $M$. pinheiroi in craniodental mea- 
TABLE 3

Measurements (mm) and Weights (g) of Adult Female Specimens of the Parvidens Group of Marmosops (Sciophanes) ${ }^{\mathrm{a}}$

\begin{tabular}{lll}
\hline \hline & $M \cdot$ parvidens $^{\mathrm{b}}$ & M. pinheiroi $^{\mathrm{c}}$ \\
\hline HBL & $96(94-97) 2$ & $100(95-108) 15$ \\
LT & $136(133-138) 2$ & $141(125-154) 15$ \\
HF & $16(15-17) 2$ & $16(14-17) 15$ \\
Ear & $21(20-21) 2$ & $20(18-23) 15$ \\
CBL & $27.3(26.7-28.0) 4$ & $28.5(27.9-29.8) 14$ \\
NL & $12.9(12.7-13.4) 4$ & $13.9(13.4-14.6) 9$ \\
NB & $3.1(2.8-3.5) 5$ & $3.3(2.9-3.8) 14$ \\
LIB & $5.2(4.9-5.4) 4$ & $5.4(5.2-5.5) 15$ \\
ZB & $14.5(13.9-14.8) 5$ & $15.1(14.6-15.9) 12$ \\
PL & $15.3(14.9-15.8) 4$ & $16.0(15.5-16.8) 9$ \\
PB & $8.3(8.1-8.7) 5$ & $8.8(8.4-9.3) 14$ \\
MTR 5 & $11.6(11.2-12.1) 15$ \\
LM & $11.1(11.1-11.2) 5$ & $5.8(5.5-6.2) 15$ \\
M1-3 & $5.5(5.3-5.6) 5$ & $5.0(4.8-5.4) 15$ \\
WM3 & $4.8(4.7-4.9) 5$ & $2.0(1.8-2.1) 15$ \\
Weight & $1.9(1.9-2.0) 5$ & $22(19-25) 11$ \\
\hline
\end{tabular}

a Female specimens of Marmosops pakaraimae are unknown.

$\mathrm{b}$ The mean, the observed range (in parentheses), and the sample size are provided for each measurement of the following series: AMNH 97333, 267344; FMNH 18545; USNM 548439, 579990.

${ }^{c}$ The mean, the observed range (in parentheses), and the sample size are provided for each measurement of the following series: AMNH 130570, 267342 267352; CM 63506; FMNH 95320; USNM 393529-393532, 461459, 461460, 461462, 461464, 461465, 545543.

surements, especially in three dimensions (LIB, LPB, and LM) that exhibit nonoverlapping variation in our samples. Visual comparisons of representative skulls (figs. 11-13) reveal similar proportional differences between $M$. pakaraimae and $M$. pinheiroi to those previously noted between M. pakaraimae and M. parvidens, namely that $M$. pakaraimae has a relatively broader interorbit but smaller orbits. Additionally, the lacrimal foramina are more prominently exposed laterally, M3 never has a complete anterior cingulum, and m4 often has a bicuspid talonid in $M$. pinheiroi.

Specimens ExAmined $(N=8)$ : GuyanaCuyuni-Mazaruni, Mt. Roraima (ROM 115129, 115148, 115254); Potaro-Siparuni, Mt. Ayanganna (ROM 114698), Mt. Wokomung (ROM 115841, 115845). Venezuela-Bolívar, $85 \mathrm{~km} \mathrm{SSE}$ El Dorado (USNM 385046), Churi-tepui (AMNH 176353).
Marmosops parvidens (Tate, 1931)

Figures 2, 5A, 7A, 11-13, 14A

Marmosa parvidens Tate, 1931: 13 (original description).

Marmosa parvidens parvidens: Pine, 1981: 60 (name combination).

Marmosops parvidens: Gardner and Creighton, 1989: 4 (name combination).

TyPE MATERIAL: The holotype (by original designation) consists of the skin and skull of an adult female (FMNH 18545; original number 8) collected by S.B. Warren on 8 September 1906 at Hyde Park (fig. 10: locality 50), a locality near sea level on the Demerara River in East DemeraraWest Coast Berbice about $35 \mathrm{~km}$ south of Georgetown. No other specimens were mentioned in the original description of this species. 


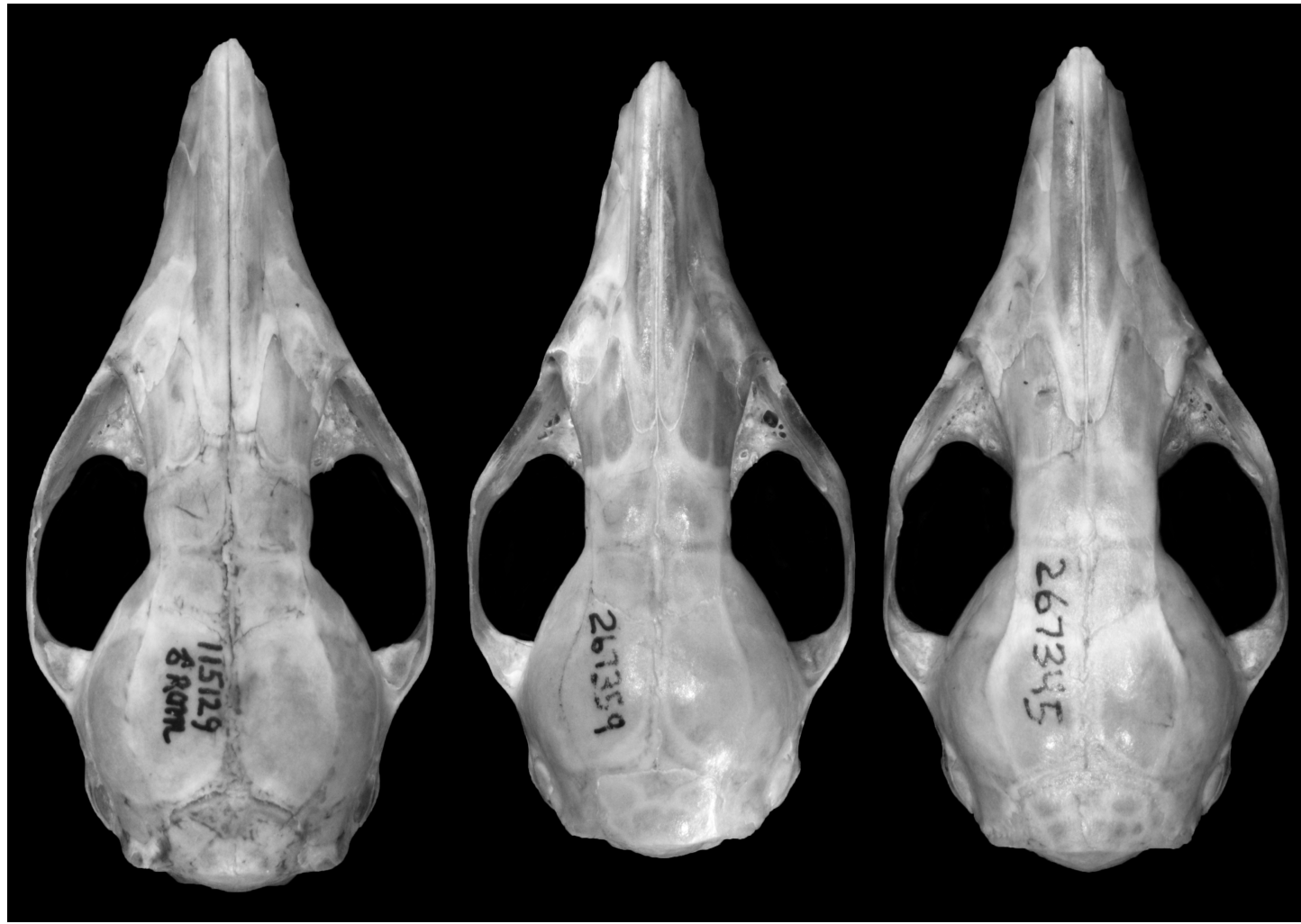

FIG. 11. Dorsal views of skulls of the Parvidens Group of Sciophanes. Left to right: Marmosops pakaraimae (ROM 115129, holotype), M. parvidens (AMNH 267359), and M. pinheiroi (AMNH 267345). All views about $\times 3$.

DisTRIBUTION, HABITATS, AND SYMPATRY: Examined specimens suggest that Marmosops parvidens occurs throughout most of the Guiana Region (north of the Amazon and east of the Rio Negro), but the species appears to be unknown from Venezuela (García et al., 2014), and we have not examined any material from northern Pará. Although we have not personally examined material from Amapá, M. parvidens has recently been reported to occur there (Silva et al., 2013). A single specimen is also known from SE Amazonia (on the lower Rio Tocantins, fig. 10: locality 13). All specimens associated with definite elevational data were collected between sea level and about $500 \mathrm{~m}$. The predominant vegetation throughout the range of this species, which broadly overlaps that of $M$. pinheiroi, is lowland rain forest (e.g., in French Guiana, where both species occur sympatrically; Voss et al., 2001; Catzeflis et al., 2014).
Description: Body pelage dusty reddish brown (near Bister or Snuff Brown) middorsally, but indistinctly paler laterally, and about 6-8 $\mathrm{mm}$ long at midback; ventral pelage extensively self-white from chin to anus (including the inner surfaces of the fore- and hind limbs), usually with only narrow lateral-abdominal borders of gray-based fur. Manus covered dorsally with uniformly pale hairs (the metacarpals not contrasting sharply in color with the digits); lateral carpal tubercles spoon shaped in all examined adult males. Mammae $3-1-3=7$ or $4-1-4=9$. Tail much longer than combined length of head and body (mean LT/HBL $\times 100=150 \%)$; dorsal caudal surface uniformly dark from base to tip, but ventral surface indistinctly paler (especially near the base of the tail).

Nasal bones long (extending well behind the lacrimals) and much wider posteriorly than ante- 


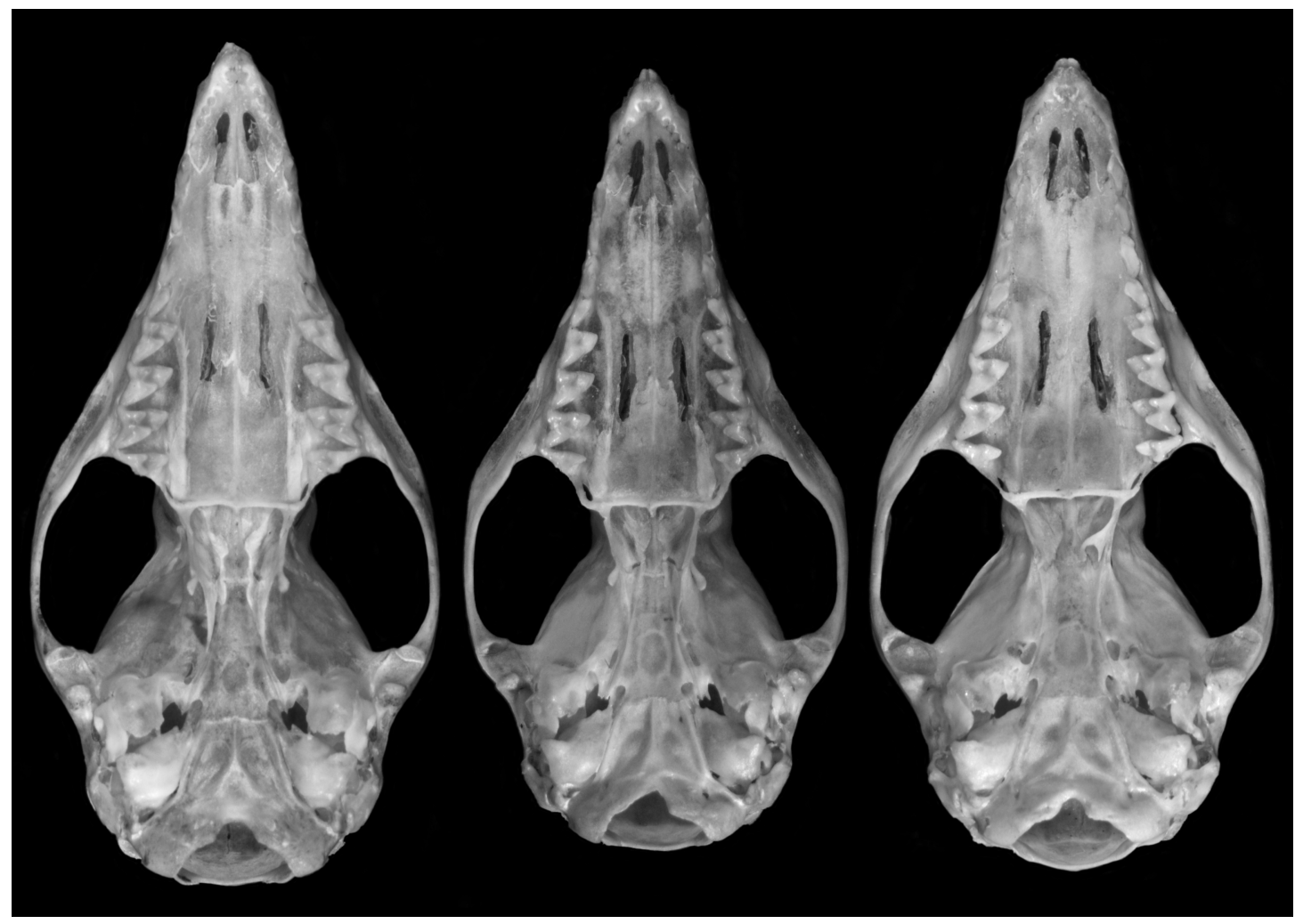

FIG. 12. Ventral views of skulls of the Parvidens Group of Sciophanes. Left to right: Marmosops pakaraimae (ROM 115129, holotype), $M$. parvidens (AMNH 267359), and M. pinheiroi (AMNH 267345). All views about $\times 3$.

riorly (laterally expanded at the maxillary-frontal suture). Lacrimal foramina usually concealed from lateral view inside anterior orbital margin; zygomatic process of squamosal broadly overlapped dorsally by the jugal. Palatine fenestrae absent. Dorsolateral margin of ethmoid foramen usually formed by the orbitosphenoid.

Upper canine (C1) short, with anterior and posterior accessory cusps in both sexes. Upper third molar (M3) anterolabial cingulum narrowly continuous with preprotocrista (anterior cingulum complete). Lower canine (c1) premolariform (procumbent, with posterior accessory cusp) and small, subequal in height to p1; 11 anterolingual accessory cusp absent. Entoconid of $\mathrm{m} 1$ subequal in height to adjacent $\mathrm{m} 2$ paraconid; unworn $\mathrm{m} 4$ talonid with three distinct cusps.

Comparisons: Marmosops parvidens is approximately the same size as $M$. pinheiroi (tables 2, 3) in external dimensions, and differences in dorsal pelage coloration (usually some shade of dusty reddish brown in M. parvidens versus dull brownish gray in $M$. pinheiroi) are sometimes less than obvious. By contrast, ventral pelage coloration provides a consistently useful external criterion for separating these broadly sympatric species: whereas $M$. parvidens has a broad, continuous band of self-whitish fur that extends from chin to groin and along the inner surfaces of the fore- and hind limbs, $M$. pinheiroi has a much narrower, discontinuous midventral streak of self-white hairs that apparently never extends onto the throat nor along the inner surfaces of the fore- and hind limbs. Marmosops parvidens averages smaller than pinheiroi in most craniodental dimensions (WM3 in males is the unique exception; tables 2, 3), but all measurements show overlapping variation between the 


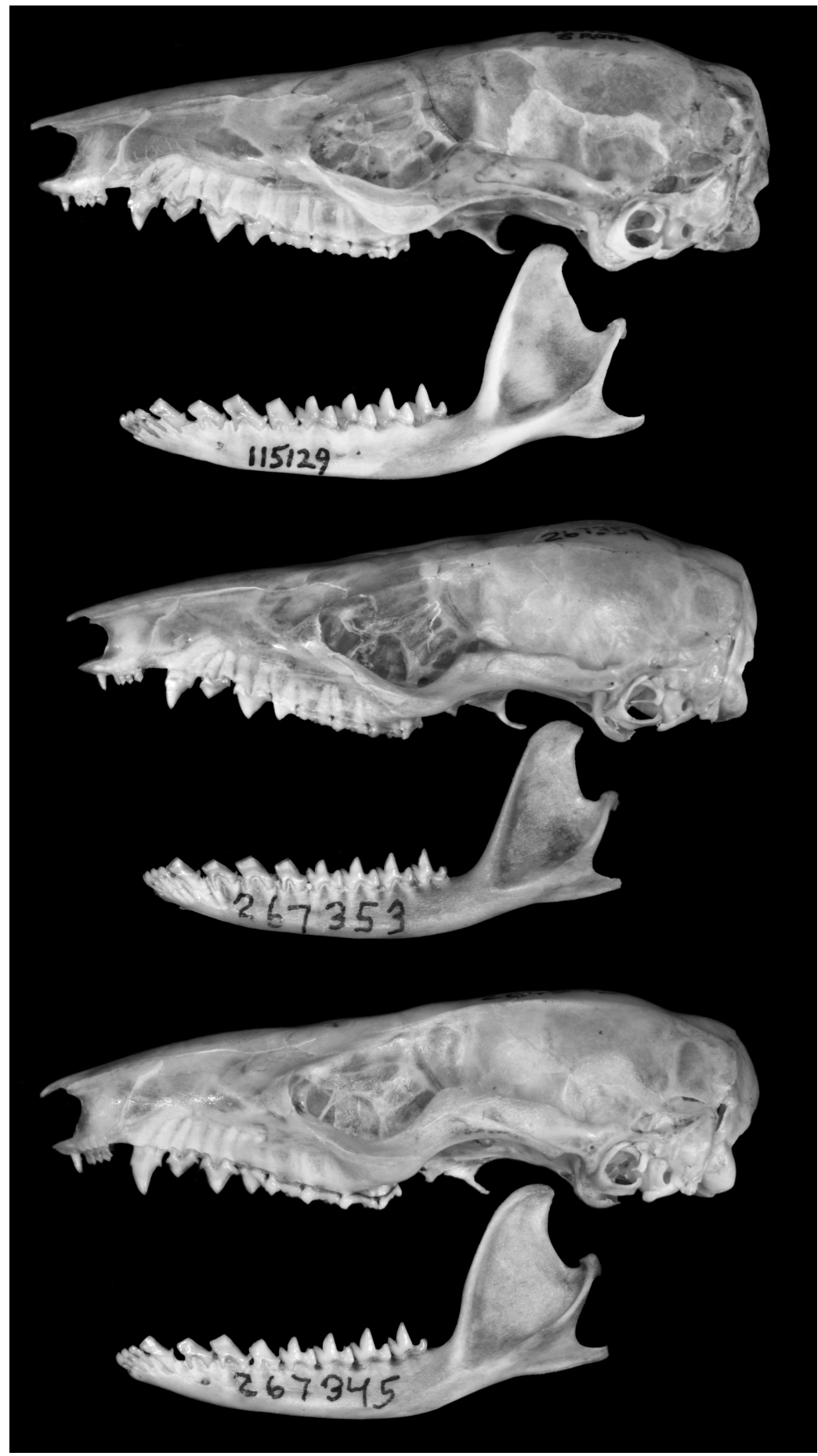

FIG. 13. Lateral views of skulls and mandibles of the Parvidens Group of Sciophanes. Top to bottom: Marmosops pakaraimae (ROM 115129, holotype), M. parvidens (AMNH 267359 [skull], 267353 [mandible]), and M. pinheiroi (AMNH 267345). All views about $\times 3$. 
TABLE 4

Diagnostic Morphological Comparisons among Members of the Parvidens Group of Marmosops (Sciophanes)

\begin{tabular}{llll}
\hline \hline Character & M. pakaraimae & M. parvidens & M. pinheiroi \\
\hline Dorsal pelage & dark brown & paler, usually reddish brown & paler, usually grayish brown \\
Ventral pelage & gray-based & mostly self-whitish & mostly gray-based, but variable \\
Lacrimal foramina & concealed inside orbit & concealed inside orbit & laterally exposed anterior to orbit \\
M3 anterior cingulum & narrowly complete & narrowly complete & incomplete \\
m4 talonid & tricuspid & tricuspid & often bicuspid \\
\hline
\end{tabular}

two species, so none is diagnostic (despite unambiguous multivariate separation; Voss et al., 2001: fig. 24). Instead, qualitative aspects of craniodental morphology provide better characters for species identification: (1) whereas M. parvidens has lacrimal foramina that are usually concealed within the orbit (fig. 14A), the lacrimal foramina of $M$. pinheiroi are more prominently exposed laterally (fig. 14B); (2) the dorsolateral margin of the ethmoid foramen is usually formed by the orbitosphenoid in M. parvidens, whereas the corresponding bony margin in $M$. pinheiroi is often formed by the frontal; (3) the unworn M3 of $M$. parvidens has a narrowly complete anterior cingulum, whereas the anterolabial cingulum and preprotocrista of this tooth are discontinuous in M. pinheiroi; (4) the talonid of $\mathrm{m} 4$ is consistently tricuspid in $M$. parvidens but often appears to be bicuspid in $M$. pinheiroi.

Comparisons between Marmosops parvidens and $M$. pakaraimae are provided in the account of the latter species (above).

Remarks: The binomina "Marmosa parvidens" and "Marmosops parvidens" were previously applied to specimens of several distinct species, including M. bishopi, M. juninensis, M. ojastii, M. pakaraimae, and others (e.g., by Handley, 1976; Pine, 1981; Linares, 1998; Patton et al., 2000). The restricted sense in which this species is now understood was first defined by Voss et al. (2001). Current phylogeographic sampling of $M$. parvidens consists of 10 $c y$ tochrome- $b$ sequences from six localities in French Guiana, Guyana, and Surinam; these differ from one another by an average uncorrected distance of just $1.6 \%$, well below the threshold value for species recognition in coalescent analyses performed by Díaz-Nieto et al. (2016a). Additionally, we have not observed any geographic variation in morphology that corresponds to geographic variation in cytochrome- $b$ sequence data from this species.

We carefully reexamined AMNH 97333, which remains the only specimen of Marmosops parvidens collected south of the Amazon. Although this specimen differs from material collected north of the Amazon in having the dorsolateral margin of the ethmoid foramen bordered by the frontal, and by lacking a continuous anterior cingulum on M3, it closely resembles typical M. parvidens in other respects, notably in its extensively self-white ventral pelage. Although molecular confirmation that $M$. parvidens occurs south of the Amazon would be welcome, we feel reasonably confident in the current identification of this unique specimen.

Specimens examined $(N=42)$ : BrazilAmazonas, Boca Rio Paratucu (AMNH 93970), $80 \mathrm{~km} \mathrm{~N}$ Manaus (INPA 1758, 1762-1769, 1772-1779; USNM 579985-579989); Pará, Ilha do Taiuna (AMNH 97333). French GuianaLes Nouragues (ISEM V-1633), Paracou (AMNH 267344, 267347, 267348, 267353, 267359, 267361; MNHN 1995-929, 1995-933, 1995-939), River Arataye (USNM 548439). Guyana-Demerara-Mahaica, Hyde Park (FMNH 18545), Upper Takutu-Upper Essequibo, Karanambo (ROM 97938). Surinam-Brokopondo, Brownsberg Nature Park (ROM 113997, 114009, 114144); Nickerie, Kayser Gebergte Airstrip (FMNH 93169); Sipaliwini, Bakhuis Transect 13 (ROM 117348). 

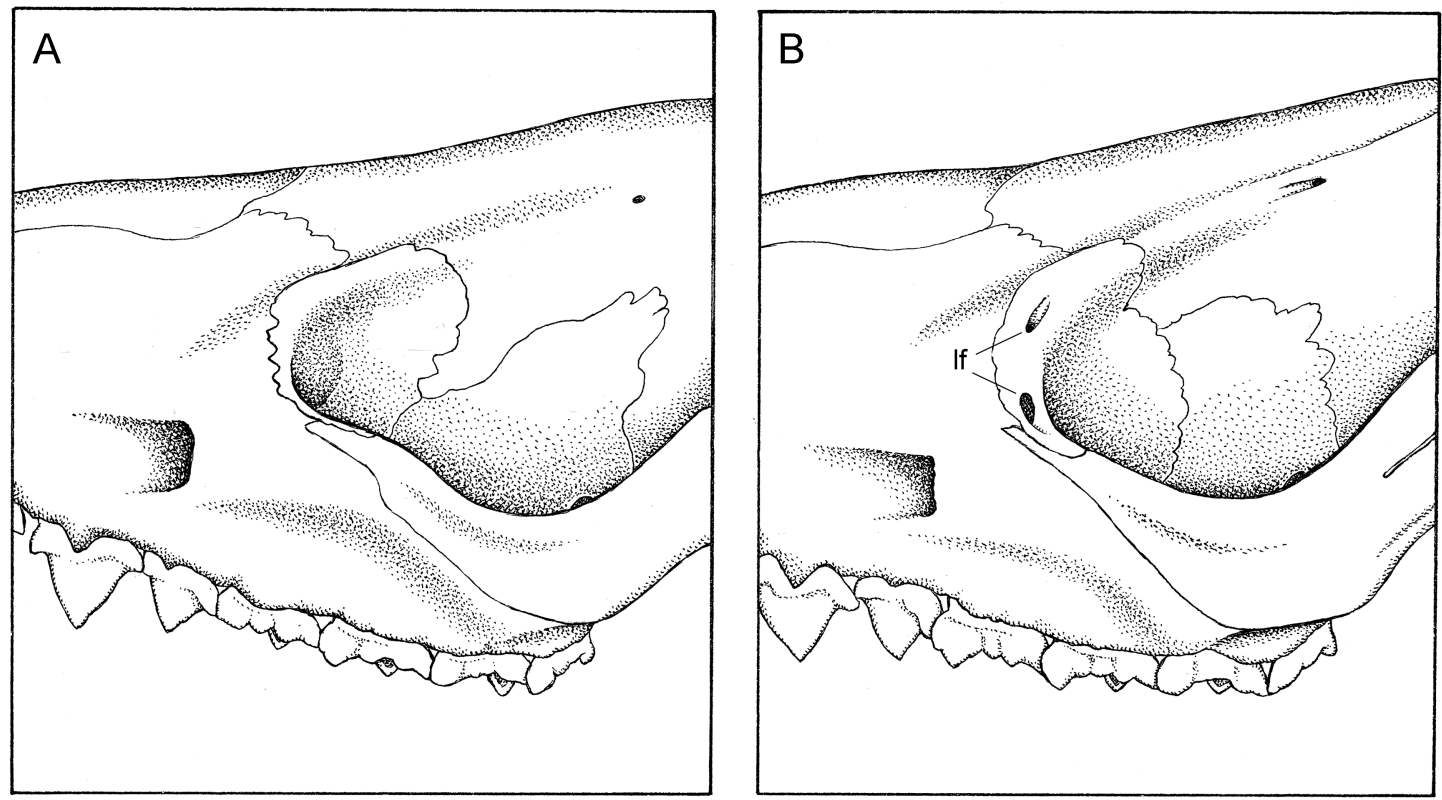

FIG. 14. Lateral views of the anterior orbital region of Marmosops parvidens (A, AMNH 267359) and M. pinheiroi (B, AMNH 267345) illustrating species differences in the lacrimal foramina (lf), which are usually concealed inside the orbit in M. parvidens, but which are laterally exposed on the orbital margin of M. pinheiroi.

\section{Marmosops pinheiroi (Pine, 1981)}

Figures 1, 3A, 6A, 9A, 11-13, 14B

Marmosa parvidens pinheiroi Pine, 1981: 61 (original description).

Marmosa parvidens woodalli Pine, 1981: 62 (original description). Type locality "Nova Area Experimental, Utinga (the wooded area surrounding the Belém waterworks), Belém ( $1^{\circ} 27^{\prime}$ S, $\left.48^{\circ} 29^{\prime} \mathrm{W}\right)$, Pará, Brazil." Marmosops parvidens: Gardner, 1993: 20, part (name combination; pinheiroi and woodalli listed as synonyms).

Marmosops pinheiroi: Voss et al., 2001: 49 (first use of current binomial).

Type material: The holotype (by original designation) consists of the skin and skull of an adult male (USNM 461459, original numbers T-391 and L5049), said to have been collected by personnel of the Instituto Evandro Chagas on 8 May 1969 at Rio Amapari, Serra do Navio (fig. 10: locality 7), Amapá, Brazil. In addition, Pine
(1981) examined 15 other specimens (paratypes), but one of these (USNM 385045) is also a paratype of M. pakaraimae, and two others (AMNH 130521, USNM 385046) might also be referable to the latter species (Voss et al., 2013).

Distribution, habitats, AND SYMPATRY: Based on the material we examined, Marmosops pinheiroi occurs in eastern Venezuela, Guyana, Surinam, French Guiana, and Brazil (Amapá and eastern Pará). We have not examined the specimens that Nascimento et al. (2015) recently identified as $M$. pinheiroi from the Brazilian state of Maranhão, which would be a significant ecogeographic range extension if their material were correctly identified (see Remarks, below). Throughout its known range, this species probably cooccurs with $M$. parvidens, but the two have been collected sympatrically only in French Guiana (Voss et al., 2001; Catzeflis et al., 2014). Specimens of $M$. pinheiroi associated with definite elevational data were collected from near sea level to about $500 \mathrm{~m}$. The predominant vegetation throughout the geographic range of this species-as documented by 
examined specimens-is lowland rain forest (e.g., at Paracou, French Guiana; Voss et al., 2001).

DesCRIPTION: Body pelage brownish gray (near Olive Brown or Fuscous) middorsally, but indistinctly paler laterally, and about $6-8 \mathrm{~mm}$ long at midback; ventral pelage superficially whitish but extensively gray based in most specimens (only the chin, groin, and a narrow midventral streak of abdominal fur are usually self-white); inner surfaces of fore- and hind limbs covered with gray-based fur, apparently never self-white. Manus covered dorsally with uniformly pale hairs (the metacarpals not contrasting sharply in color with the digits); lateral carpal tubercles spoon shaped in all examined adult males. Mammae 3-1-3 = 7 or $4-1-4=9$. Tail much longer than combined length of head and body (mean LT/HBL $\times 100=150 \%$ ); dorsal caudal surface uniformly dark from base to tip, but ventral surface indistinctly paler (especially near the base of the tail).

Nasal bones long (extending well behind the lacrimals) and much wider posteriorly than anteriorly (laterally expanded at the maxillary-frontal suture). Lacrimal foramina usually exposed in lateral view; zygomatic process of squamosal bone broadly overlapped dorsally by the jugal. Palatine fenestrae absent. Dorsolateral margin of ethmoid foramen formed by the orbitosphenoid in some specimens (e.g., ROM 108920, AMNH 267340,267346 ), by the frontal in others (e.g., AMNH 267341, 267342), occasionally with bilateral variation (e.g., AMNH 267345).

Upper canine (C1) short, apparently always with anterior and posterior accessory cusps in both sexes. Upper third molar (M3) anterolabial cingulum discontinuous with preprotocrista (anterior cingulum incomplete). Lower canine (c1) premolariform (procumbent, with posterior accessory cusp) and subequal in height to p1; 1 anterolingual accessory cusp absent. Entoconid of $\mathrm{m} 1$ shorter than adjacent $\mathrm{m} 2$ paraconid in some specimens (e.g., AMNH 266423, 267342, 267345), but these cusps subequal in others (e.g., AMNH 267349, 267357); unworn $m 4$ talonid often with only two distinct cusps.
COMPARISONS: Diagnostic comparisons of Marmosops pinheiroi with M. pakaraimae and $M$. parvidens are provided in earlier species accounts (see above).

REMARKS: In our previous analyses of molecular sequence data (Voss et al., 2013; Díaz-Nieto et al., 2016a), we recovered two cytochrome- $b$ haplogroups among the material here referred to Marmosops pinheiroi, the first consisting of six sequences from the Guianas and the second including two sequences from southeastern Pará (south of the Amazon and east of the Rio Xingu). On the assumption that these haplogroups are physically separated by the lower Amazon, then the epithet pinheiroi could be associated with the former group and woodalli with the latter. Although this phylogeographic structure is robustly supported, these haplogroups differ on average by only $3.9 \%$ in uncorrected pairwise sequence comparisons, and we are unable to morphologically distinguish their corresponding voucher material. Therefore, we continue to treat woodalli as a junior (subjective) synonym.

The specimens that Nascimento et al. (2015) identified as Marmosops pinheiroi extend the potential range of this species by almost $700 \mathrm{~km}$, into the Brazilian state of Maranhão. These specimens are also remarkable for having been collected in savanna, whereas all others known to us have been taken in lowland rain forest. Unfortunately, the identification of this interesting material is apparently based only on sequence analysis and external measurements. Supporting evidence from craniodental morphology would be very welcome.

Specimens examined $(N=33)$ : BrazilAmapá, Serra do Navio (USNM 461459, 461460, 461462-461465); Pará, 52 km SSW Altamira (USNM 549294), Belém (USNM 545543), Utinga (USNM 393529-393532, 393534). French Guiana-Paracou (AMNH 266423, 267340, 267341, 267342, 267345, 267346, 267349, 267352, 267357; MNHN 1995-931, 1995-932). Guyana-Potaro-Siparuni, Forest Canopy Walkway (ROM 119852), 10 km NW Kurupukari (ROM 108920), Kabukalli Landing (ROM 111558, 111663). Surinam-Bokopondo, 
TABLE 5

Measurements (mm) and Weights (g) of Adult Male Specimens of the Fuscatus Group of Marmosops (Sciophanes)

\begin{tabular}{|c|c|c|c|c|}
\hline & M. carri ${ }^{\mathrm{a}}$ & M. fuscatus ${ }^{\mathrm{b}}$ & M. handleyic & M. invictus ${ }^{\mathrm{d}}$ \\
\hline HBL & $139(126-155) 17$ & $136(132-140) 2$ & $116(110-122) 2$ & $111(106-115) 5$ \\
\hline LT & $169(152-183) 17$ & $149(147-150) 2$ & $149(149-149) 2$ & $136(124-147) 5$ \\
\hline $\mathrm{HF}$ & $21(20-23) 17$ & $20(19-20) 2$ & $19(19-20) 2$ & $18(17-19) 5$ \\
\hline Ear & $26(23-29) 17$ & 25 & $21(20-21) 2$ & $21(21-22) 3$ \\
\hline $\mathrm{CBL}$ & $36.7(33.8-41.2) 20$ & $33.3(31.8-35.4) 5$ & $29.1(27.7-30.5) 2$ & $30.0(29.8-30.3) 4$ \\
\hline NL & $18.1(15.6-20.4) 17$ & $15.9(15.2-16.7) 5$ & $14.2(12.7-15.6) 2$ & $14.5(14.1-14.9) 5$ \\
\hline NB & $3.1(2.7-3.5) 22$ & $3.1(2.7-3.3) 5$ & $3.6(3.5-3.7) 2$ & $3.5(3.2-3.8) 5$ \\
\hline LIB & $6.5(6.2-7.0) 20$ & $6.3(6.0-6.6) 5$ & $5.8(5.5-6.0) 2$ & $5.9(5.7-6.0) 5$ \\
\hline ZB & $19.5(17.1-21.8) 20$ & $17.7(16.5-19.5) 4$ & $15.0(14.5-15.5) 2$ & $15.8(15.2-16.1) 4$ \\
\hline PL & $20.8(19.1-23.0) 21$ & $18.9(18.4-19.6) 5$ & $16.1(15.3-17.0) 2$ & $16.6(16.2-17.0) 5$ \\
\hline PB & $10.9(10.1-11.8) 22$ & $10.0(9.7-10.7) 5$ & 8.5 & $9.0(8.6-9.5) 5$ \\
\hline MTR & $15.2(14.3-17.2) 22$ & $13.6(13.3-13.9) 5$ & $12.0(11.6-12.5) 2$ & $12.3(12.1-12.5) 5$ \\
\hline LM & $7.2(7.0-7.7) 22$ & $6.6(6.5-6.7) 5$ & $6.1(6.0-6.3) 2$ & $6.3(6.3-6.5) 5$ \\
\hline M1-3 & $6.2(5.9-6.5) 22$ & $5.7(5.7-5.7) 5$ & $5.3(5.2-5.5) 2$ & $5.4(5.3-5.7) 5$ \\
\hline WM3 & $2.3(2.1-2.5) 22$ & $2.2(2.1-2.2) 5$ & 1.7 & $2.1(2.0-2.2) 5$ \\
\hline Weight & $60(41-85) 10$ & 69 & 30 & - \\
\hline
\end{tabular}

a The mean, the observed range (in parentheses), and the sample size are provided for each measurement of the following series: AMNH 150007, 186437, 186438, 214439, 259978; KU 372934; USNM 370023, 370024, 370031, 370034, 370035, 370039, 372934 406926, 406928, 406931, 418515, 443787, 443789, 517258-517260.

b The mean, the observed range (in parentheses), and the sample size are provided for each measurement of the following series: AMNH 276509, 276580; BMNH 3.1.5.2, 3.1.5.3; FMNH 22174.

c The mean, the observed range (in parentheses), and the sample size are provided for each measurement of the following series: CTUA 433; FMNH 69823.

$\mathrm{d}$ The mean, the observed range (in parentheses), and the sample size are provided for each measurement of the following series: USNM 178708, 309265, 309267, 337960, 337962.

Finisanti (FMNH 95320); Nickerie, Sipaliwini Airstrip (CM 63506); Sipaliwini, Bakhuis Transect (ROM 116974). Venezuela-Bolivar, Auyántepui (AMNH 130568, 130570).

\section{Species of the Fuscatus Group}

Species of the Marmosops fuscatus group are distinguished from other members of the subgenus Sciophanes by their entirely gray-based ventral fur, bladelike lateral carpal tubercles (in adult males), females with 3-1-3 = 7 mammae, and $\mathrm{m} 1$ entoconid usually subequal to the adjacent $\mathrm{m} 2$ paraconid. The four recognized species are found in eastern Panama, the northern part of the Cordillera Central of Colombia, the Cordillera de Mérida in western Venezuela, the coastal sierras and adjacent rain-forested lowlands of northern Venezuela, and the continental-shelf islands of Trinidad and Tobago. Diagnostic quantitative and qualitative comparisons are summarized in tables 5-7.

Marmosops carri (Allen and Chapman, 1897)

Figures $6 \mathrm{C}, 7 \mathrm{~B}, 8 \mathrm{~B}, 15,16$

Thylamys carri Allen and Chapman, 1897: 27 (original description).

Didelphys (Marmosa) carri: Trouessart, 1905: 856 (name combination).

Marmosa (Thylamys) carri: Cabrera, 1919: 40 (name combination).

Marmosops fuscatus: Gardner, 1993: 19; part (carri treated as a subjective junior synonym of fuscatus Thomas, 1896) 
TABLE 6

Measurements $(\mathrm{mm})$ and Weights $(\mathrm{g})$ of Adult Female Specimens of the Fuscatus Group of Marmosops (Sciophanes)

\begin{tabular}{|c|c|c|c|c|}
\hline & M. carri ${ }^{\mathrm{a}}$ & M. fuscatus ${ }^{\mathrm{b}}$ & M. handleyic & M. invictus ${ }^{\mathrm{d}}$ \\
\hline HBL & $130(125-134) 5$ & - & $109(104-113) 5$ & $109(104-112) 5$ \\
\hline LT & $156(145-171) 5$ & - & $135(129-141) 5$ & $133(124-140) 5$ \\
\hline $\mathrm{HF}$ & $20(19-21) 5$ & - & $18(17-19) 5$ & $17(17-18) 5$ \\
\hline Ear & $25(24-26) 5$ & - & $20(19-21) 5$ & $22(21-22) 4$ \\
\hline $\mathrm{CBL}$ & $33.7(32.3-34.9) 6$ & - & 29.9 (29.4-30.7) 5 & $29.3(28.2-29.9) 5$ \\
\hline NL & $16.1(15.1-16.5) 6$ & - & $15.1(14.5-15.5) 5$ & $14.1(13.6-14.9) 5$ \\
\hline NB & $2.9(2.5-3.2) 6$ & 3.6 & $3.5(3.3-3.7) 5$ & $3.6(3.3-4.1) 5$ \\
\hline LIB & $6.2(6.0-6.4) 6$ & 6.1 & $6.0(5.9-6.2) 5$ & $5.9(5.7-6.1) 5$ \\
\hline ZB & $17.1(16.1-17.7) 4$ & - & $15.1(14.5-15.5) 4$ & $15.7(14.9-16.2) 5$ \\
\hline PL & $19.3(19.1-19.6) 5$ & 18.0 & $16.7(16.3-17.0) 5$ & $16.5(16.0-17.0) 5$ \\
\hline PB & $10.7(10.3-11.3) 5$ & 9.4 & $9.0(8.8-9.4) 5$ & $9.2(9.1-9.5) 5$ \\
\hline MTR & $14.4(13.9-15.0) 6$ & 13.0 & $12.5(12.0-12.9) 5$ & $11.9(11.8-12.1) 5$ \\
\hline LM & $7.2(7.0-7.6) 6$ & 6.3 & $6.3(5.9-6.6) 5$ & $6.2(6.0-6.4) 5$ \\
\hline M1-3 & $6.2(5.9-6.5) 6$ & 5.5 & $5.4(5.2-5.6) 5$ & $5.3(5.2-5.5) 5$ \\
\hline WM3 & $2.3(2.2-2.6) 6$ & 2.2 & 1.6 & $2.1(2.0-2.1) 5$ \\
\hline Weight & $42(41-42) 2$ & - & $27(21-31) 4$ & - \\
\hline
\end{tabular}

a The mean, the observed range (in parentheses), and the sample size are provided for each measurement of the following series: AMNH 5921; USNM 370030, 370037, 406929, 443786, 517256.

b Measurements of BMNH 96.11.1.6 (holotype).

c The mean, the observed range (in parentheses), and the sample size are provided for each measurement of the following series: CTUA 411, 413, 414, 416; FMNH 69838.

$\mathrm{d}$ The mean, the observed range (in parentheses), and the sample size are provided for each measurement of the following series: USNM 178709, 306386, 309266, 337959, 337961.

Marmosops fuscatus carri: Gardner and Creighton, 2008: 66 (name combination).

Marmosops fuscatus fuscatus: Gardner and Creighton, 2008: 66 (name combination); part (Venezuelan material of carri misidentified as $M . f$. fuscatus).

Type Material: The holotype (by original designation) consists of the skin and skull of an adult male (AMNH 7314/5922, original number 731) collected by Frank M. Chapman at Caparo (fig. 17: locality 97), Trinidad, on 20 March 1894. Two other specimens (paratypes) were also part of Allen and Chapman's type series: one is AMNH 7313/5921 (a young adult female), and the other was AMNH 7315/5923 (said to be an adult male; not examined and presumed lost).

Distribution, habitATS, AND Sympatry: Marmosops carri is known from Trinidad,
Tobago, and Venezuela (fig. 17). ${ }^{4}$ On the Venezuelan mainland, examined specimens have been collected in premontane and montane rain forest along the northern coastal cordilleras (e.g., at Hotel Humboldt; Handley, 1976: 79) and the Cordillera de Trujillo (e.g., at Hacienda Misisí; Handley, 1976: 71) between about $1000 \mathrm{~m}$ and 2300 m (but see Remarks). On Trinidad, however, it is definitely known to occur near sea level (e.g., at Rio Grande Forest; Appendix 1: locality $100)$, presumably in lowland rain forest. Although the known range of $M$. carri overlaps with that of M. ojastii (a member of the Bishopi Group; see below) and might be expected to contact that of $M$. fuscatus, these species have apparently not been collected sympatrically.

\footnotetext{
${ }^{4}$ Our material of Marmosops carri from Tobago, the first to be reported from that island, was originally identified as such by Darrin P. Lunde.
} 
TABLE 7

Diagnostic Morphological Comparisons among Members of the Fuscatus Group of Marmosops (Sciophanes)

\begin{tabular}{|c|c|c|c|c|}
\hline Character & M. carri & M. fuscatus & M. handleyi & M. invictus \\
\hline Dorsal pelage of manus & all-white & all-white & metacarpals dark & metacarpals dark \\
\hline Nasal shape & uniformly narrow & uniformly narrow & wider posteriorly & wider posteriorly \\
\hline Palatine fenestrae & variable & variable & present & absent \\
\hline \multirow[t]{2}{*}{$\mathrm{C} 1$ accessory cusps } & $\widehat{o}:$ absent & $\widehat{o}:$ absent & đ: posterior only & ऽ: posterior only \\
\hline & q: variable & $q$ : posterior only & $q$ : anterior \& posterior & q : posterior only \\
\hline Heights c1, p1 (males) & $\mathrm{c} 1>\mathrm{p} 1$ & $\mathrm{cl}>\mathrm{p} 1$ & $\mathrm{c} 1 \approx \mathrm{p} 1$ & $\mathrm{c} 1 \approx \mathrm{p} 1$ \\
\hline c1 lingual accessory cusp & absent & absent & present & usually present \\
\hline $\mathrm{m} 1$ entoconid, $\mathrm{m} 2$ paraconid & subequal & subequal & subequal & $\mathrm{m} 2$ paraconid taller \\
\hline Length of molars (LM) & $7.0-7.7 \mathrm{~mm}$ & $6.0-6.7 \mathrm{~mm}^{\mathrm{a}}$ & $5.9-6.6 \mathrm{~mm}$ & $6.0-6.5 \mathrm{~mm}$ \\
\hline
\end{tabular}

a Observed range includes measurements from two subadults (USNM 418503, 442719) with completely erupted molar dentitions (not included in tables 5 and 6).

DESCRIPTION: Body pelage grayish brown (near Fuscous or Hair Brown) middorsally, sometimes indistinctly paler laterally, and about 7-9 mm long at midback; ventral pelage superficially whitish, but hairs of throat, chest, and abdomen uniformly gray based in most specimens (a few have patches or narrow streaks of self-white fur on the throat, chest, groin, or along the insides of the thighs; e.g., AMNH 144832, USNM 370037). Manus covered dorsally with uniformly pale hairs (the metacarpals not contrasting sharply in color with the digits); lateral carpal tubercles bladelike in all examined adult males. Mammae 3-1-3 = 7 in all examined females with visible teats. Tail longer than combined length of head and body (mean LT/HBL $\times 100=120 \%$ ); dorsal caudal surface dark, but indistinctly paler distally in some specimens; ventral caudal surface distinctly paler than dorsal surface.

Nasal bones long (extending well behind the lacrimals) and uniformly narrow, without conspicuous lateral expansion at the maxillary-frontal suture. Interorbital region broad, with rounded supraorbital margins in females and young adult males, but relatively narrower and tending to develop squared supraorbital margins in large adult males; postorbital processes absent or indistinct. Lacrimal foramina usually visible in lateral view; zygomatic process of the squamosal broadly overlapped dorsally by the jugal. Palatine fenestrae present or absent (when present, palatine fenestrae usually consist of several small irregular perforations, but in a few specimens they are large). Dorsolateral margin of ethmoid foramen usually formed by the orbitosphenoid.

Upper canine (C1) sexually dimorphic (taller and unicuspid in males, shorter and with one or two accessory cusps in females). ${ }^{5}$ Upper third molar (M3) anterolabial cingulum discontinuous with preprotocrista (anterior cingulum incomplete). Lower canine (c1) sexually dimorphic (erect, without accessory cusps, and taller than p1 in males versus procumbent, with posterior accessory cusp, and subequal in height to $\mathrm{p} 1$ in females); cl anterolingual accessory cusp usually absent in both sexes. Entoconid of $\mathrm{m} 1$ apparently subequal to $\mathrm{m} 2$ paraconid (but few specimens with unworn molars examined for this trait); unworn $\mathrm{m} 4$ talonid with three distinct cusps.

COMPARISONs: Marmosops carri is externally similar to M. fuscatus (with which it was formerly synonymized; see Remarks) but has somewhat paler dorsal fur, averages larger in all external measurements (tables 5,6 ), and has a relatively longer tail (e.g., LT/HBL $\times 100=122 \%$

\footnotetext{
${ }^{5}$ All examined females have posterior accessory $\mathrm{C} 1$ cusps, and insular populations (from Trinidad and Tobago) usually also have small anterior accessory cusps (e.g., AMNH 5921, 234951, 234954, 234956, 259979). By contrast, females from mainland populations usually lack anterior accessory cusps on C1 (e.g., AMNH 144832; USNM 370030, 517256).
} 


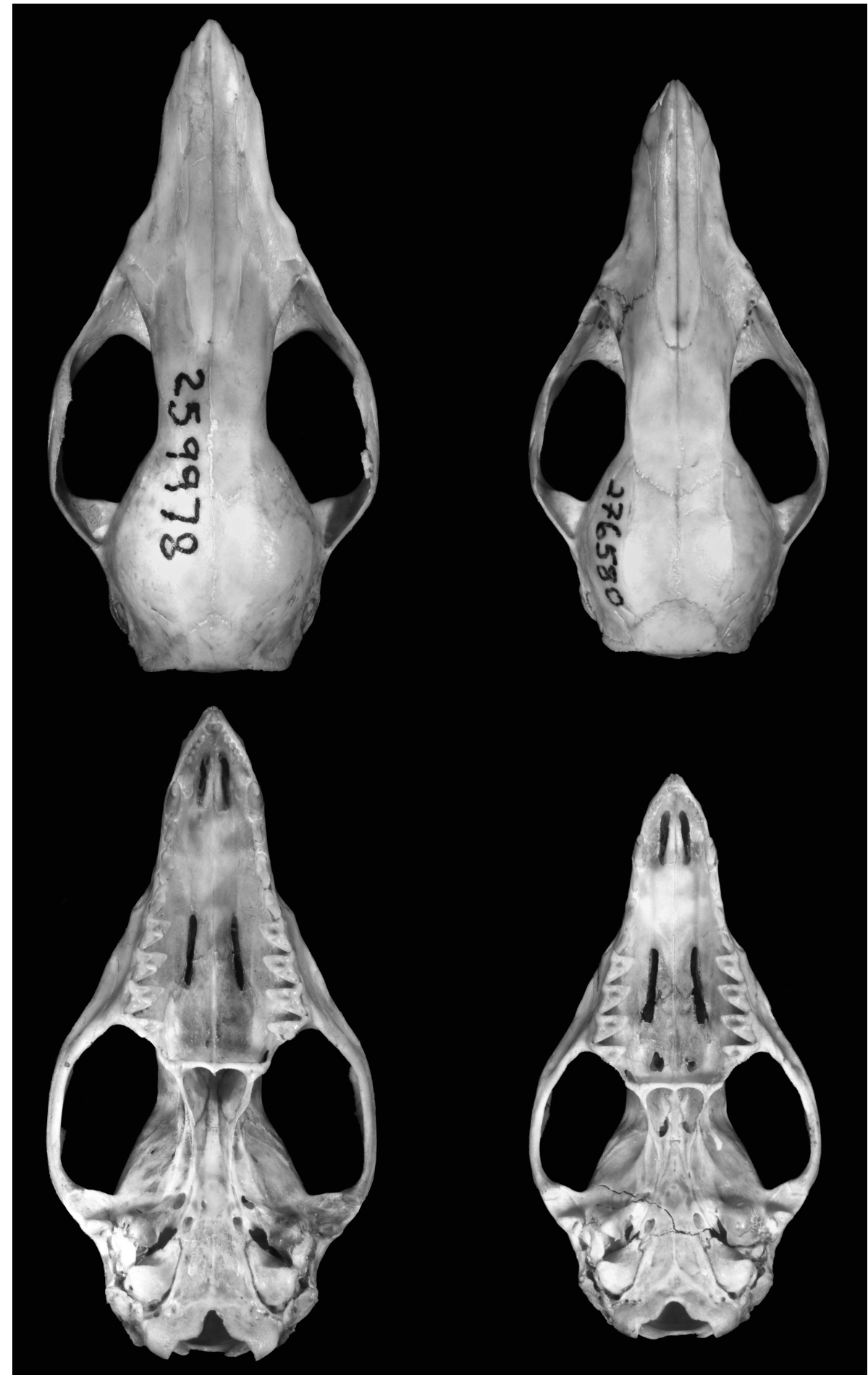

FIG. 15. Dorsal and ventral views of skulls of Marmosops carri (left, AMNH 259978) and M. fuscatus (right, AMNH 276580). All views about $\times 2.5$. 


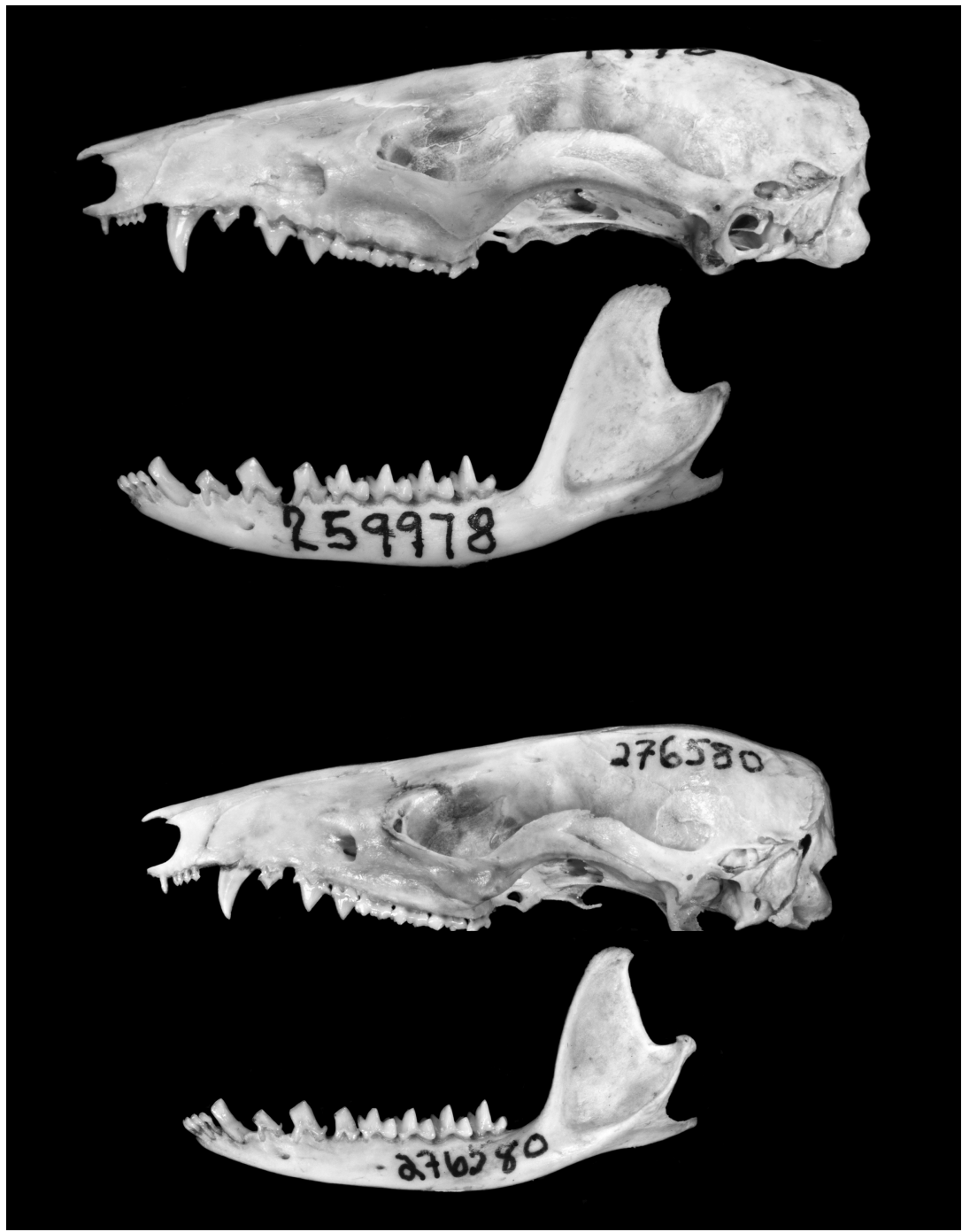

FIG. 16. Lateral views of skulls and mandibles of Marmosops carri (above, AMNH 259978) and M. fuscatus (below, AMNH 276580). All views about $\times 2.5$.

in male carri versus $110 \%$ in male fuscatus). Marmosops carri averages larger than M. fuscatus in all measured craniodental dimensions (except nasal breadth, NB) but especially in three dental dimensions (MTR, LM, M1-3) that exhibit nonoverlapping variation. In other (qualitative) aspects of craniodental morphology the two species cannot be consistently distinguished, although there are modal differences in some characters. For example, the dorsolat- eral margin of the ethmoid foramen is usually formed by the orbitosphenoid in M. carri, whereas this foramen is bordered dorsolaterally by the frontal in M. fuscatus. Handley and Gordon (1979) implied that carri and fuscatus (which they regarded as no more than subspecifically distinct) differ in nasal morphologythe nasals were said to be more expanded posteriorly in fuscatus than in carri-but we did not observe a consistent taxonomic difference in 


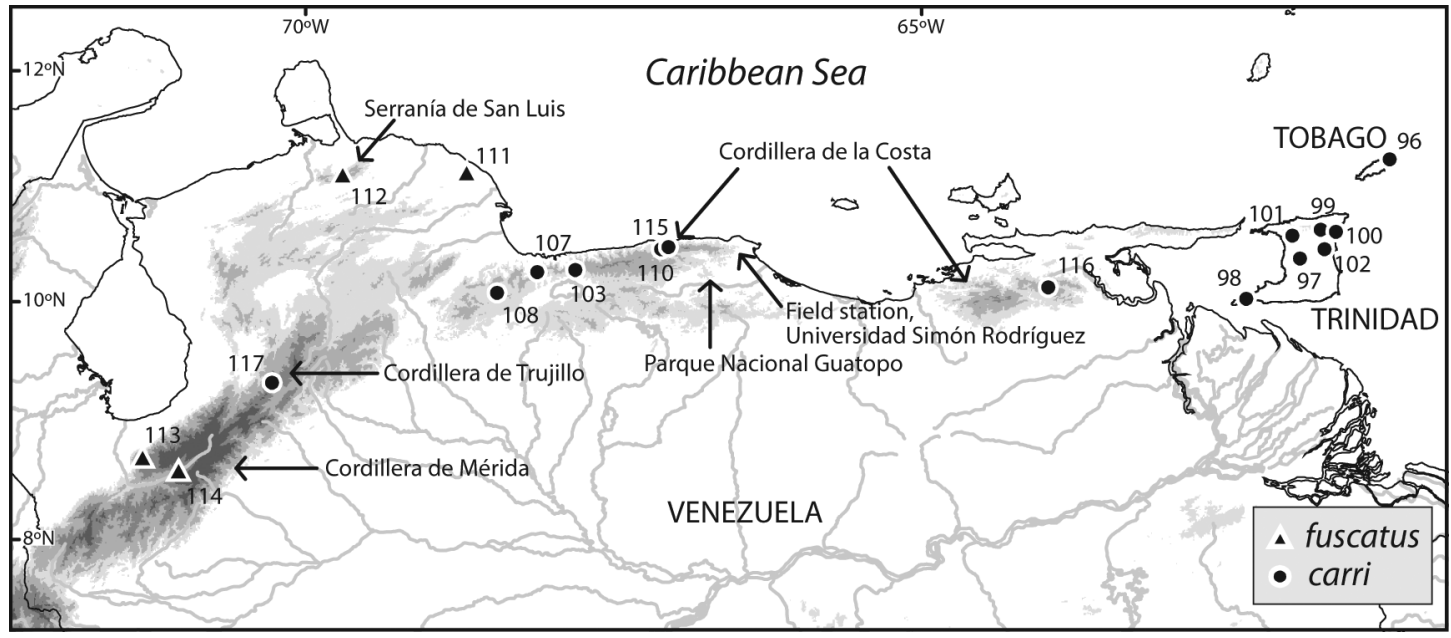

FIG. 17. Collecting localities of examined specimens of Marmosops carri and M. fuscatus. Numbers are keyed to entries in the gazetteer (appendix 1). Progressively darker shading indicates higher elevations: pale gray $\geq 500 \mathrm{~m}$, medium gray $\geq 1000 \mathrm{~m}$, dark gray $\geq 2000 \mathrm{~m}$, darkest gray $\geq 3000 \mathrm{~m}$.

our comparisons of representative specimens of these taxa.

Marmosops carri is substantially larger than $M$. handleyi in all external measurements, especially in three dimensions (HBL, LT, and Ear) that exhibit nonoverlapping variation in samesex sample comparisons. In qualitative external comparisons, these species principally differ in coloration: whereas $M$. carri has grayish-brown dorsal body pelage and entirely white forefeet, $M$. handleyi has dark-brown dorsal pelage and dark metacarpals that contrast in color with its whitish manual digits. Skulls and dentitions of $M$. carri are considerably larger than those of $M$. handleyi, exhibiting nonoverlapping variation in same-sex comparisons of eight dimensions (CBL, ZB, PL, PB, MTR, LM, M1-3, and WM3). Overall, the skull of $M$. carri is more heavily built (especially in males) by comparison with the more delicate cranial construction of $M$. handleyi. In qualitative aspects of craniodental morphology, M. carri principally differs from $M$. handleyi by its uniformly narrow nasals (the nasals are posteriorly expanded in $M$. handleyi); unicuspid male $\mathrm{C} 1$ (this tooth has a posterior accessory cusp in male M. handleyi), and absence of a lingual accessory cusp on $\mathrm{cl}$ in most specimens of both sexes (a lingual accessory cusp on $\mathrm{cl}$ is present in both sexes of $M$. handleyi).

Marmosops carri is much larger than M. invictus, with no overlapping variation in same-sex comparisons of most measured dimensions. These species also differ strikingly in dorsal pelage coloration (much paler in M. carri than in $M$. invictus), coloration of the forefeet (entirely whitish in $M$. carri, whereas the metacarpals are dark in M. invictus), and tail markings (the tail is much more distinctly bicolored in M. carri). Qualitative craniodental comparisons reveal several additional contrasting differences. Among others, M. carri has uniformly narrow nasals, whereas the nasals are laterally expanded near the maxillary-frontal suture in M. invictus; at least the ventral lacrimal foramen is consistently visible in lateral view in $M$. carri, whereas this foramen is concealed inside the orbit in M. invictus; palatine fenestrae are often present in $M$. carri, whereas palatine perforations are consistently absent in $M$. invictus); $\mathrm{cl}$ is a tall unicuspid tooth in male $M$. carri, whereas this tooth is short and premolariform in male $M$. invictus; and the $\mathrm{m} 1$ entoconid is subequal in height to the adjacent $\mathrm{m} 2$ paraconid in $M$. carri, whereas 
the $\mathrm{m} 1$ entoconid is shorter than the $\mathrm{m} 2$ paraconid in $M$. invictus.

REMARKs: Marmosops carri exhibits noteworthy sexual size dimorphism, with adult males averaging larger than adult females in most measured dimensions, especially those prone to strong positive allometry (e.g., zygomatic breadth; tables 5,6 ). The sexes additionally differ in interorbital and canine morphology as described above. Maturational changes in the interorbital morphology of adult males appear to result from enlargement of the temporalis musculature, which is accommodated by an increasingly well-defined postorbital constriction and by supraorbital remodeling.

This species was long regarded (e.g., by Tate, 1933) as endemic to Trinidad, but Handley and Gordon (1979) correctly observed that specimens from the coastal cordilleras on the adjacent Venezuelan mainland are morphologically indistinguishable from Trinidadian material. Handley and Gordon recognized that specimens referable to Marmosops carri are distinctively larger than topotypical material of Marmosops fuscatus (from the Mérida Andes), but they judged these taxa to be conspecific and used the older name (fuscatus) for both.

Although Marmosops carri and M. fuscatus are morphologically similar (in particular, these are the only species of Sciophanes that exhibit large size and uniformly narrow nasals), they form distinct cytochrome- $b$ haplogroups (Díaz-Nieto et al., 2016a), and measured specimens have nonoverlapping molar dimensions: $\mathrm{LM}=7.0-7.7 \mathrm{~mm}$ in $M$. carri $(N=28)$ versus $6.0-6.7 \mathrm{~mm}$ in $M$. fuscatus $(N=8)$. The specimen from Trujillo (USNM 372934) that Handley and Gordon (1979) believed to be intermediate to M. carri and M. fuscatus has large molars $(\mathrm{LM}=7.0 \mathrm{~mm})$ and belongs to the same haplogroup that occurs on Trinidad (DíazNieto et al., 2016a: fig. S1); therefore, we refer this specimen (and others collected in the Cordillera de Trujillo) to $M$. carri.

We have not examined any voucher material from two ecological studies of mouse opossums identified as Marmosops fuscatus, one by O'Connell
(1979) and the other by Cordero (2001). O'Connell's study was carried out at Parque Nacional Guatopo in the interior coastal range of northern Venezuela (ca. $10^{\circ} 05^{\prime} \mathrm{N}, 66^{\circ} 30^{\prime} \mathrm{W}$; on the border between the states of Miranda and Guárico), where " $M$. fuscatus" was said to occur only at higher elevations, presumably in premontane rain forest. Cordero's study was carried out at a field station of the Universidad Simón Rodríguez, close to the Caribbean coast in northern Venezuela $\left(10^{\circ} 20^{\prime} \mathrm{N}, 6^{\circ} 15^{\prime} \mathrm{W}\right.$; in Miranda), where "M. fuscatus" was trapped in lowland rain forest near sea level. Based on their geographic locations (fig. 17), we expect that the species observed in both of these studies was M. carri. Also unexamined by us are a substantial number of Venezuelan specimens identified as M. fuscatus (see Pérez-Hernández, 1989), many of which seem likely to represent $M$. carri. A careful review of this and subsequently collected in-country material should contribute to a more accurate assessment of the geographic ranges of these taxa, and we encourage additional sequencing efforts to test the correlation between haplotype membership and morphometric divergence upon which our hypothesis of full species status is largely based.

Specimens examined $(N=70)$ : Trinidad and Tobago-Tobago, near Charlotteville (AMNH 259970, 259978, 259979); Trinidad, Caparo (AMNH 7313/5921, 7314/5922), Cedros (AMNH 234951), Cumaca (AMNH 169759, 169760), Rio Grande Forest (AMNH 186437, 186438, 188353), St. Augustine (AMNH 150007), Turure Forest (AMNH 214439, 214441, 234952 234956, 234959, 234974). Venezuela-Aragua, Rancho Grande (AMNH 144832; USNM 517256-517260); Carabobo, 4 km NW Montalbán (USNM 418515, 443731, 443783-443789, 496520, 496521), Cumbre de Valencia (AMNH 31531); Distrito Federal, Los Venados (USNM 370022-370024); Miranda/Vargas, Hotel Humboldt (USNM 370027-370031, 370033-370039, 370041, 370042, 371300, 496517); Monagas, San Agustín (USNM 406925-406932, 4069324); Trujillo, 13-14 km E Trujillo (KU 120254, USNM 372933, 372934). 
Marmosops fuscatus (Thomas, 1896)

Figures 4B, 15, 16

Marmosa fuscata Thomas, 1896: 313 (original description).

Didelphys (Marmosa) fuscata: Trouessart, 1898: 1240 (name combination).

Marmosa (Marmosa) fuscata: Cabrera, 1919: 36 (name combination).

Marmosa cracens Handley and Gordon, 1979: 66 (original description). Type locality "near La Pastora, 14 km ENE Mirimire, Falcón, Venezuela."

Marmosa crascens: Reig et al., 1985: 342 (incorrect subsequent spelling of $M$. cracens Handley and Gordon, 1979).

Marmosops cracens: Gardner and Creighton, 1989: 4 (name combination).

Marmosops fuscatus: Gardner and Creighton, 1989: 4 (first use of current binomial).

Marmosa (Marmosops) cracens: Pérez-Hernández et al., 1994: 35 (name combination).

Marmosa (Marmosops) fuscata: Pérez-Hernández et al., 1994: 37 (name combination); part (not including misidentified specimens of M. carri).

Marmosops fuscatus fuscatus: Gardner and Creighton, 2008: 66 (name combination); part (not including misidentified specimens of $M$. carri).

TyPe MATERIAL: The holotype (by original designation) consists of the skin and skull of an old adult female (BMNH 1896.11.1.6) collected by "S. Briceno" (= Salomón Briceño-Gabaldón, a commercial collector) at $1630 \mathrm{~m}$ elevation along the Río Albarregas (misspelled "Abbaregas" by Thomas, 1896) near the city of Mérida (fig. 17: locality 114) in the Venezuelan state of Mérida on 6 April 1896.

Distribution, habitats, AND SYMPATRY: Examined specimens of Marmosops fuscatus are from four Venezuelan localities, two in the Mérida Andes (Cordillera de Mérida), one in the Serranía de San Luis of western Falcón, and one in the Caribbean coastal lowlands of eastern Fal- cón (fig. 17). Although recorded elevations range from 125 to $2350 \mathrm{~m}$ above sea level, capture habitats seem to be either premontane or montane rain forest. ${ }^{6}$ Previous reports of this species from Colombia (e.g., Gardner and Creighton, 2008: map 28) were based on misidentified material (see Remarks, below). Marmosops fuscatus is not known to occur sympatrically with any congeneric species, although it could be expected to do so with M. carri and M. ojastii, which have adjacent or overlapping geographic ranges.

Description: Body pelage dark grayish brown (near Sepia) middorsally, indistinctly paler laterally, and about 7-9 $\mathrm{mm}$ long at midback (shorter in specimens from lower elevations than in those from the Mérida Andes); ventral pelage superficially whitish but uniformly gray based except for the apex of the chin, oral margins, and scrotum (which are covered with selfwhitish hairs). (One examined specimen, AMNH 276509, has small patches of self-white hairs along the inner thighs.) Manus covered dorsally with uniformly pale hairs (the metacarpals not contrasting in color with the digits); lateral carpal tubercles bladelike in all examined adult males. Mammary formula unknown. Tail longer than combined length of head and body (mean $\mathrm{LT} / \mathrm{HBL} \times 100=110 \%$ ); dorsal caudal surface dark, but indistinctly paler distally in some specimens; ventral surface distinctly paler.

Nasal bones long (extending well behind the lacrimals) and uniformly narrow (without distinct lateral expansion at the maxillary-frontal suture). Interorbital region broad, with rounded supraorbital margins in females and young adult males, but relatively narrower and tending to develop squared supraorbital margins in large adult males; postorbital processes absent or

\footnotetext{
${ }^{6}$ Handley and Gordon (1979) reported that the type series of Marmosa cracens was collected between 125 and $170 \mathrm{~m}$ above sea level on "the steep, moist, north slope of an isolated, low mountain" near the Caribbean coast. Vegetation of distinctly montane character can extend downslope to within $100 \mathrm{~m}$ above sea level on such isolated peaks, which intercept moisture-laden sea breezes and are often shrouded in low-lying clouds. The cloud forest (montane rain forest) vegetation at capture localities in the Serranía de San Luis was briefly described by Anderson et al. (2012).
} 
indistinct. Lacrimal foramina variable (the upper foramen is usually not visible in lateral view, but the lower foramen can be either laterally visible or concealed inside the anterior orbital margin); ${ }^{7}$ zygomatic process of squamosal broadly overlapped dorsally by the jugal. Palatine fenestrae present or absent (when present these can appear as a single small perforation on each side or as several small irregular perforations on both sides). Dorsolateral margin of ethmoid foramen usually formed by the frontal.

Upper canine (C1) sexually dimorphic (longer and unicuspid in males, shorter and with posterior accessory cusp in young female specimens with unworn teeth). Upper third molar (M3) anterolabial cingulum discontinuous with preprotocrista (anterior cingulum incomplete). Lower canine (c1) sexually dimorphic (erect, without a posterior accessory cusp, and taller than $\mathrm{p} 1$ in males versus procumbent, with a posterior accessory cusp, and subequal in height to p1 in females); c1 anterolingual accessory cusp usually absent in both sexes. Entoconid of $\mathrm{m} 1$ subequal in height to adjacent $\mathrm{m} 2$ paraconid; unworn $\mathrm{m} 4$ talonid with three distinct cusps.

Comparisons: Comparisons between Marmosops fuscatus and M. carri have already been described (see above).

Marmosops fuscatus is substantially larger than $M$. handleyi in head-and-body length and has a proportionately shorter tail (tables 5,6 ). Externally the two species differ in the same characters that distinguish $M$. carri from $M$. handleyi, namely dorsal pelage coloration (dark grayish brown in fuscatus, dark brown in handleyi) and forefoot coloration (the manus is entirely whitish in fuscatus, whereas the pale digits contrast with the dark metacarpals in handleyi). Marmosops fuscatus also averages larger than $M$. handleyi in most craniodental dimen-

\footnotetext{
7 The lower lacrimal foramen is laterally visible in some specimens (e.g., BMNH 3.1.5.2, 3.1.5.3, FMNH 22174, USNM 442719) but not in others (e.g., AMNH 276580, 276509). The specimens in which this foramen is visible are the largest in overall size and have the most heavily ossified skulls, but we lack sufficient material to determine whether or not this trait is age correlated.
}

sions, including four measurements $(\mathrm{CBL}, \mathrm{ZB}$, PL, MTR, and WM3) that exhibit nonoverlapping variation in same-sex comparisons. These species also differ in some of the same qualitative craniodental characters that distinguish $M$. carri and $M$. handleyi; in particular, M. fuscatus has much narrower nasals than $M$. handleyi (in which these bones are conspicuously expanded laterally at the maxillary-frontal suture), and males of $M$. fuscatus have unicuspid $\mathrm{C} 1$ and $\mathrm{cl}$, whereas these teeth consistently have a small posterior accessory cusp in males of $M$. handleyi. Additionally, the dorsolateral margin of the ethmoid foramen is usually formed by the frontal in M. fuscatus, whereas the dorsolateral margin of this foramen is formed by the orbitosphenoid in $M$. handleyi. Lastly, the distinct lingual accessory cusp of $\mathrm{cl}$ that appears to be consistently present in $M$. handleyi is absent in M. fuscatus.

Marmosops fuscatus is substantially larger than $M$. invictus in all external dimensions. In qualitative external characters, M. fuscatus is most readily distinguished from $M$. invictus by its paler dorsal coloration (the dorsal pelage of invictus is consistently much darker), by its entirely pale forefeet (the metacarpals are dark in $M$. invictus), and by its more distinctly bicolored tail (the tail is only indistinctly paler ventrally than dorsally in M. invictus). Marmosops fuscatus averages larger than $M$. invictus in most craniodental dimensions, including five measurements (CBL, NL, ZB, PL, MTR) that exhibit nonoverlapping variation in same-sex comparisons. Craniodental qualitative differences between these quite dissimilar species include the shape of the nasals (uniformly narrow in M. fuscatus, laterally expanded in $M$. invictus), dorsolateral margin of the ethmoid foramen (usually formed by the frontal in M. fuscatus, by the orbitosphenoid in M. invictus), C1 posterior accessory cusp (absent in males of $M$. fuscatus, present in both sexes of $M$. invictus), M3 anterior cingulum (incomplete in $M$. fuscatus, narrowly complete in $M$. invictus), c1 morphology (erect and unicuspid in male $M$. fuscatus, procumbent and premolariform in $M$. invictus), c1 lingual accessory cusp 
(absent in M. fuscatus, usually present in $M$. invictus), and $\mathrm{m} 1$ entoconid (subequal to adjacent $\mathrm{m} 2$ paraconid in fuscatus, shorter than $\mathrm{m} 2$ paraconid in $M$. invictus).

Remarks: Marmosa perfusca, a nominal species that Thomas (1924) described from the Cordillera Oriental of Colombia, was synonymized with M. fuscatus by Tate (1933: 173), and some authors (e.g., Gardner and Creighton, 2008: 66) have treated it as a valid subspecies ("Marmosops fuscatus perfuscus"). However, the type of perfusca (BMNH 1923.11.13.18, consisting of the skin and skull of an old adult female) has posteriorly widened nasals, a short subsquamosal foramen (not exposing the petrosal behind the sulcus of the prootic sinus), and only one antebrachial vibrissa. In these and other characters it closely resembles Marmosops caucae (Thomas, 1900), a member of the nominotypical subgenus of Marmosops. A second Colombian specimen that Tate (1933) referred to Marmosa fuscata is AMNH 34641, also from the Cordillera Oriental; ${ }^{8}$ like BMNH 1923.11.13.18, this specimen appears to represent $M$. caucae. To the best of our knowledge, there are no valid records of Marmosops fuscatus from Colombia.

Handley and Gordon (1979: 67) described Marmosa cracens as "in almost every respect of pelage and skull character ... a miniature replica of M. fuscata, distinguishable from it only by its small size and the short, broad shape of its palate." Indeed, the male holotype of cracens (USNM 418503) is substantially smaller than any adult male specimen of Marmosops fuscatus that we measured. For example, the condylobasal length of the skull of USNM 418503 is $28.4 \mathrm{~mm}$, whereas the range of condylobasal lengths of five adult male $M$. fuscatus is $31.8-35.4 \mathrm{~mm}$. How-

\footnotetext{
8 This specimen was collected by G. O'Connell on 4 April 1913 at "El Roble," a locality that Tate (1933: 173) erroneously placed in Departamento Cauca and that Gardner and Creighton (2008: 66) located in Departamento Quindío (on the western slope of the Cordillera Central; Paynter, 1997). However, Geoffroy O'Connell was a member of the 1913 AMNH expedition that worked at a different place called El Roble, "a posada on the trail from Bogotá to Fusugasugá [= Fusagasugá]" on the western slope of the Cordillera Oriental (Chapman, 1917: 645); according to Paynter (1997), this locality is near $4^{\circ} 23^{\prime} \mathrm{N}, 74^{\circ} 19^{\prime} \mathrm{W}$.
}

ever, this size difference is plausibly explained by ontogeny: the type series of cracens consists of subadults (with incompletely erupted P3s), not young adults (contra Handley and Gordon, 1979). The subadult holotype and paratype of cracens do have relatively wider palates $(\mathrm{PB} / \mathrm{PL}=$ 0.57-0.59) than topotypical adult fuscatus (0.51$0.53)$, but relative width of the palate is another ontogenetically variable trait because didelphid palates become proportionately longer and narrower with advancing age (Abdala et al., 2001). Lastly, we (Díaz-Nieto et al., 2016a) amplified partial (579-619 bp) cytochrome- $b$ sequences from the holotype and a paratype of cracens, which differ by only $2.2 \%$ (uncorrected) from a partial (1008 bp) cytochrome- $b$ sequence that we amplified from a topotype of $M$. fuscatus (BMNH 1903.1.5.2). Because this genetic distance is well within the range of values commonly obtained from comparisons of conspecific sequences of other mammals, and because the phenotypic differences that Handley and Gordon (1979) alleged between cracens and fuscatus seem to be attributable to the immaturity of their type series, we treat the former as a subjective junior synonym.

Specimens examined $(N=8)$ : VenezuelaFalcón, Near La Pastora (USNM 418503 [holotype of cracens], 442719), Serranía de San Luís (AMNH 276509, 276580); Mérida, La Azulita (FMNH 22174), Mérida (BMNH 1896.11.1.6 [holotype], 1903.1.5.2, 1903.1.5.3).

\section{Marmosops handleyi (Pine, 1981)}

Figures 2, 18, 19

Marmosa handleyi Pine, 1981: 67 (original description).

Marmosops handleyi: Gardner and Creighton, 1989: 4 (first use of current binomial).

TyPe MATERIAL: The holotype (by original designation) consists of the skin, skull, and postcranial skeleton of an adult female (FMNH 69838; original number $\mathrm{PH}$ 4371) collected by Philip Hershkovitz at a site $9 \mathrm{~km}$ south of Valdivia (fig. 20: locality 24) in the Colombian 
department of Antioquia at an elevation of 1400 $m$ on 16 June 1950. In addition, Pine's (1981) original material included an adult male paratype (FMNH 70926).

Distribution, HABITATS, AND SYMPATRY: Examined specimens of Marmosops handleyi are all from the northern terminus of the Cordillera Central (central Andes) of Colombia, where they have been collected in humid premontane and montane rain forest at elevations ranging from 1400 to $1950 \mathrm{~m}$ (fig. 20). This species has been collected sympatrically with $M$. chucha (a new species of the Bishopi Group; see below) and with $M$. caucae (a member of the nominotypical subgenus; Díaz-N. et al., 2011).

Description: Body pelage dark brown to chestnut brown middorsally, indistinctly paler laterally, about 9-10 $\mathrm{mm}$ long at midback, and somewhat woolly in texture; ventral pelage superficially whitish, but hairs of throat, chest, and abdomen uniformly gray based (only the apex of the chin, the oral margins, the scrotum, and mammary region consistently have selfwhite fur)..$^{9}$ Metacarpals covered dorsally with dark hairs (contrasting in color with the pale manual digits); lateral carpal tubercles bladelike. Mammary formula 3-1-3 = 7 in all examined females with conspicuous teats. Tail longer than combined length of head and body (mean LT/ HBL $\times 100=125 \%)$, dorsal caudal surface dark gray but somewhat paler distally; ventral caudal surface distinctly paler.

Nasal bones long (extending well behind the lacrimals) and much wider posteriorly than anteriorly (laterally expanded at the maxillary-frontal suture). Upper lacrimal foramen not visible in lateral view, but lower foramen laterally exposed; zygomatic process of squamosal broadly overlapped dorsally by the jugal. Palatine fenestrae present (usually as a pair of large rounded perforations). Dorsolateral margin of ethmoid foramen with equal contribution of frontal and orbitosphenoid.

9 Pine (1981: 68) described the dorsal pelage as "fuscous," a grayer shade than we observed in fresh skins. Unfortunately, none were compared by us with color swatches in Ridgway (1912). One specimen (CTUA 415, a subadult male) has a $5 \times$ $15 \mathrm{~mm}$ midventral streak of self-white abdominal hairs.
Upper canine (C1) short in both sexes but sexually dimorphic in shape: male $\mathrm{C} 1$ with posterior accessory cusp only, female $\mathrm{C} 1$ with both anterior and posterior accessory cusps. Upper third molar (M3) anterolabial cingulum discontinuous with preprotocrista (anterior cingulum incomplete). Lower canine (c1) premolariform (procumbent, with posterior accessory cusp) and small, subequal in height to $\mathrm{p} 1 ; \mathrm{cl}$ anterolingual accessory cusp present. Entoconid of $\mathrm{m} 1$ subequal in height to adjacent $\mathrm{m} 2$ paraconid; unworn $\mathrm{m} 4$ talonid with three distinct cusps.

Comparisons: Comparisons of Marmosops handleyi with $M$. carri and M. fuscatus have already been described (see above).

Although Marmosops handleyi averages slightly larger than $M$. invictus in most same-sex comparisons of external dimensions (tables 5, 6), sample sizes for both species are small, and it seems unlikely that any external measurement will prove to be diagnostic as more material becomes available. A more consistent external difference between these species is pelage color (distinctly brownish in handleyi versus dark grayish brown to blackish gray in invictus) and fur length (9-10 mm middorsally in handleyi versus $6-7 \mathrm{~mm}$ in invictus). The two species broadly overlap in craniodental measurements, none of which, therefore, is useful for identification. Instead, M. handleyi is more readily distinguished from $M$. invictus by the consistent presence of palatine fenestrae (consistently absent in $M$. invictus), by the presence of both anterior and posterior accessory $\mathrm{C} 1$ cusps in females (females usually have only a posterior accessory $\mathrm{C} 1$ cusp in $M$. invictus), by lacking a complete M3 anterior cingulum (M3 has a narrowly complete anterior cingulum in $M$. invictus), and by having an $\mathrm{m} 1$ entoconid that is subequal in height to the adjacent $\mathrm{m} 2$ paraconid (the $\mathrm{m} 1$ entoconid is shorter than the $\mathrm{m} 2$ paraconid in invictus).

Remarks: Marmosops handleyi had not been collected for 60 years before it was rediscovered and redescribed by Díaz-N. et al. (2011), whose report should be consulted for additional mor- 


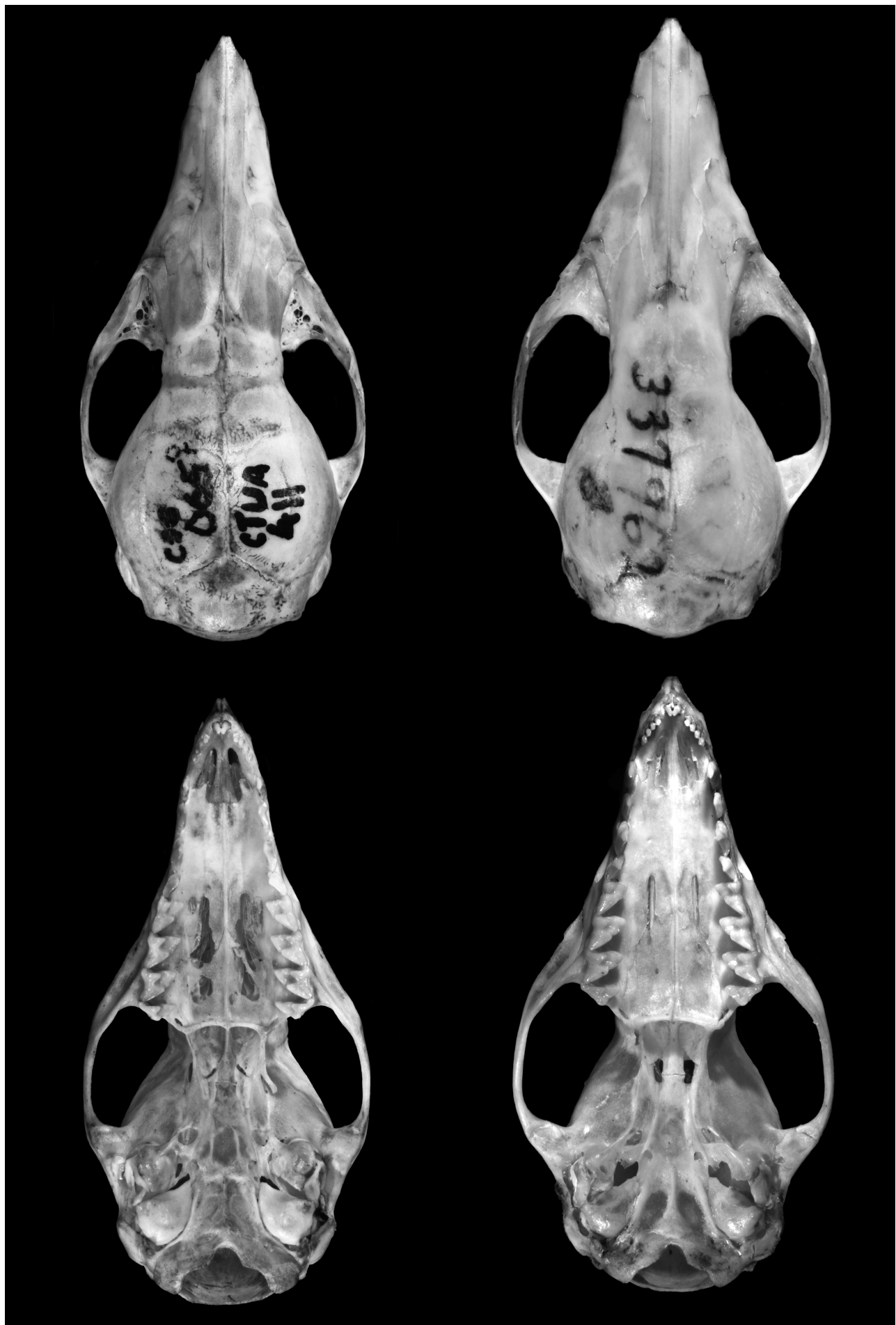

FIG. 18. Dorsal and ventral views of skulls of Marmosops handleyi (left, CTUA 411) and M. invictus (right, USNM 337962). All views about $\times 3$. 


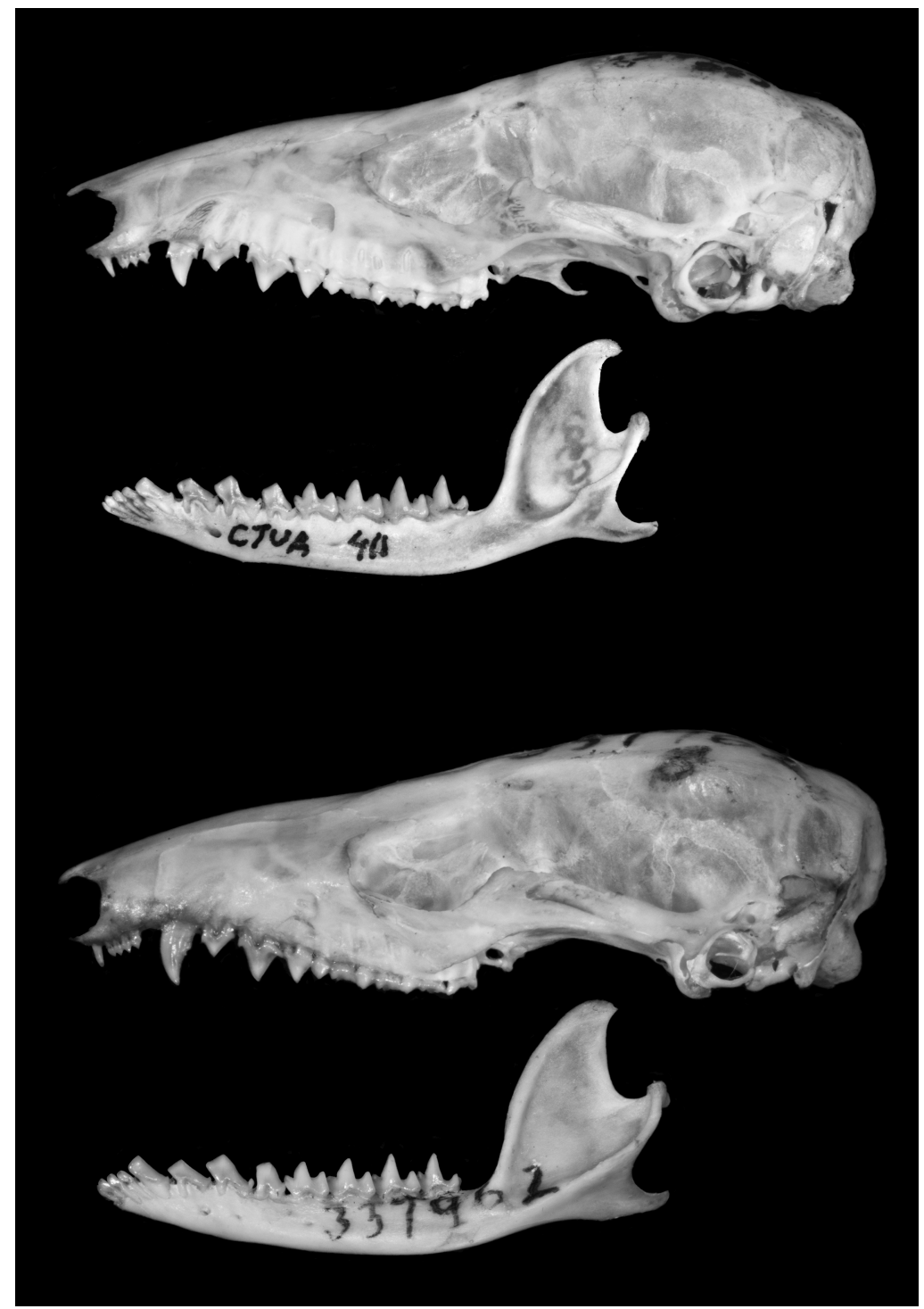

FIG. 19. Lateral views of skulls and mandibles of Marmosops handleyi (above, CTUA 411) and M. invictus (below, USNM 337962). All views about $\times 3$.

phological, geographical, and ecological information. Using the dichotomous key in Gardner and Creighton (2008), this species would be misdidentified as $M$. juninensis.

Specimens examined $(N=10)$ : ColombiaAntioquia, Finca Costa Rica (CTUA 410-412, 433); Finca El Bosque (CTUA 413, 414), Finca Villa Nueva (CTUA 415, 416), $9 \mathrm{~km} \mathrm{~S}$ Valdivia (FMNH 69823, 69838).
Marmosops invictus (Goldman, 1912)

Figures 4A, 18, 19

Marmosa invicta Goldman, 1912: 3 (original description).

Didelphis (Marmosops) invicta: Matschie, 1916: 270 (name combination).

Marmosops invictus: Gardner and Creighton 1989: 4 (first use of current binomial). 


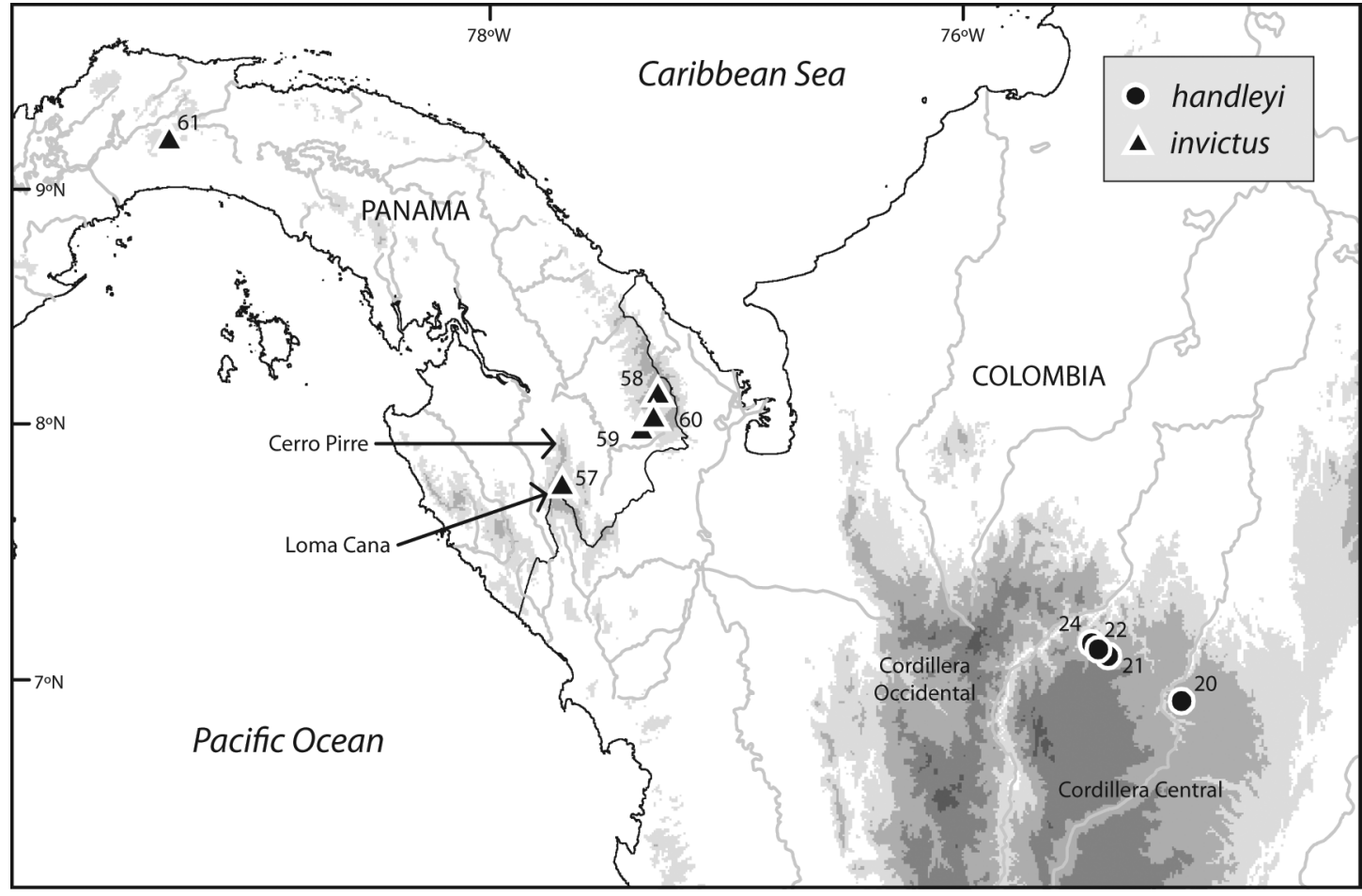

FIG. 20. Collecting localities of examined specimens of Marmosops handleyi and M. invictus. Numbers are keyed to entries in the gazetteer (appendix 1). Progressively darker shading indicates higher elevations: pale gray $\geq 500 \mathrm{~m}$, medium gray $\geq 1000 \mathrm{~m}$, dark gray $\geq 2000 \mathrm{~m}$, darkest gray $\geq 3000 \mathrm{~m}$.

TyPe Material: The holotype (by original designation) consists of the skin and skull of an adult male (USNM 178708; original number 21517) collected by E.A. Goldman at Cana (fig. 20: locality 57), in Darién province, Panama, on 14 March 1912. In addition to the holotype, Goldman's original material included an adult female paratype (USNM 178709).

Distribution, habitats, AND Sympatry: Examined specimens of Marmosops invictus are all from eastern Panama with recorded elevations between 600 and $1500 \mathrm{~m}$ above sea level (fig. 20). Handley (1966), who may have examined more material than we have seen, gave the elevational range as ca. 450-1200 $\mathrm{m}$ and remarked that the species might occur throughout Panama in suitable habitat. Although the lower elevations at which this species occurs would support lowland rain forest in Amazonia, humid forests of distinctly montane character (e.g., those at the type locality; Goldman, 1920: figs. 1, 2) can be found well below $1000 \mathrm{~m}$ on the low mountains and foothills of Central America (Myers, 1969). Premontane rain forest seems likely to be the usual habitat of this species, which is not known to occur sympatrically with any other species of the subgenus Sciophanes. However, M. caucae, a member of the nominotypical subgenus, occurs at elevations $>1400 \mathrm{~m}$ in the Darién highlands of eastern Panama (Loma Cana and Cerro Pirre) and probably coexists with $M$. invictus in some places.

DesCription: Dorsal body pelage uniformly dark grayish brown to blackish gray (near Bone Brown to Blackish Brown) - not appreciably paler laterally-and only about 6-7 $\mathrm{mm}$ long at midback; ventral fur silvery gray (the hairs with dark-gray bases and whitish tips) over throat, chest, and abdomen (only the chin, oral margins, and groin have self-white fur). Manus with dark 
fur over all or part of metacarpals (contrasting in color with whitish digits); lateral carpal tubercles bladelike. Mammae 3-1-3 = 7 in all examined females with visible teats. Tail longer than combined length of head and body (mean LT/HBL $\times$ $100=122 \%$ ); dorsal caudal surface dark gray from base to tip; ventral caudal surface indistinctly paler in some specimens (e.g., USNM 306386), almost as dark as dorsal surface in others (e.g., USNM 309265).

Nasal bones long (extending well behind the lacrimals in most specimens) and much wider posteriorly than anteriorly (laterally expanded at the maxillary-frontal suture). Lacrimal foramina concealed from lateral view inside anterior orbital margin; zygomatic process of squamosal broadly overlapped dorsally by the jugal. Palatine fenestrae absent (but some specimens have minute palatine perforations on one or both sides). Dorsolateral margin of ethmoid foramen formed by the orbitosphenoid.

Upper canine (C1) short, usually with posterior accessory cusps in male and female specimens (two females-USNM 178709, 306386- have indistinct anterior accessory C1 cusps, and the holotype completely lacks accessory cusps). Upper third molar (M3) anterolabial cingulum narrowly continuous with preprotocrista (anterior cingulum complete). Lower canine (c1) premolariform (procumbent, with posterior accessory cusp) and small, subequal in height to $\mathrm{p} 1$; $\mathrm{cl}$ anterolingual accessory cusp usually present. Entoconid of $\mathrm{m} 1$ subequal in height to adjacent $\mathrm{m} 2$ paraconid; unworn $\mathrm{m} 4$ talonid with three distinct cusps.

Comparisons: Comparisons of Marmosops invictus with other members of the Fuscatus Group have already been described (see above).

REMARKs: All of the material we examined for this revision was collected $>50$ years ago, and we are not aware of any recently collected specimens. However, Mangan and Adler (2000) reported trapping Marmosops invictus in the course of an ecological study in western Panama, well outside the specimen-documented range of this species. In the absence of voucher material, the identity of the animals they trapped and released remains to be determined.

In a recent discussion of cytochrome oxidase subunit I (COI) barcoding results, Lim (2012) reported the occurrence of Marmosops invictus in Panama and Ecuador, but the specimens he sequenced (ROM 116281, 118844, and F41897) ${ }^{10}$ appear to have been misidentified. We examined the Panamanian specimen (ROM 116281), which consists of a skin and skull with all the diagnostic attributes of the nominotypical subgenus, not Sciophanes. In addition, its teeth are larger than those of any measured specimen of $M$. invictus (e.g., $\mathrm{LM}=6.8 \mathrm{~mm}$ versus $6.0-6.5 \mathrm{~mm}$ ), its ventral pelage includes a median streak of self-white fur, and it has well-developed palatine fenestrae. In these and other traits ROM 116281 resembles numerous specimens of a widespread species (or species complex) for which M. caucae is the oldest available name, and the cytochrome- $b$ sequence that we (Díaz-Nieto et al., 2016a) obtained from ROM 116281 also unequivocally associates this specimen with the $M$. caucae complex. The two Ecuadorean specimens (ROM 118844, F41897) cannot be found at present (Jacqueline Miller, personal commun.), but as their COI barcodes clustered with the barcode obtained from ROM 116281 , it seems likely that they are also members of the $M$. caucae complex, which is abundantly represented among other sequenced Ecuadorean material (Díaz-Nieto et al., 2016a).

Specimens examined $(N=10)$ : PanamaDarién, Cana (USNM 178708 [holotype], 178709), Cerro Tacarcuna (USNM 337959-337962), Tacarcuna Casita Camp (USNM 309265), Tacarcuna Laguna Camp (USNM 309266, 309267); Panamá, Cerro Azul (USNM 306386).

\section{Species of the Bishopi Group}

Species of the Marmosops bishopi group are distinguished from other members of the subgenus Sciophanes by their extensively self-white ventral

\footnotetext{
${ }^{10}$ Corresponding to records ABSMS616-06, ABECB166-08, and ABRMM151-07 in the Barcode of Life Data system (www. boldsystems.org; accessed in January 2016).
} 
fur (except $M$. juninensis), bladelike lateral carpal tubercles, 4-1-4 = 9 mammae, narrowly complete M3 anterior cingulum, and an $\mathrm{m} 1$ entoconid that is shorter than the adjacent $\mathrm{m} 2$ paraconid. This clade is widely distributed in western Amazonia, along the eastern slopes of the Peruvian Andes, in northern Colombia, and in northwestern Venezuela. Diagnostic quantitative and qualitative comparisons are summarized in tables $8-10$.

\section{Marmosops bishopi (Pine, 1981)}

Figures 3B, 8A, 21, 22, 23A

Marmosa parvidens bishopi Pine, 1981: 63 (original description).

Marmosops parvidens bishopi: Gardner, 1993: 20 (name combination).

Marmosops bishopi: Voss et al., 2001: 48 (first use of current binomial).

TyPe MATERIAL: The holotype (by original designation) consists of the skin and skull of an adult female (USNM 393535; original number RHP 5157) collected by Ronald H. Pine near the base camp of the Royal Geographical Society's Xavantina-Cachimbo expedition, 264 km N (by road) Xavantina in the Serra do Roncador, Mato Grosso, Brazil (fig. 24: locality 12). Although Pine (1981) did not examine any other referred material, he mentioned two topotypical BMNH specimens that we have been unable to locate.

Distribution, habitats, AND Sympatry: Examined specimens that we refer to Marmosops bishopi are from the western Amazonian lowlands of southeastern Colombia, eastern Ecuador, eastern Peru, northeastern Bolivia, and western Brazil; the eastern Andean foothills of Peru and Bolivia; and the Cerrado of central Brazil and eastern Bolivia (fig. 24). The species has been collected from gallery forest in savannadominated landscapes (e.g., at the Serra do Roncador; Ratter et al., 1973; Eiten, 1975), in lowland rainforest (Patton et al., 2000; Hice and Velazco, 2012), and in premontane rain forest. Recorded elevations range from 100 to $1300 \mathrm{~m}$. Not surprisingly, the broad geographic range of
M. bishopi overlaps those of several congeneric species. Among other reports of sympatry, this species has been collected together with $M$. juninensis (in eastern Peru; Peralta and Pacheco, 2014); M. noctivagus, M. caucae, and an undescribed species (in western Brazil; Patton et al., 2000); and M. ocellatus (in eastern Bolivia; Emmons et al., 2006).

DesCription: Dorsal body pelage geographically variable, but usually some shade of grayish brown (near Bister) middorsally, ${ }^{11}$ often indistinctly paler laterally, and about 7-9 $\mathrm{mm}$ at midback; ventral pelage predominantly self-white from chin to groin (including the inside surfaces of the fore- and hind limbs), with or without narrow lateral borders of gray-based abdominal fur. Manus covered dorsally with uniformly pale hairs (the metacarpals not contrasting sharply in color with the digits); lateral carpal tubercles bladelike. Mammae 4-1-4 = 9 in all examined females with visible teats. Tail substantially longer than combined length of head and body (mean LT/HBL $\times 100=130 \%$ ); often indistinctly bicolored (dark above, somewhat paler below), but unicolored-dark in some specimens (e.g., AMNH 276723) and distinctly bicolored in others (e.g., USNM 584464).

Nasals proportionately shorter than in species of Parvidens and Fuscatus groups (often not extending behind lacrimals) and much wider posteriorly than anteriorly (laterally expanded at the maxillary-frontal suture). Lacrimal foramina usually concealed from lateral view inside anterior orbital margin (but in some specimens-e.g., AMNH 67243, KU 157970, MUSM 23803-the lower foramen is partially exposed in lateral view); zygomatic process of the squamosal broadly overlapped dorsally by jugal. Distinct palatine fenestrae absent (but a few specimens have minute palatine perforations on one or both sides). Dorsolateral margin of ethmoid foramen formed by the frontal.

\footnotetext{
${ }^{11}$ Cerrado specimens (e.g., USNM 393535, 584464) are paler (near Snuff Brown) than those from lowland rain forest, and a few specimens (e.g., FMNH 84251) are distinctly reddish (near Cinnamon Brown).
} 
TABLE 8

Measurements (mm) and Weights (g) of Adult Male Specimens of the Bishopi Group of Marmosops (Sciophanes)

\begin{tabular}{|c|c|c|c|c|c|}
\hline & M. bishopia & M. juninensis ${ }^{\mathrm{b}}$ & M. ojastiic & M. chuch $a^{\mathrm{d}}$ & M. magdalenae \\
\hline $\mathrm{HBL}$ & $103(93-111) 20$ & 98 & $94(90-97) 2$ & $105(99-109) 5$ & $103(99-106) 2$ \\
\hline LT & $141(126-153) 21$ & 135 & $134(130-138) 2$ & $137(134-141) 5$ & $129(125-132) 2$ \\
\hline HF & $17(15-19) 19$ & $17(16-18) 2$ & $18(17-18) 2$ & $18(17-19) 5$ & $18(17-18) 2$ \\
\hline Ear & $21(18-23) 20$ & $21(20-21) 2$ & $20(19-22) 2$ & $21(20-21) 4$ & $19(18-19) 2$ \\
\hline CBL & $28.3(26.4-29.8) 20$ & 27.7 & $25.8(25.3-26.3) 2$ & 28.9 & $28.3(27.3-28.9) 3$ \\
\hline NL & $13.1(12.2-13.9) 17$ & - & - & $13.4(13.3-13.6) 2$ & $13.1(12.5-13.9) 3$ \\
\hline NB & $3.6(3.2-4.1) 24$ & $3.7(3.6-3.7) 2$ & $3.0(2.9-3.2) 2$ & $3.9(3.8-3.9) 2$ & $3.8(3.7-3.8) 3$ \\
\hline LIB & $5.6(5.1-6.0) 24$ & $5.6(5.6-5.7) 2$ & $5.3(5.3-5.3) 2$ & $5.6(5.5-5.9) 4$ & $5.5(5.5-5.6) 3$ \\
\hline ZB & $14.7(13.7-15.6) 24$ & $13.9(13.8-14.1) 2$ & $13.6(13.3-13.8) 2$ & 15.2 & $15.1(14.8-15.5) 3$ \\
\hline PL & $15.8(14.6-16.8) 22$ & 15.8 & $14.2(13.8-14.7) 2$ & $15.8(15.7-15.9) 2$ & $15.6(14.9-16.0) 3$ \\
\hline PB & $8.6(8.0-9.0) 24$ & $8.3(8.3-8.3) 2$ & $8.2(8.2-8.3) 2$ & $8.9(8.8-9.0) 2$ & $8.7(8.5-8.8) 3$ \\
\hline MTR & $11.5(10.6-12.0) 24$ & $11.3(11.2-11.4) 2$ & $10.6(10.5-10.8) 2$ & $11.4(10.9-11.7) 3$ & $11.3(10.8-11.6) 3$ \\
\hline LM & $5.9(5.4-6.3) 24$ & $5.8(5.7-5.8) 2$ & $5.6(5.6-5.6) 2$ & $5.9(5.7-6.1) 4$ & $6.0(5.9-6.1) 3$ \\
\hline M1-3 & $5.1(4.8-5.4) 24$ & $5.0(4.9-5.1) 2$ & $5.0(4.9-5.0) 2$ & $5.2(5.1-5.3) 4$ & $5.2(5.1-5.2) 3$ \\
\hline WM3 & $1.9(1.8-2.1) 24$ & $1.8(1.8-1.8) 2$ & $1.8(1.8-1.9) 2$ & $1.9(1.7-2.0) 4$ & $1.9(1.9-2.0) 3$ \\
\hline Weight & $25(18-34) 16$ & - & - & $26(25-26) 2$ & 24 \\
\hline
\end{tabular}

a The mean, the observed range (in parentheses), and the sample size are provided for each measurement of the following series: AMNH 276700, 276705; CBF 7531; EPN 127, 10706; FMNH 84251, 169802, 203328, 203509; ICN 18338; KU157969; MSB 55843; MUSM 16237, 16240, 16803, 17691, 17723, 17930; MVZ 168966; QCAZ 10308; TTU 99031, 99032, 101239; USNM 584464.

$\mathrm{b}$ The mean, the observed range (in parentheses), and the sample size are provided for each measurement of the following series: AMNH 230014, 230016.

c The mean, the observed range (in parentheses), and the sample size are provided for each measurement of the following series: EBRG 27474, 29540 (data from García et al., 2014); USNM 371299.

$\mathrm{d}$ The mean, the observed range (in parentheses), and the sample size are provided for each measurement of the following series: FMNH 69825, 70925, 70927; MHNUC 986, MHNUC uncataloged (DCV069).

e The mean, the observed range (in parentheses), and the sample size are provided for each measurement of the following series: FMNH 70926; ICN 18788, ICN uncataloged (YMS1820).

Upper canine short and sexually dimorphic (males with posterior accessory cusp only, females with both posterior and anterior accessory cusps). Upper third molar (M3) anterolabial cingulum narrowly continuous with preprotocrista (anterior cingulum complete). Lower canine (c1) premolariform (procumbent, with posterior accessory cusp) and small, subequal in height to $\mathrm{p} 1$; $\mathrm{cl}$ anterolingual accessory cusp absent. Entoconid of $\mathrm{m} 1$ shorter (sometimes much shorter) than adjacent $\mathrm{m} 2$ paraconid; unworn $\mathrm{m} 4$ talonid with three distinct cusps.

Comparisons: Marmosops bishopi overlaps broadly in all measured external and craniodental dimensions with $M$. juninensis, from which it cannot be distinguished morphometrically (tables 8,9 ). Similarly, the coloration of the dorsal pelage offers no useful criterion for identifying these species due to the wide variation in this trait observed in M. bishopi. By contrast, the ventral pelage is taxonomically diagnostic: whereas a broad zone of self-white fur extends continuously from chin to anus, including the inside surfaces of the fore- and hind limbs in M. bish$o p i$, the ventral fur of $M$. juninensis is almost entirely gray based (including the insides of the fore- and hind limbs), with only a narrow, discontinuous midventral streak of self-white fur in some specimens. Additionally, M. bishopi can be distinguished from M. juninenis by having the 
TABLE 9

Measurements (mm) and Weights (g) of Adult Female Specimens of the Bishopi Group of Marmosops (Sciophanes) ${ }^{\mathrm{a}}$

\begin{tabular}{|c|c|c|c|c|}
\hline & M. bishopi ${ }^{\mathrm{b}}$ & M. juninensis ${ }^{\mathrm{c}}$ & M. chuch $a^{\mathrm{d}}$ & M. magdalenae ${ }^{\mathrm{e}}$ \\
\hline $\mathrm{HBL}$ & $101(90-114) 7$ & $104(96-110) 3$ & $100(90-112) 4$ & $99(99) 2$ \\
\hline LT & $129(116-141) 7$ & $131(122-137) 3$ & $126(119-133) 4$ & $130(129-130) 2$ \\
\hline $\mathrm{HF}$ & $16(15-18) 8$ & $16(14-18) 3$ & $16(13-17) 4$ & 17 (17) 2 \\
\hline Ear & $20(18-22) 8$ & $19(17-20) 2$ & $19(18-20) 4$ & $20(20) 2$ \\
\hline CBL & $27.5(26.6-29.6) 9$ & 28.3 & $27.2(26.9-27.6) 3$ & $27.1(26.9-27.3) 2$ \\
\hline NL & $12.2(11.7-13.1) 3$ & $13.1(13.0-13.3) 2$ & $12.4(11.7-12.7) 4$ & $12.7(12.5-12.8) 2$ \\
\hline NB & $3.5(3.2-3.8) 11$ & $3.4(3.3-3.4) 2$ & $3.5(3.4-3.6) 4$ & 3.7 \\
\hline LIB & $5.4(5.1-5.6) 11$ & $5.7(5.6-5.9) 3$ & $5.4(5.4-5.5) 4$ & $5.5(5.4-5.5) 2$ \\
\hline $\mathrm{ZB}$ & $14.6(13.4-15.5) 11$ & $14.2(13.9-14.5) 2$ & $14.4(14.2-14.5) 2$ & 14.8 \\
\hline PL & $15.3(14.7-16.3) 9$ & $15.8(15,7-16.0) 2$ & $15.2(14.9-15.4) 3$ & $14.9(14.9) 2$ \\
\hline $\mathrm{PB}$ & $8.8(8.4-9.3) 10$ & $8.6(8.3-8.9) 3$ & $8.4(8.3-8.5) 3$ & $8.8(8.7-8.8) 2$ \\
\hline MTR & $11.4(11.0-11.8) 11$ & $11.4(11.1-11.7) 3$ & $11.2(10.9-11.6) 4$ & $10.9(10.8-11.1) 2$ \\
\hline LM & $5.9(5.6-6.1) 11$ & $5.9(5.6-6.0) 3$ & $5.8(5.5-6.0) 4$ & $5.8(5.8-5.9) 2$ \\
\hline M1-3 & $5.1(4.8-5.3) 11$ & $5.1(4.9-5.2) 3$ & $5.0(4.8-5.2) 4$ & $5.1(5.1-5.2) 2$ \\
\hline WM3 & $2.0(1.8-2.1) 11$ & $1.9(1.8-2.1) 3$ & $1.9(1.8-2.0) 4$ & $2.0(1.9-2.0) 2$ \\
\hline Weight & $21(17-29) 5$ & 27 & 18 & - \\
\hline
\end{tabular}

a We have not examined any female specimen of Marmosops ojastii; according to García et al. (2014), adult female specimens of M. ojastii are unknown.

$\mathrm{b}$ The mean, the observed range (in parentheses), and the sample size are provided for each measurement of the following series: AMNH 268938; MUSM 17661, 23802, 24432, 33487; QCAZ 8168, 8169; TTU 98964, 101238, 101257; USNM 393535.

${ }^{c}$ The mean, the observed range (in parentheses), and the sample size are provided for each measurement of the following series: AMNH 63864; 230015; MUSM 40617.

$\mathrm{d}$ The mean, the observed range (in parentheses), and the sample size are provided for each measurement of the following series: CTUA 434; FMNH 69822, 69837, 70928.

${ }^{\mathrm{e}}$ Measurement of the following specimen: ICN 19924.

zygomatic process of the squamosal broadly overlapped dorsally by the jugal (the zygomatic process of the squamosal is not or is only slightly overlapped by the jugal in M. juninensis; fig. 23), by having unfenestrated palatines (palatine fenestrae are consistently present in M. juninensis), and by lacking a c1 anterolingual accessory cusp (c1 usually has a small anterolingual accessory cusp in M. juninensis).

Marmosops bishopi is substantially larger, on average, than $M$. ojastii in head-and-body length and in many craniodental measurements, but these morphometric comparisons need to be interpreted cautiously because only two adult males of M. ojastii have been measured, and one of these (USNM 371299) is quite young. The dorsal pelage of the single skin of $M$. ojastii that we examined (USNM 371299) is somewhat paler than is usual in M. bishopi, but this contrast does not seem to be consistent with pelage color descriptors used by García et al. (2014: table 2). Instead, those authors distinguished $M$. bishopi from M. ojastii based on several other characters, including the size and shape of the lateral carpal tubercle (said to be larger and more flattened in M. bishopi versus smaller and triangular in $M$. ojastii), size and position of the hypothenar pad of the manus (said to be larger than the interdigital pads in $M$. bishopi versus smaller than the interdigitals in M. ojastii), position of the lacrimal foramina (said to be exposed outside the orbit in M. bishopi versus concealed from lateral 
TABLE 10

Diagnostic Comparisons among Members of the Bishopi Group of Marmosops (Sciophanes)

\begin{tabular}{|c|c|c|c|c|c|}
\hline Character & M. bishopi & M. juninensis & M. ojastii & M. chucha & M. magdalenae \\
\hline Distribution & cis-Andean & Andean & trans-Andean & trans-Andean & trans-Andean \\
\hline Self-white ventral fur & broad & $\begin{array}{l}\text { absent/ } \\
\text { discontinuous }\end{array}$ & broad & broad & broad \\
\hline $\begin{array}{l}\text { Squamosal-jugal } \\
\text { overlap }\end{array}$ & broad & shallow/absent & broad & broad & broad \\
\hline Palatine fenestrae & usually absent & large/multiple & absent & absent & large \\
\hline \multirow[t]{2}{*}{ C1 accessory cusps } & $\begin{array}{l}\delta: \text { posterior } \\
\text { only }\end{array}$ & $\delta$ : posterior only & $\begin{array}{l}\delta: \text { posterior } \\
\text { only }\end{array}$ & $\delta$ : posterior only & $\begin{array}{l}\delta: \text { posterior } \\
\text { only }\end{array}$ \\
\hline & †: variable ${ }^{\mathrm{a}}$ & ${ }^{\prime}$ : posterior only & $\begin{array}{l}\text { o: posterior } \\
\text { only }^{\mathrm{b}}\end{array}$ & $\begin{array}{l}\text { : anterior \& poste- } \\
\text { rior }\end{array}$ & $\begin{array}{l}\text { \&: posterior } \\
\text { only }\end{array}$ \\
\hline
\end{tabular}

a All females have a posterior accessory cusp, but some also have an anterior accessory cusp.

${ }^{\mathrm{b}}$ We did not examine females of this species, but García et al. (2014) described juvenile females with posterior accessory cusps.

view inside the orbit in M. ojastii), development of lambdoid crests on the occiput (said to be larger in M. bishopi than in M. ojastii), position of the posterolateral palatal foramina (said to be larger and to extend anteriorly to the protocone of M4 in M. bishopi versus smaller and not extending anteriorly to the protocone of M4 in M. ojastii), and width of the masseteric fossa of the mandible (said to differ in some undefined way between these species). Although our observations (based on USNM 371299) are not entirely consistent with García et al's (2014), we have not examined their type material. The only other potentially diagnostic character we noted is the dorsolateral margin of the ethmoid foramen, which is usually formed by the frontal in $M$. bishopi, whereas the dorsolateral margin of this foramen is formed by the orbitosphenoid in USNM 371299.

Marmosops bishopi is morphometrically similar to M. chucha, with which it exhibits overlapping variation in all same-sex comparisons of homologous measurement values. Apparently, the only diagnostically useful external character for these species is the coloration of the ventral pelage, which is almost entirely self-white in most specimens of M. bishopi, whereas the selfwhite midventral fur of $M$. chucha is often narrowed by lateral zones of gray-based fur. Craniodentally, these species can be distin- guished by the dorsolateral margin of the ethmoid foramen (which is usually formed by the frontal bone in M. bishopi, but by the orbitosphenoid in M. chucha) and by the morphology of $\mathrm{c} 1$ (which has only a posterior accessory cusp in both sexes of M. bishopi, whereas female specimens of $M$. chucha have both anterior and posterior accessory cusps.

Marmosops bishopi is also morphometrically similar to M. magdalenae, with which it overlaps broadly in all external and craniodental measurements. However, these species differ-to about the same extent already described between $M$. bishopi and M. chucha-in ventral pelage color pattern: whereas most specimens of $M$. bishopi have entirely self-white ventral fur, all examined specimens of M. magdalenae have a narrower midventral zone of self-white fur flanked by broad lateral bands of gray-based hairs that sometimes extend onto the fore- and hind limbs. In addition, palatine fenestrae are consistently absent (or present as small, usually unilateral or asymmetrical perforations) in $M$. bishopi, whereas palatine foramina are large and well developed in M. magdalenae. Lastly, the talonid of $\mathrm{m} 4$ seems to be consistently tricuspid in M. bishopi, whereas the $\mathrm{m} 4$ talonid is usually bicuspid in M. magdalenae.

Remarks: Marmosops bishopi is a very widespread species that includes at least six cyto- 


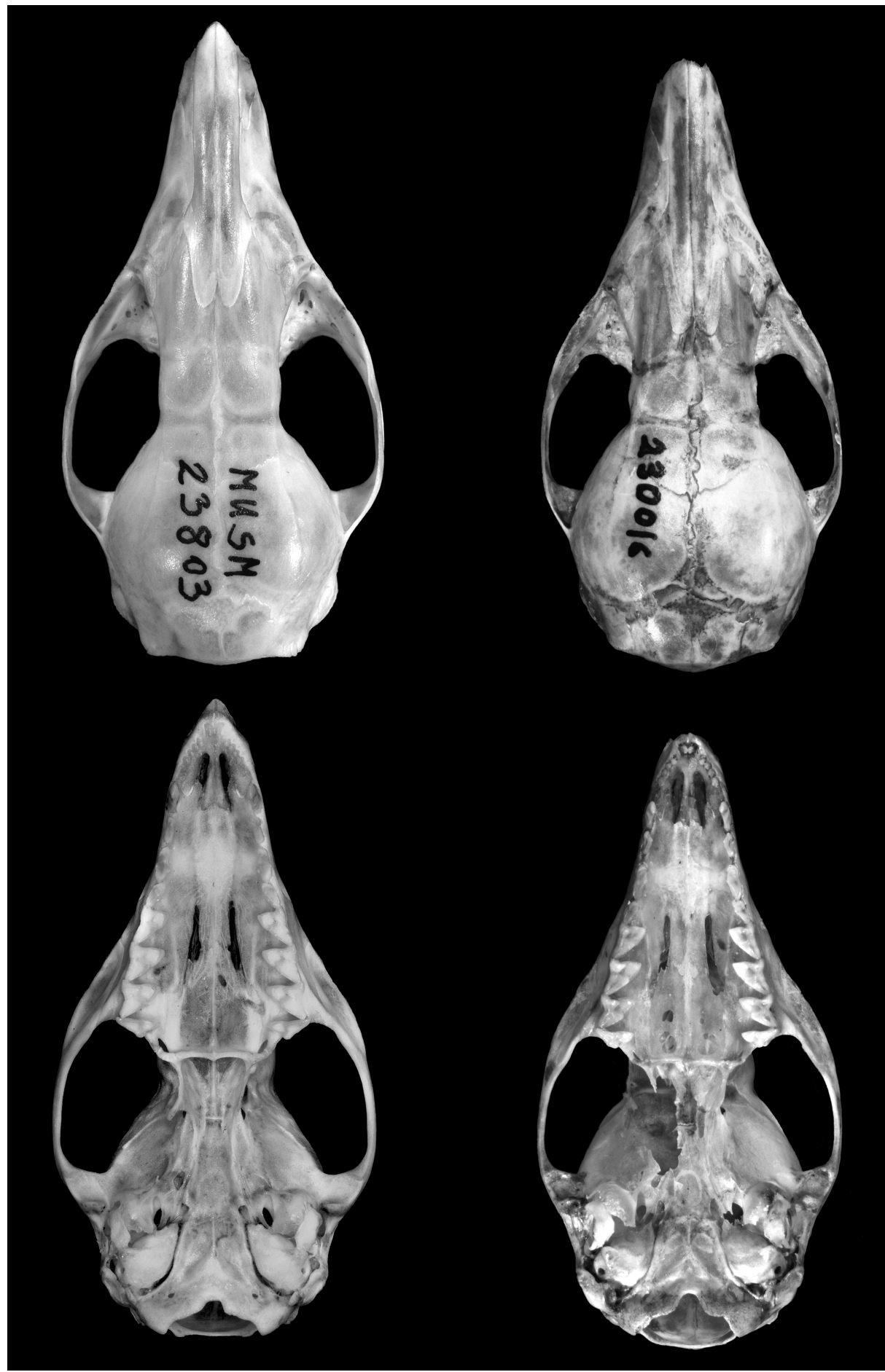

FIG. 21. Dorsal and ventral views of skulls of Marmosops bishopi (left, MUSM 23803) and M. juninensis (right, AMNH 230016). All views about $\times 3$. 


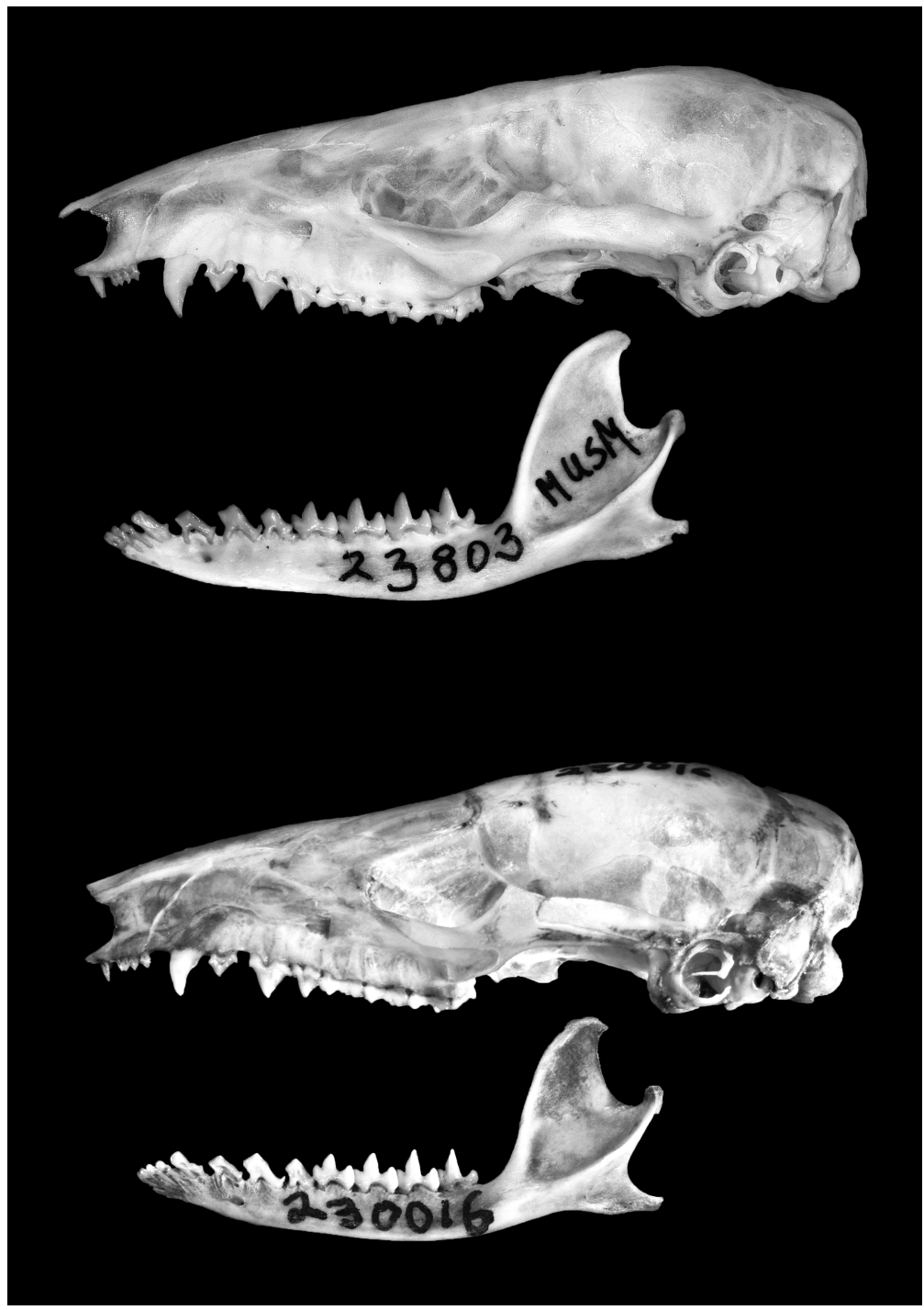

FIG. 22. Lateral views of skulls and mandibles of Marmosops bishopi (above, MUSM 23803) and M. juninensis (below, AMNH 230016). All views about $\times 3$.

chrome- $b$ haplogroups, which Díaz-Nieto et al. (2016a) distinguished by alphabetic labels (table 11). Genetic divergence among these haplogroups is impressively high, but we are unable to distinguish them morphologically. The most divergent haplogroup is "F," which differs from all of the others by $>10 \%$ in uncorrected pairwise cytochrome- $b$ sequence comparisons, whereas pairwise cytochrome- $b$ distances among haplogroups A-E range from 3.5 to 5.3\% (Díaz-
Nieto et al., 2016a: supplementary information, table S3). We did not obtain any sequence data from the holotype, but the type locality is closest (geographically and ecologically) to the Cerrado site in eastern Bolivia (fig. 24: locality 5 ) where specimens with haplotype "E" were collected.

Specimens EXAmined $(N=91)$ : BoliviaBeni, $1 \mathrm{~km}$ E La Emboscada (UMMZ 156014); Cochabamba, Serranía Mosetenes (CBF 7531); La Paz, Alto Río Madidi (USNM 579249), La Reserva 

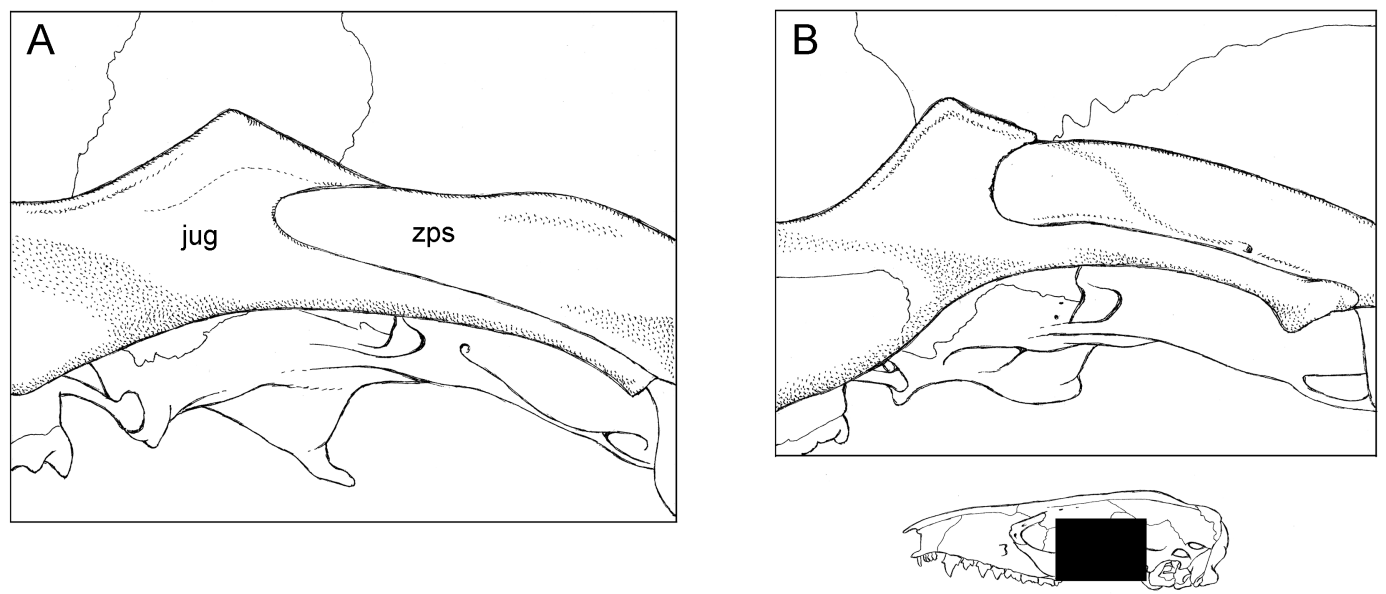

FIG. 23. Lateral view of zygomatic arch of Marmosops bishopi (A, MUSM 23803) and M. juninensis (B, AMNH 230016) illustrating species differences in the extent of dorsal overlap between the zygomatic process of the squamosal (zps) and the jugal (jug).

(AMNH 268938); Santa Cruz, El Refugio (USNM 584464, 584465), San Rafael de Amboró (MSB 55843). Brazil-Amazonas, Barro Vermelho (MVZ 190283), Vai-Quem-Quer (MVZ 190284); Mato Grosso, 264 km N Xavantina (USNM 393535 [holotype]). Colombia-Amazonas, Vereda Peña Roja (ICN 18338). Ecuador-Morona Santiago, Wisui (EPN 11947); Napo, Ituamani (EPN 127), Río Hollín (EPN 129); Orellana, Parque Nacional Yasuní (EPN 10706; QCAZ 8168, 8169, 11004); Pastaza, Arajuno (QCAZ 9954, 10074, 10308, 10606, 10608, 10661, 10758); Sucumbíos, Cantón Shushufindi (EPN 11686), El Reventador (QCAZ 316). Peru-Amazonas, Puerto Tunduza (MUSM 16237, 16240, 16241, 16243); Cuzco, Camisea (MUSM 14857), Cosñipata (FMNH 84251); Huánuco, Puerto Márquez (AMNH 67243); Loreto, Cocha Coconilla (MUSM 17691, 17723), Collpa Salvador (MUSM 17661), El Triunfo (MUSM 33445, 33487), Estación Biológica Allpahuayo (LACM 96113; TTU 98653, 98702, 98857, 98964, 99031, 99032, 100941, 101238, 101239, 101155, 101257), Jenaro Herrera (AMNH 276697, 276700, 276705, 276718, 276723; MUSM 15978-15981, 23799-23803), La Habana km 52 carretera Iquitos-Nauta (MUSM 33446), Nuevo San Juan (MUSM 13287), Quebrada Agua Negra (MUSM 24432), San Jacinto (KU 157969), San Lucas km
44 carretera Iquitos-Nauta (MUSM 33448, 33450, 33451), San Pedro (UF 30454), Teniente López (KU 157970, 157971), Trece de Febrero km 31.5 carretera Iquitos-Nauta (MUSM 33452); Madre de Dios, 2.75 km E Shintuya (FMNH 169802; MUSM 16803, 16804), 12 km E Puerto Maldonado (MVZ 168966), Blanquillo (MUSM 8396), Reserva Cuzco Amazónico (MUSM 6060, 6061), Río La Torre (MUSM 20087), S.N. Pampas del Heath (MUSM 11652); San Martín, Caserío El Diamante (FMNH 203328, 203509); Ucayali, Cerros de Canchaguaya (MUSM 17902, 17930, 17952).

\section{Marmosops juninensis (Tate, 1931)}

Figures 5B, 21, 22, 23B

Marmosa juninensis Tate, 1931: 13 (original description).

Marmosa parvidens juninensis: Pine, 1981: 64 (name combination).

Marmosops parvidens juninensis: Gardner, 1993: 20 (name combination).

Marmosops juninensis: Emmons, 1990: 22 (first use of current binomial).

TyPe MATERial: The holotype (by original designation) consists of the skin and skull of a young adult female (AMNH 63864) collected by 
TABLE 11

Cytochrome-b Haplogroups of Marmosops bishopi ${ }^{a}$

\begin{tabular}{|c|c|c|c|c|}
\hline Haplogroup & $N^{\mathrm{b}}$ & Distribution $^{c}$ & Biome(s) & Habitat(s) \\
\hline A & 7 & eastern Peru \& western Brazil & Amazonia \& Andean foothills & lowland \& premontane rain forest \\
\hline B & 1 & northeastern Bolivia & Andean foothills & premontane rain forest \\
\hline $\mathrm{C}$ & 1 & southeastern Colombia & Amazonia & lowland rain forest \\
\hline $\mathrm{D}$ & 2 & northeastern Bolivia & Andean foothills & lowland \& premontane rain forest \\
\hline $\mathrm{E}$ & 2 & eastern Bolivia & Cerrado & semideciduous gallery forest \\
\hline $\mathrm{F}$ & 3 & northeastern Peru & Amazonia & lowland rain forest \\
\hline
\end{tabular}

a After Díaz-Nieto et al. (2016a).

${ }^{b}$ Number of sequences.

c See Díaz-Nieto et al. (2016a: fig. 2) for mapped localities.

H. Watkins on 25 February 1929 at Utcuyacu (fig. 24: locality 68), between Tarma and Chanchamayo, in Junín department, Peru, at an altitude of 4800 feet $(1463 \mathrm{~m})$.

Distribution, habitats, AND SYMPATRY: Examined specimens suggest that Marmosops juninensis has a restricted distribution in premontane and montane rain forest on the eastern slopes of the Peruvian Andes in the departments of Junín and Pasco between 1387 and $2316 \mathrm{~m}$ above sea level. According to Peralta and Pacheco (2014), at the lower limit of its elevational range $M$. juninensis occurs sympatrically with $M$. bishopi, where at least two species of the nominotypical subgenus (M. noctivagus and a member of the $M$. caucae complex) could also be expected to occur.

DESCRIPTION: Body pelage reddish brown (near Prout's Brown) middorsally, indistinctly paler laterally, and about 7-9 $\mathrm{mm}$ long at midback; ventral pelage superficially whitish, but hairs extensively gray based on throat, chest, and abdomen (including the insides of the fore- and hind limbs), with or without a narrow, discontinuous midventral streak of self-white fur. ${ }^{12}$ Manus covered dorsally with uniformly pale hairs (the metacarpals not contrasting sharply in color with the digits); lateral carpal tubercles bladelike. Mam-

12 Voss et al. (2001: 48) described the ventral fur as "entirely gray-based," corresponding to the phenotype seen in AMNH specimens, but Peralta and Pacheco (2014) described and illustrated recently collected material with a midventral streak of self-white fur. mary formula unknown (no female specimens with visible teats were examined). Tail substantially longer than combined length of head and body (mean LT/HBL $\times 100=126 \%-137 \%)$; dorsal caudal surface dark (perhaps brownish in life), ventral surface indistinctly paler.

Nasals long (extending well behind the lacrimals) and much wider posteriorly than anteriorly (laterally expanded at the maxillary-frontal suture). Lacrimal foramina concealed from lateral view inside anterior orbital margin; apex of zygomatic process of squamosal distinctively rounded anteriorly and not (or only slightly) overlapped dorsally by jugal. Palatine fenestrae consistently present, but sometimes irregular in size and shape. Dorsolateral margin of ethmoid foramen formed by the frontal.

Upper canine (C1) with only posterior accessory cusp in both sexes. Upper third molar (M3) anterolabial cingulum narrowly continuous with preprotocrista (anterior cingulum complete). Lower canine $(\mathrm{cl})$ premolariform (with posterior accessory cusp) and small, subequal in height to $\mathrm{p} 1 ; \mathrm{cl}$ anterolingual accessory cusp usually present but very small. First lower molar ( $\mathrm{m} 1)$ entoconid shorter than $\mathrm{m} 2$ paraconid; unworn $\mathrm{m} 4$ talonid with three distinct cusps.

Comparisons: Comparisons of Marmosops juninensis with $M$. bishopi are provided in the preceding account.

Marmosops juninensis seems to be about the same size as $M$. ojastii (table 8), but with the 


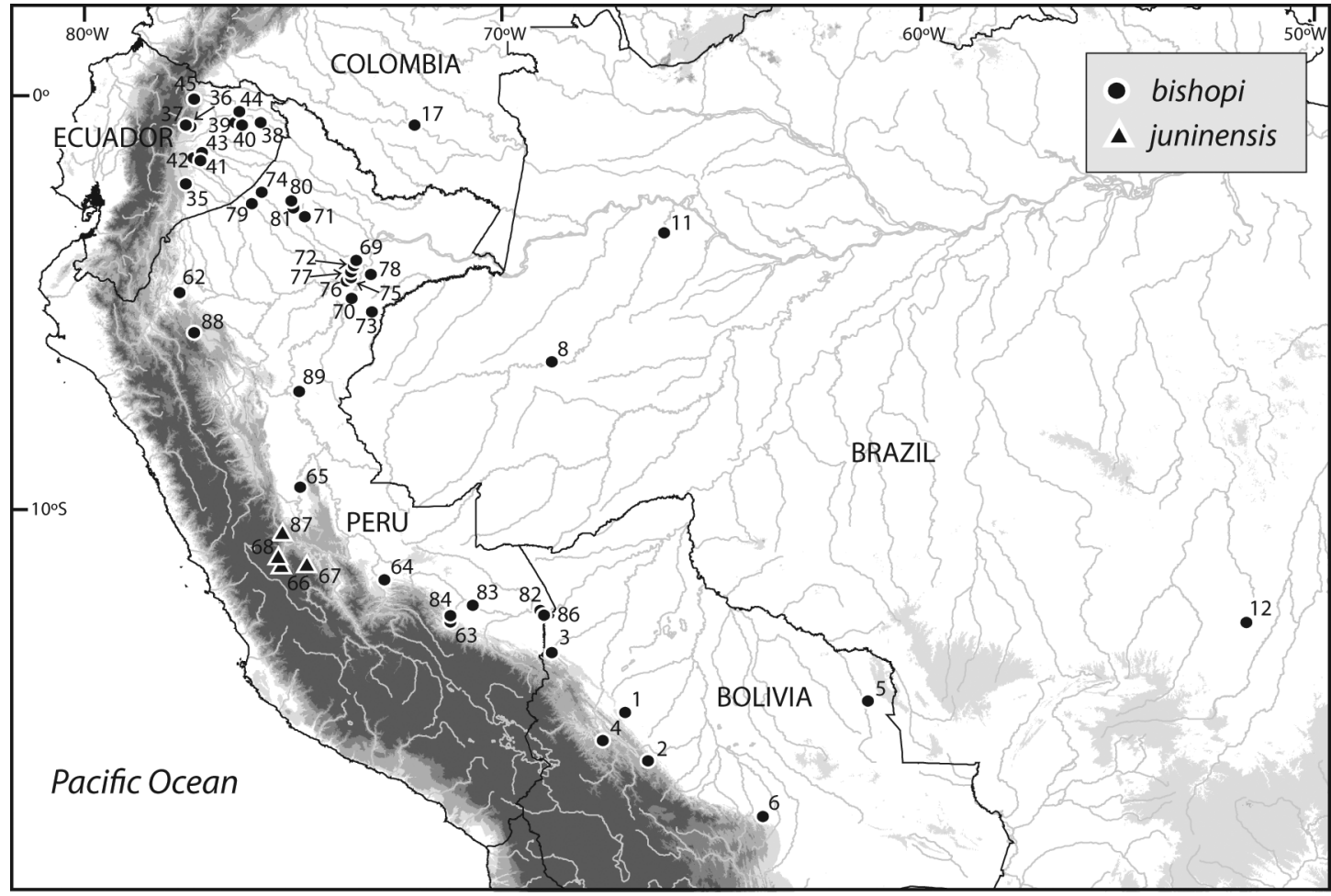

FIG. 24. Collecting localities of examined specimens of Marmosops bishopi and M. juninensis. Numbers are keyed to entries in the gazetteer (appendix 1). Progressively darker shading indicates higher elevations: pale gray $\geq 500 \mathrm{~m}$, medium gray $\geq 1000 \mathrm{~m}$, dark gray $\geq 2000 \mathrm{~m}$, darkest gray $\geq 3000 \mathrm{~m}$.

small samples available for both species, morphometric inference is problematic. In side-byside comparisons of skins these species are most readily distinguished by ventral pelage coloration: whereas the ventral pelage of $M$. juninensis is extensively gray based (with only a discontinuous midventral streak of self-white fur), the ventral pelage of $M$. ojastii is almost entirely self-white with no trace of gray-based hairs. Marmosops juninensis can also be unambiguously distinguished from $M$. ojastii by several craniodental characters including dorsal overlap between the squamosal and jugal (shallow or absent in $M$. juninensis versus extensive in $M$. ojastii), the dorsolateral margin of the ethmoid foramen (usually formed by the frontal in $M$. juninensis versus by the orbitosphenoid in $M$. ojastii), palatine fenestrae (consistently present in M. juninensis versus absent in M. ojastii), and a lingual accessory cusp on c1 (present in $M$. juninensis but absent in M. ojastii).

Insofar as can be judged from our small samples, Marmosops juninensis and M. chucha are about the same size. Skins of these species are distinguishable by ventral pelage coloration, which is extensively gray based in M. juninensis (notably on the throat and inside surfaces of the fore- and hind limbs) but broadly self-white in $M$. chucha (in which the throat is always selfwhite and the inside surfaces of the limbs usually have some self-white markings). In qualitative cranial comparisons, these species can be readily distinguished based on squamosal-jugal overlap (the jugal only slightly overlaps the zygomatic process of the squamosal in M. juninensis, whereas dorsal overlap between the jugal and squamosal bone is extensive in $M$. chucha), palatine fenestration (palatine fenestrae are consis- 
tently present and large in $M$. juninensis whereas palatine fenestrae are minute or absent in $M$. chucha), and the lingual accessory cusp of $\mathrm{cl}$ (usually present in M. juninensis versus usually absent in M. chucha).

Marmosops juninensis is likewise similar in size to M. magdalenae, from which it cannot confidently be distinguished based on measurement data alone. However, these species are distinguishable by ventral pelage coloration (extensively gray based in $M$. juninensis versus extensively self-white in $M$. magdalenae), dorsal overlap between the jugal and squamosal zygomatic process (shallow or absent in M. juninensis versus extensive in $M$. magdalenae), the lingual accessory cusp on $\mathrm{cl}$ (usually present in $M$. juninensis versus usually absent in M. magdalenae), and the number of $\mathrm{m} 4$ talonid cusps (three in $M$. juninensis versus two in M. magdalenae).

Remarks: The Pasco specimen (LSU 25902) is a juvenile male, but it is a good match in pelage and dental traits with other material referred to this species. In particular, the ventral fur of LSU 25902 is entirely gray based, C1 has a distinct posterior accessory cusp, and the combined length of M1-M2 is $3.5 \mathrm{~mm}$ (versus $3.4-3.6 \mathrm{~mm}$ in $\mathrm{AMNH}$ specimens, including the holotype).

Specimens examined $(N=7)$ : Peru-Junín, San Antonio (MUSM 40616, 40617), $22 \mathrm{mi} \mathrm{E}$ Tarma (AMNH 230014-230016), Utcuyacu (AMNH 63864); Pasco, Santa Cruz (LSU 25902).

\section{Marmosops ojastii García et al., 2014}

Figures 25-27

Marmosops ojastii García et al., 2014: 704 (original description).

Type material: The holotype (by original designation) consists of a fluid preserved body and skull of an adult male (EBRG 27474) said to have been collected by Frank Steines on 27 February 1996 at Pico Guacamaya (fig. 28: locality A), Parque Nacional Henri Pittier, Cordillera de la Costa, Aragua, Venezuela. Additionally, García et al. (2014: 705) designated one paratype (EBRG 29540), but excluded four other examined speci- mens (EBRG 27475, 27476, 29566, 29587) from the type series.

Distribution, HABITATS, AND SYMPATRY: Marmosops ojastii occurs in the Cordillera de la Costa and adjacent lowlands of northern Venezuela and in the Cordillera de Mérida of western Venezuela (fig. 28) from near sea level to at least $1850 \mathrm{~m}$. Habitats within this elevational range include lowland rain forest (e.g., near Urama; Handley, 1976: 84) and premontane rainforest (e.g., at Pico Guacamayo; García et al., 2014: 713, fig. 7). This species apparently occurs sympatrically with $M$. carri at Rancho Grande (appendix 1: locality 103) and may do so throughout its geographic range.

Description: Dorsal body pelage pale reddish brown and about 8-10 $\mathrm{mm}$ long at midback; ${ }^{13}$ ventral pelage self-white from chin to groin (including the inside surfaces of the foreand hind limbs), without lateral zones of graybased hairs. Manus covered dorsally with uniformly pale hairs (the metacarpals not contrasting sharply in color with the digits); lateral carpal tubercle bladelike, not spoon shaped. Mammary formula unknown (no adult female specimens examined by us or by García et al., 2014). Tail considerably longer than combined length of head and body (mean LT/HBL $\times 100=$ $143 \%)$ and indistinctly bicolored.

Nasals apparently not very long (not extending posteriorly much behind the lacrimals) and wider posteriorly than anteriorly (laterally expanded at the maxillary-frontal suture). Lacrimal foramina concealed from lateral view inside anterior orbital margin; zygomatic process of the squamosal broadly overlapped dorsally by the jugal. Palatine fenestrae absent. Dorsolateral margin of ethmoid foramen formed by the orbitosphenoid.

Upper canines short and apparently not sexually dimorphic; males and females with posterior

\footnotetext{
${ }^{13}$ Near Buffy Brown middorsally and somewhat paler laterally in USNM 371299, "marrón rojizo" in specimens examined by García et al. (2014: 707). The dorsal fur is a little shorter in USNM 371299 (collected near sea level) than in the material measured by García et al. (2014) from higher elevations.
} 


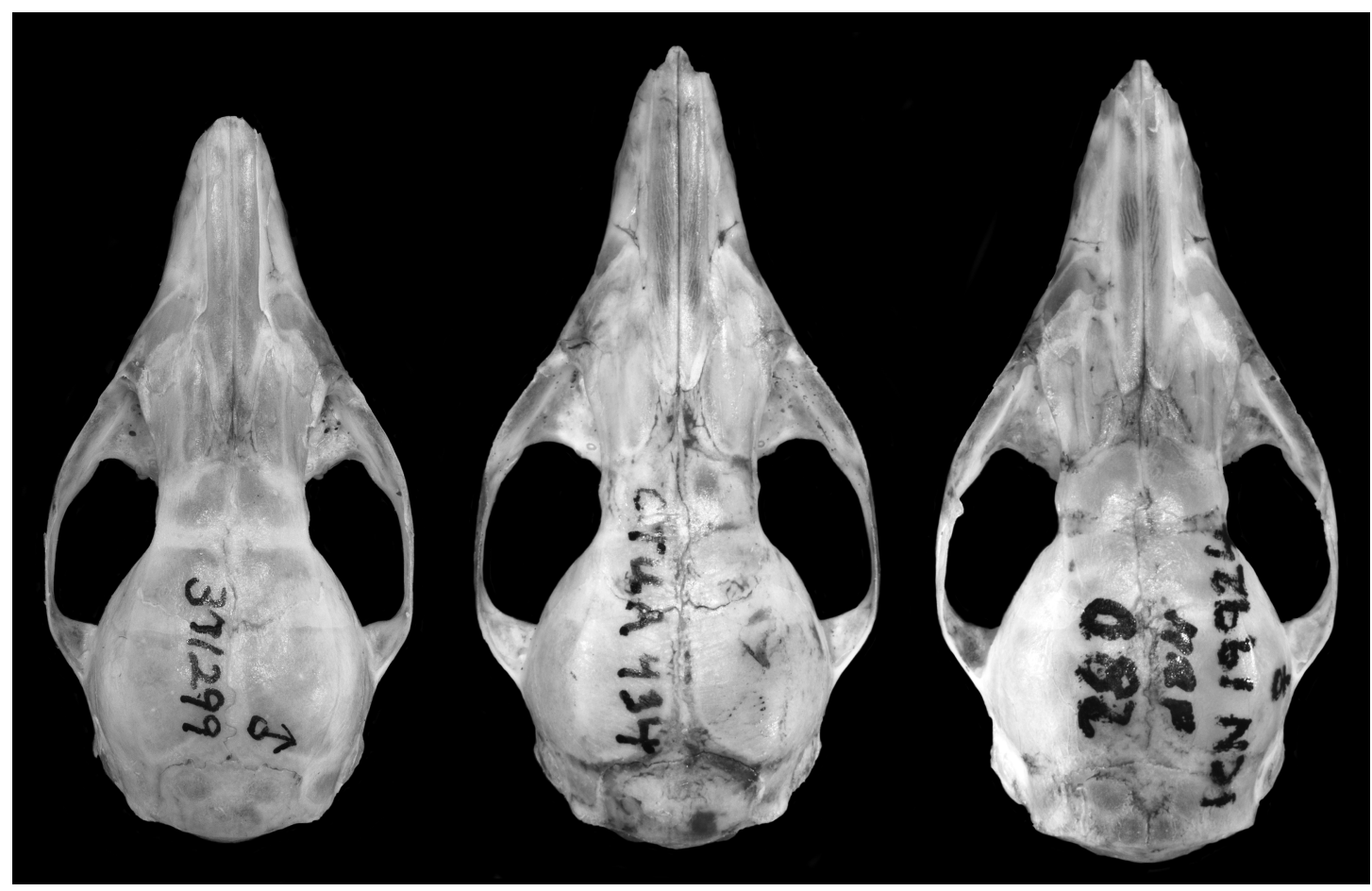

FIG. 25. Dorsal views of skulls of Marmosops ojastii (left, USNM 371299), M. chucha (center, CTUA 434), and M. magdalenae (right, ICN 19924). All views about $\times 3$.

accessory cusp only. ${ }^{14}$ Upper third molar (M3) anterolabial cingulum narrowly continuous with preprotocrista (anterior cingulum complete). Lower canine (c1) premolariform (procumbent, with posterior accessory cusp) and small, subequal in height to $\mathrm{p} 1$; $\mathrm{cl}$ anterolingual accessory cusp absent. Entoconid of $\mathrm{m} 1$ shorter than adjacent $\mathrm{m} 2$ paraconid; unworn $\mathrm{m} 4$ talonid with three distinct cusps.

Comparisons: Comparisons of Marmosops ojastii with $M$. bishopi and M. juninensis have already been provided in the preceding species accounts (above).

Marmosops ojastii appears to be smaller, on average, than $M$. chucha (table 8). In fact, males of these allopatric species exhibit nonoverlapping variation in several external and craniodental dimensions (e.g., HBL, NB, LIB, PL, PB, MTR,

${ }^{14}$ We have not examined any female specimens, but García et al. (2014) described two juvenile females with a posterior accessory cusp on $\mathrm{C} 1$.
$\mathrm{LM}$ ), although the diagnostic value of these data is compromised by small sample sizes. The single skin of M. ojastii available for side-by-side comparisons with skins of $M$. chucha is conspicuously paler than any of the latter species, and it has more extensively self-white underparts than most skins of M. chucha (which often have lateral zones of gray-based ventral fur). Additionally, M. ojastii appears to have a relatively longer tail (about $140 \%$ of HBL) by comparison with M. chucha (about 130\% of HBL). Skulls of the two species are qualitatively similar, but (in addition to the aforementioned size difference) the nasals of M. ojastii are visibly narrower in proportion to interorbital breadth than are those of M. chucha $(\mathrm{NB} / \mathrm{LIB}=$ ca. 0.57 versus 0.70 , respectively, for males). Whereas males and females of $M$. ojastii have only a posterior accessory cusp on C1, most female specimens of $M$. chucha have both anterior and posterior $\mathrm{C} 1$ accessory cusps.

Marmosops ojastii appears to differ from $M$. magdalenae in many of the same traits that 


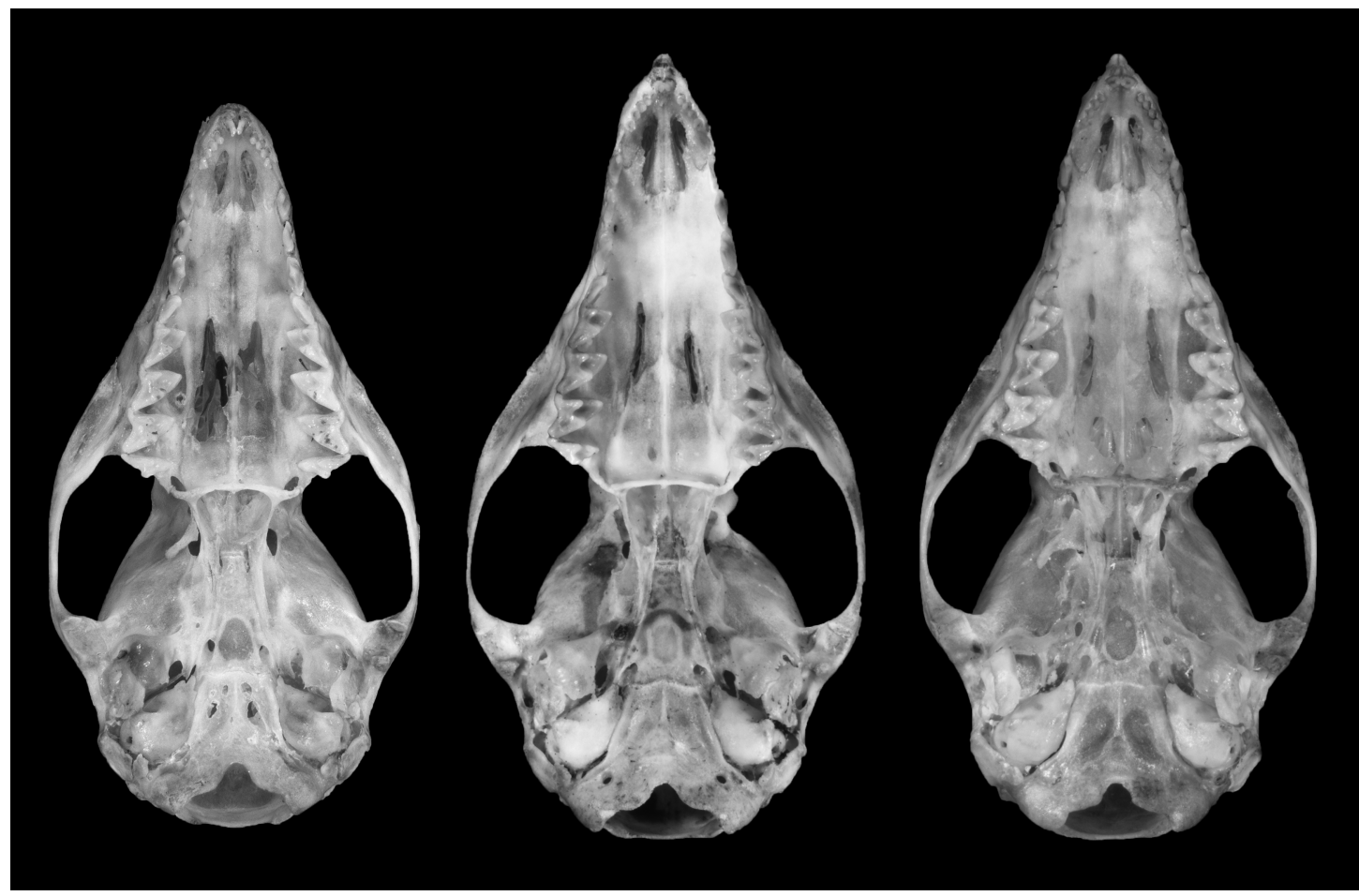

FIG. 26. Ventral views of skulls of Marmosops ojastii (left, USNM 371299), M. chucha (center, CTUA 434), and M. magdalenae (right, ICN 19924). All views about $\times 3$.

apparently distinguish it from $M$. chucha, including smaller size, paler dorsal pelage, more extensively self-white ventral pelage, longer tail (relative to head-and-body), and narrower nasals (relative to interorbital breadth). Additionally, palatine fenestrae are absent in both intact adult skulls of M. ojastii (fig. 26; García et al., 2014: fig. 2B), whereas these openings are consistently present in examined specimens of $M$. magdalenae (figs. 5C, 26). Other possibly diagnostic characters include the dorsolateral margin of the ethmoid foramen (formed by the orbitosphenoid in USNM 371299, but by the frontal in examined specimens of $M$. magdalenae), and the number of $\mathrm{m} 4$ talonid cusps (three in USNM 371299, usually two in M. magdalenae).

Remarks: The single specimen of Marmosops ojastii that we examined (USNM 371299) was not part of García et al.s (2014) type material, but it agrees with their morphological description in all important respects, its measurements correspond closely to their measurements of the holotype skull and paratype skin, and it was collected within the geographic range of their material (fig. 28). Those authors did not analyze any genetic data, so it is relevant to note that the cytochrome- $b$ sequence we obtained from USNM 371299 is highly divergent (by $9 \%-15 \%$ in average pairwise uncorrected comparisons; Díaz-Nieto et al., 2016a: supplementary information, table S3) from those of previously described taxa in the subgenus Sciophanes and tends to support the conclusion that $M$. ojastii is a valid species. This specimen was previously identified as M. parvidens by Pine (1981) and Voss et al. (2001: 48-49), although the latter authors remarked several of the traits that we now recognize as diagnosing the Bishopi Group (e.g., its bladelike carpal tubercle and lack of an anterior $\mathrm{C} 1$ accessory cusp). ${ }^{15}$

\footnotetext{
15 According to García et al. (2014: 715), USNM 371299 is a juvenile, but in fact it is a young adult.
} 


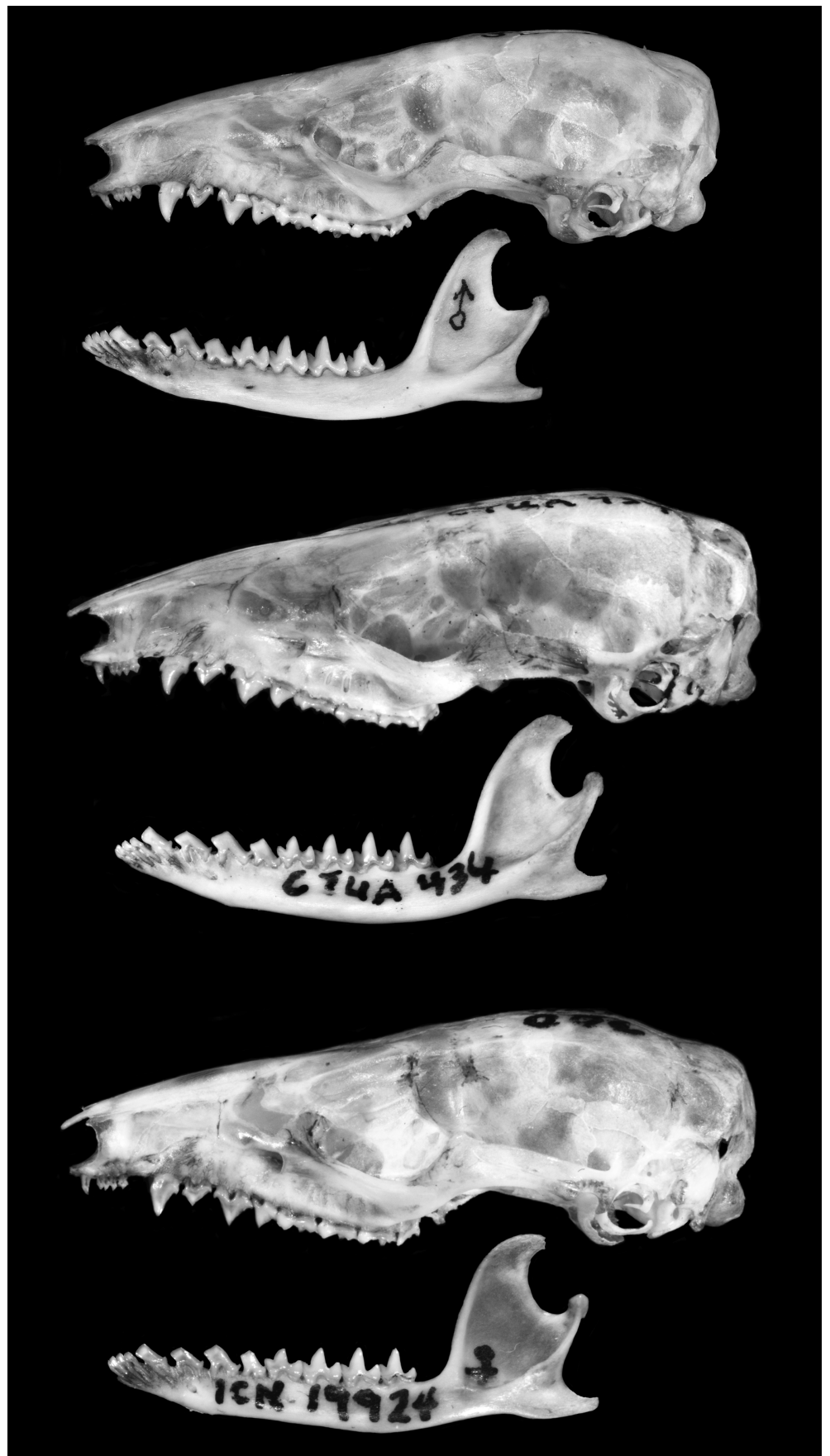

FIG. 27. Lateral views of skulls of Marmosops ojastii (above, USNM 371299), M. chucha (center, CTUA 434), and M. magdalenae (below, ICN 19924). All views about $\times 3$. 
A single specimen from the Maracaibo Basin of western Venezuela (UMMZ 53222), a fluidpreserved adult male with an extracted skull, might also represent this species. Like other members of the Bishopi Group, it has bladelike carpal tubercles, and the anterior cingulum of M3 is narrowly continuous. Like $M$. ojastii, it has completely self-white underparts, lacks palatine fenestrae, and has narrow nasals relative to interorbital breadth $(\mathrm{NB} / \mathrm{LIB}=0.54)$. Unlike M. ojastii, however, the upper canine of UMMZ 53222 has well-developed anterior and posterior accessory cusps. Unfortunately, we were unable to amplify DNA from this old specimen (collected in 1914; see appendix 1: locality 118), and we are unaware of any additional material from the Maracaibo lowlands, which are now extensively deforested.

In their phylogenetic analyses of Marmosops, Díaz-Nieto et al. (2016a: figs. 4, 5) were not able to convincingly resolve the position of M. ojastii, which was either recovered as the sister taxon of M. chucha + M. magdalenae (using cytochrome$b$ sequences only) or as the sister species of $M$. bishopi (using sequences from cytochrome- $b$ and the Breast Cancer Activating 1 nuclear gene).

Specimens examined $(N=1)$ : VenezuelaCarabobo/Falcón/Yaracuy, 19 km NW Urama (USNM 371299).

\section{Marmosops chucha, new species}

Figures 25-27

Holotype: CTUA 434 (original number CACE004), consisting of the skin, skull, fluidpreserved carcass, and associated tissues of an adult female collected by Camilo A. CalderónAcevedo on 15 July 2010 at Hacienda Vegas de La Clara (fig. 28: locality 18), municipio Gómez Plata, Antioquia, Colombia.

Distribution, habitats, AND Sympatry: Examined specimens of Marmosops chucha are from west of the Río Magdalena in northern Colombia between $130 \mathrm{~m}$ and $1400 \mathrm{~m}$; known collection localities are in the foothills of the Ser- ranía de Abibe (the northwestern terminus of the Cordillera Occidental), the northeastern part of the Cordillera Central, and the interandean valley of the Río Porce (fig. 28). Recorded capture habitats include premontane rain forest (Sánchez-Giraldo and Díaz-Nieto, 2015), premontane moist forest (Estrada-Pareja et al., 2007), and lowland rain forest (Castaño and Corrales, 2010), all of which now occur as fragments within an anthropogenic matrix of pastures and agricultural fields. At the upper limit of its known elevational range, $M$. chucha occurs sympatrically with M. handleyi (e.g., near Valdivia [appendix 1: locality 24]; see Díaz-N. et al., 2011).

DesCRIPTION: Body pelage brownish (near Prout's Brown in darker specimens, closer to Dresden Brown in others) middorsally, indistinctly paler laterally, and about 7-10 $\mathrm{mm}$ long at midback; ventral pelage continuously selfwhite from chin to groin (usually including the insides of the fore- and hind limbs), but selfwhite fur narrowed by lateral zones of gray-based abdominal fur (tipped with brown) in some specimens. ${ }^{16}$ Manus covered dorsally with uniformly pale hairs (the metacarpals not contrasting sharply in color with the digits); lateral carpal tubercle bladelike, not spoon shaped. Mammary formula $4-1-4=9$ in all examined females with visible teats. Tail substantially longer than combined length of head and body (mean LT/HBL $\times$ $100=130 \%$ ), usually indistinctly bicolored and sometimes indistinctly paler distally than basally.

Nasals not very long (usually not extending posteriorly behind the lacrimals) and much wider posteriorly than anteriorly (laterally expanded at the maxillary-frontal suture). Lacrimal foramina concealed from lateral view inside anterior orbital margin; zygomatic process of squamosal broadly overlapped dorsally by the jugal. Palatine fenestrae absent or minute. Dorsolateral margin of ethmoid foramen formed by the orbitosphenoid.

\footnotetext{
16 This might be a sexually dimorphic trait. The midventral zone of self-white fur-measured across the sternum-seems to be wider in females $(17-20 \mathrm{~mm}, N=3)$ and narrower in males $(7-12 \mathrm{~mm}, N=5)$.
} 


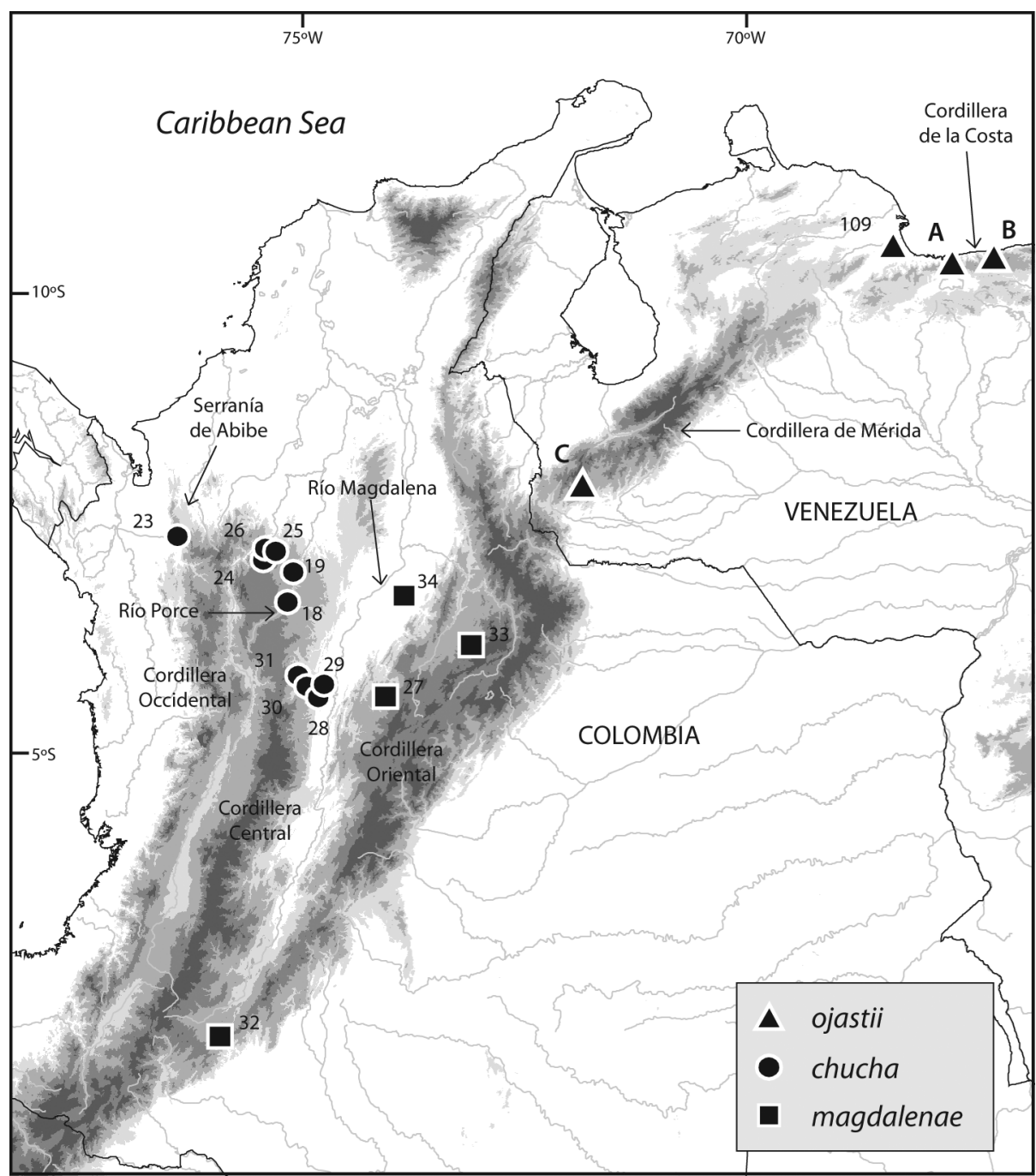

FIG. 28. Collecting localities of Marmosops ojastii, M. chucha, and M. magdalenae. Numbers are keyed to entries in the gazetteer for material examined by us; letters indicate collection localities of unexamined material of M. ojastii reported by García et al. (2014): A, Pico Guacamaya, Parque Nacional Henri Pittier, Aragua, Venezuela $\left(10^{\circ} 21^{\prime} \mathrm{N}, 67^{\circ} 40^{\prime} \mathrm{W}\right)$; B, Sector Buenos Aires, Monumento Nacional Pico Codazzi, Aragua, Venezuela $\left(10^{\circ} 25^{\prime} \mathrm{N}, 67^{\circ} 21^{\prime} \mathrm{W}\right)$; C, Campamento La Trampita, Uribante-Caparo, Táchira, Venezuela $\left(7^{\circ} 50^{\prime} \mathrm{N}\right.$, $\left.71^{\circ} 57^{\prime} \mathrm{W}\right)$. Progressively darker shading indicates higher elevations: pale gray $\geq 500 \mathrm{~m}$, medium gray $\geq 1000$ $\mathrm{m}$, dark gray $\geq 2000 \mathrm{~m}$, darkest gray $\geq 3000 \mathrm{~m}$.

Upper canines short in both sexes but apparently sexually dimorphic: males usually with only posterior accessory cusp and females usually with both anterior and posterior accessory cusps (MHNUC 986, a male with both anterior and posterior accessory cusps, and FMNH 69822, a female with just a posterior accessory cusp, are exceptions). Upper third molar (M3) anterolabial cingulum narrowly continuous with preprotocrista (anterior cingulum complete). Lower canine (c1) premolariform (procumbent, with posterior accessory cusp) and small, subequal in height to $\mathrm{p} 1$; $\mathrm{cl}$ anterolingual accessory cusp absent in most examined material (but dis- 
tinctly present in FMNH 70925). Entoconid of $\mathrm{m} 1$ shorter than adjacent $\mathrm{m} 2$ paraconid; unworn $\mathrm{m} 4$ talonid with three distinct cusps.

Comparisons: Comparisons of Marmosops chucha with M. bishopi, M. juninensis, and M. ojastii have already been provided in the accounts for those species (above).

Marmosops chucha and M. magdalenae are similar in most qualitative and morphometric traits, but palatine fenestrae are consistently absent or indistinct in $M$. chucha, whereas these openings are consistently large in $M$. magdalenae. Additionally, the dorsolateral margin of the ethmoid foramen is usually formed by the orbitosphenoid in $M$. chucha whereas the dorsolateral margin of this foramen is usually formed by the frontal in M. magdalenae. Lastly, there are apparent taxonomic differences in the presence of $\mathrm{C} 1$ accessory cusps: in $M$. chucha most males have only posterior accessory cusps and most females have both anterior and posterior cusps, whereas in M. magdalenae both sexes have only posterior accessory cusps.

EтумоLogy: From chucha, a colloquial term for "opossum" in Colombian Spanish (Comisión de Lingüística de la Academia Colombiana, 2012), here treated as a noun in apposition.

REMARKs: The known geographic ranges of Marmosops chucha and M. magdalenae are separated by the Río Magdalena, an important geographic barrier (Chapman, 1917; Gutiérrez-Pinto et al., 2012), and they differ from one another by about $5.9 \%$ in average uncorrected pairwise comparisons of partial cytochrome- $b$ sequences. Although additional phenotypic and genetic evidence that these are fully differentiated species would be welcome, the results at hand seem sufficient to justify their recognition as such in the context of this revision.

The material that we refer to Marmosops chucha was previously identified as Marmosa parvidens by Pine (1981), as Marmosops parvidens by Díaz-N. et al. (2011), and as Marmosops "West Magdalena” by Díaz-Nieto et al. (2016a).

SPecimens examined $(N=10)$ : ColombiaAntioquia, Amalfi (CTUA 428), Gómez Plata
(CTUA 434), Valdivia (FMNH 69822, 69825, 69826), Villa Arteaga (FMNH 69837); Caldas, Norcasia (MNHUC 750, 986), Samaná (FMNH 70925; MNHUC uncataloged DCV69).

\section{Marmosops magdalenae, new species}

Figures 5C, 6B, 25-27

HolOTYPE: ICN 19924 (original number MRP82), consisting of the skin and skull of an adult female collected by Miguel E. RodríguezPosada on 18 July 2002 at Bosque de Roble Cerca de Torre, Reserva Biológica Cachalú (fig. 28: locality 33), vereda Rionegro, municipio Encino, Santander, Colombia.

Distribution AND SyMPATRY: Examined specimens of Marmosops magdalenae are from east of the Río Magdalena in northern Colombia, where it has been collected between $104 \mathrm{~m}$ and $1940 \mathrm{~m}$ above sea level (fig. 28). Capture habitats include lowland rain forest along the right bank of the Río Magdalena (e.g., at Corregimiento Campo Capote [fig. 28: locality 34]) and lower montane moist forest on the western slope of the Cordillera Oriental (e.g., at Reserva Biológica Cachalú [fig. 28: locality 33]; OtáloraArdila, 2003; Ávila et al., 2010). This species is not known to occur sympatrically with any other congener, but at the upper limit of its elevational range it might cooccur with $M$. caucae, a member of the nominotypical subgenus that is widespread in Andean cloud forests (Díaz-Nieto et al., 2016a).

DESCRIPTION: Body pelage fuscous to reddish brown (near Dresden Brown) middorsally, indistinctly paler laterally, and about $9 \mathrm{~mm}$ long at midback (based on FMNH 70926); ventral pelage self-white from chin to groin (including the inside surface of the forelimbs and sometimes also the hind limbs), but midventral band of self-white fur narrowed by lateral zones of gray-based abdominal hairs (sometimes with brownish tips) on abdomen. Manus covered dorsally with uniformly pale fur, without pigmental contrast between the metacarpal and digital pelage; lateral carpal tuber- 
cles bladelike in all examined adult males. Mammary formula unknown. ${ }^{17}$ Tail longer than combined length of head and body (mean LT/ HBL $\times 100=125 \%-130 \%$ ), indistinctly bicolored, and somewhat paler distally than proximally (but not distinctly particolored).

Nasals not very long (usually not extending posteriorly behind lacrimals) and much wider posteriorly than anteriorly (laterally expanded at the maxillary-frontal suture). Lacrimal foramina concealed from lateral view inside anterior orbital margin; zygomatic process of squamosal broadly overlapped dorsally by jugal. Palatine fenestrae consistently present and large. Dorsolateral margin of ethmoid foramen usually formed by the frontal.

Upper canines short, with posterior accessory cusps in both sexes (anterior accessory cusps consistently absent in all examined material). Upper third molar (M3) anterolabial cingulum narrowly continuous with preprotocrista (anterior cingulum complete). Lower canine (c1) premolariform (procumbent, with posterior accessory cusp) and small, subequal in height to p1; c1 anterolingual accessory cusp absent or indistinct. Entoconid of $\mathrm{m} 1$ shorter than adjacent $\mathrm{m} 2$ paraconid; unworn $\mathrm{m} 4$ talonid usually with only two distinct cusps.

Comparisons: Comparisons between Marmosops magdalenae and other species of the Bishopi Group have already been provided in the preceding accounts.

Eтymology: For the Río Magdalena, economically and culturally the most important river of Colombia, and a well-known dispersal barrier for the terrestrial vertebrate fauna of northwestern South America (Chapman, 1917; Gutiérrez-Pinto et al., 2012).

Remarks: The material that we refer to Marmosops magdalenae was previously identified in

\footnotetext{
17 The skin tag of ICN 19924 mentions the presence of "6 mamas," but no mammary formula was provided. We inspected the skin of this specimen and found 6 teats in the arrangement 3-1-2. Because no species of Marmosops is known to have unpaired lateral mammae it seems probable that additional mammae are normally present in this species.
}

the literature as Marmosa parvidens by Pine (1981), as Marmosops parvidens by Díaz-N. et al. (2011), and as Marmosops "East Magdalena" by Díaz-Nieto et al. (2016a).

Specimens examined $(N=3)$ : ColombiaBoyacá, Muzo (FMNH 70926); Huila, near San Adolfo (FMNH 70927, 70928); Santander, Encino (ICN 19924), Puerto Parra (ICN 18788).

\section{DISCUSSION}

Specimens of the subgenus Sciophanes are not common in museum collections. Although we examined all the material that we were able to locate in North American, Colombian, and Ecuadorean museums, the total available for this study of 12 species amounted to fewer than 300 specimens. By contrast, Rossi et al. (2010) were able to examine almost 1500 specimens for their revision of just seven species of Marmosa. This difference in specimen availability perhaps reflects the difficulty of trapping very small marsupials like Sciophanes with commercially available equipment. Pitfall trapping appears to be a more effective collecting method (Voss et al., 2001: table 48), but pitfalls have only recently come into routine use for Neotropical rainforest mammal inventory work (Umetsu et al., 2006; Ribeiro-Júnior et al., 2011). As pitfall trapping continues to gain in popularity, we predict a corresponding increase in numbers of fresh specimens of Sciophanes, which should provide abundant material for evaluating the taxonomic conclusions of our study.

Even a cursory examination of the maps in this report suggests where new discoveries are likely to be made. We have not seen any material of Sciophanes from vast Amazonian landscapes, including those drained by such major rivers as the Rio Negro, the Tapajos, the Madeira, and the upper Xingu. No specimens are known from the eastern slopes of the Colombian Andes, nor from the Chocó lowlands of western Colombia. Based on the distribution of other small didelphids that often cooccur with Sciophanes, it seems likely that the subgenus does occupy many regions 
from which specimens are currently unknown. Therefore, we confidently predict that future collecting will result either in significant geographicrange extensions of currently recognized taxa, or in the discovery of new species. In effect, this report is no more than a preliminary assessment of the species-level diversity of Sciophanes based on the material now at hand.

Future research might also profitably focus on assessing the genetic independence of several mtDNA haplogroups that we are currently unable to distinguish by phenotypic criteria. In particular, coalescent analyses of nuclear markers could help determine whether any of the several haplogroups of $M$. bishopi (table 11) are cryptic species. On the other hand, morphological analyses would be welcome in any future attempt to evaluate the taxonomic status of populations with $M$. pinheiroi-like mtDNA sequences from savanna landscapes in Maranhão (Nascimento et al., 2015), and larger sample sizes would certainly be helpful for testing the statistical significance of morphometric differences inferred from small numbers of specimens in this study.

There is still much to learn.

\section{ACKNOWLEDGMENTS}

We are grateful to the curators and collection support staff that hosted our visits and processed the loans that made this study possible, especially (in no particular order) Alejandra Camacho and Santiago Burneo (QCAZ); Bruce Patterson and the late Bill Stanley (FMNH); Burton K. Lim and Jacqueline Miller (ROM); Hugo López-Arévalo, Catalina Cárdenas, and Miguel E. Rodríguez-Posada (ICN); James L. Patton, Eileen Lacey, and Chris Conroy (MVZ); John R. Wible and Susan B. McLaren (CM); Joseph Cook and Jonathan Dunnum (MSB); Julián A. Salazar and Juan D. Corrales-Escobar (MHNUC); Kristofer M. Helgen, Linda K. Gordon, and Darrin P. Lunde (USNM); Luis Albuja V. (EPN); Paula Jenkins (BMNH); Phil Myers (UMMZ); Sergio Solari and Juan M. Martínez-C. (CTUA); Victor Pacheco (MUSM); Mark Hafner
(LSUMZ); Jim Dines (LACM); and François Catzeflis (ISEM).

We also thank Patricia J. Wynne, illustratorin-residence in the Department of Mammalogy at the AMNH for her splendid line art, and Suzann Goldberg (in the AMNH Department of Paleontology) for her excellent cranial photographs. As ever, R.S.V. is grateful to Eileen Westwig, departmental loan officer in the AMNH Department of Mammalogy, for patiently and meticulously processing dozens of loans for this project over many years. Alfred L. Gardner and an anonymous reviewer provided helpful comments on an earlier draft that helped improve the accuracy of this report.

This work was funded in part by a National Science Foundation research grant (DEB-743039, to R.S.V.) and by a Doctoral Dissertation Improvement Grant (DDIG-1311163, to J.F.D.N.). The senior author also acknowledges a Grant-in-Aid of Research from the American Society of Mammalogists and a James W. Wilkie Fund for Natural History Fellowship from the J.F. Bell Museum of Natural History (University of Minnesota), both of which provided additional funding to visit museum collections. J.F.D.-N. is currently supported by a Francisco José de Caldas Fellowship from the Colombian department of science, technology, and innovation (COLCIENCIAS). Lastly, J.F.D.-N. is grateful to Paúl M. Velazco for his company and friendship during museum visits to Chicago and New York.

\section{REFERENCES}

Abdala, F., D.A. Flores, and N.P. Giannini. 2001. Postweaning ontogeny of the skull of Didelphis albiventris. Journal of Mammalogy 82: 190-200.

Albuja-V, L., and A. Arguero. 2011. Mamíferos. In L. Albuja V (editor), Fauna de Guiyero. Parque Nacional Yasuní: 27-62. Quito: Ecofondo.

Allen, J.A., and F.M. Chapman. 1897. On a second collection of mammals from the island of Trinidad, with descriptions of new species and a note on some mammals from the island of Dominica, W.I. Bulletin of the American Museum of Natural History 9 (2): 13-30. 
Anderson, R.P. 1999. Preliminary review of the systematics and biogeography of the spiny pocket mice (Heteromys) of Colombia. Revista de la Academia Colombiana de Ciencias Exactas, Físicas y Naturales 23 (suplemento especial): 613-630.

Anderson, R.P., and E.E. Gutiérrez. 2009. Taxonomy, distribution, and natural history of the genus Heteromys (Rodentia: Heteromyidae) in central and eastern Venezuela, with the description of a new species from the Cordillera de la Costa. In Robert S. Voss and Michael D. Carleton (editors), Systematic mammalogy: contributions in honor of Guy G. Musser. Bulletin of the American Museum of Natural History 331: 33-93.

Anderson, R.P., E.E. Gutiérrez, J. Ochoa-G., F.J. García, and M. Aguilera. 2012. Faunal nestedness and species-area relationship for small non-volant mammals in "sky islands" of northern Venezuela. Studies on Neotropical Fauna and Environment 47: 157-170.

Anderson, S. 1997. Mammals of Bolivia, taxonomy and distribution. Bulletin of the American Museum of Natural History 231: 1-652.

Archer, M. 1976. The basicranial region of marsupicarnivores (Marsupialia), interrelationships of carnivorous marsupials, and affinities of the insectivorous marsupial peramelids. Zoological Journal of the Linnaean Society 59: 217-322 + 21 pls.

Arguero, A., O. Jiménez-Robles, F. Sánchez-Karste, A. Baile, G. de la Cadena, and K. Barboza-M. 2012. Observaciones sobre dispersión de semillas por murciélagos en la alta Amazonía del sur de Ecuador. In D.G. Tirira and S.F. Burneo (editors), Investigación y conservación sobre murciélagos en el Ecuador (Fundación Mamíferos y Conservación y Asociación Ecuatoriana de Mastozoología Publicación Especial sobre los Mamíferos del Ecuador 9): 37-46. Quito: Pontificia Universidad Católica del Ecuador.

Ávila, F.A., S.P. Ángel, and R. López-C. 2010. Diversidad y estructura de un robledal en la Reserva Biológica Cachalú, Encino (Santander-Colombia). Revista Colombia Forestal 13: 87-116.

Barnes, R.D. 1977. The special anatomy of Marmosa robinsoni. In D. Hunsaker (editor), The biology of marsupials: 387-413. New York: Academic Press.

Bown, T.M., and M.J. Kraus. 1979. Origin of the tribosphenic molar and metatherian and eutherian dental formulae. In J.A. Lillegraven, Z. Kielan-Jaworowska, and W.A. Clemens (editors), Mesozoic mammals, the first two-thirds of mammalian history: 172-181. Berkeley: University of California Press.

Brown, J.C. 1971. The description of mammals. 1. The external characters of the head. Mammal Review 1: $151-168$.
Brown, J.C., and D.W. Yalden. 1973. The description of mammals. 2. Limbs and locomotion of terrestrial mammals. Mammal Review 3: 107-134.

Cabrera, A. 1919. Genera mammalium: Monotremata, Marsupialia. Madrid: Museo de Ciencias Naturales.

Cabrera, A. 1958 (“1957”). Catálogo de los mamíferos de América del Sur [part 1]. Revista del Museo Argentino de Ciencias Naturales "Bernardino Rivadavia” (Ciencias Zoológicas) 4: 1-307.

Cadena, C.D., J. Klicka, and R.E. Ricklefs. 2007. Evolutionary differentiation in the Neotropical montane region: molecular phylogenetics and phylogeography of Buarremon Brush-finches (Aves, Emberizidae). Molecular Phylogenetics and Evolution 44: 993-1016.

Castaño, J.H., and J.D. Corrales. 2010. Mamíferos de la cuenca del río La Miel (Caldas): Diversidad y uso cultural. Boletín Científico. Centro de Museos. Museo de Historia Natural 14: 56-75.

Catzeflis, F., S. Barrioz, J.-F. Szpigel, and B. de Thoisy. 2014. Marsupiaux et rongeurs de Guyane. Cayenne: Institut Pasteur de la Guyane.

Chapman, F.M. 1917. The distribution of birdlife in Colombia; a contribution to a biological survey of South America. Bulletin of the American Museum of Natural History 36: 1-729.

Comisión de Lingüística de la Academia Colombiana. 2012. Breve diccionario de colombianismos, $4^{\mathrm{a}}$ edición revisada. Bogotá: Academia Colombiana de la Lengua.

Cope, E.D. 1880. On the foramina perforating the posterior part of the squamosal bone of the Mammalia. Proceedings of the American Philosophical Society 18: 452-461.

Cordero R., G.A. 2001. Ecological data on Marmosops fuscatus in a lowland tropical forest in northern Venezuela. Mammalia 65: 228-231.

Cunha, A.A., and M.V. Vieira. 2002. Support diameter, incline, and vertical movements of four didelphid marsupials in the Atlantic forest of Brazil. Journal of Zoology (London) 258: 419-426.

Díaz-N., J.F. 2012. New records of Marmosops noctivagus (Tschudi, 1845) (Didelphimorphia: Didelphidae) and first record of Marmosops bishopi (Pine, 981) for Colombia. Check List 8: 805-809.

Díaz-N., J.F., M. Gómez-Laverde, and C. SánchezGiraldo. 2011. Rediscovery and redescription of Marmosops handleyi (Pine, 1981) (Didelphimorphia: Didelphidae), the least known Andean slender mouse opossum. Mastozoología Neotropical 18: 45-61.

Díaz-Nieto, J.F., S.A. Jansa, and R.S. Voss. 2016a. DNA sequencing reveals unexpected Recent diversity and an ancient dichotomy in the American marsupial 
genus Marmosops (Didelphidae: Thylamyini). Zoological Journal of the Linnean Society 176: 914-940. Díaz-Nieto, J.F., S.A. Jansa, and R.S. Voss. 2016b. Phylogenetic relationships of Chacodelphys (Marsupialia: Didelphidae) based on "ancient" DNA sequences. Journal of Mammalogy [doi.org/10.1093/jmammal/ gyv197].

DMA. 1993. Gazetteer of Venezuela, 2nd ed. (2 vols.). Washington, DC: Defense Mapping Agency.

Duellman, W.E., and J.R. Mendelson III. 1995. Amphibians and reptiles from northern Departamento Loreto, Peru: taxonomy and biogeography. University of Kansas Science Bulletin 55: 329-376.

Eiten, G. 1975. The vegetation of the Serra do Roncador. Biotropica 7: 112-135.

Emmons, L.H. 1990. Neotropical rainforest mammals, a field guide. Chicago: University of Chicago Press.

Emmons, L.H., et al. [ 6 coauthors]. 2006. The non-flying mammals of Noel Kempff Mercado National Park (Bolivia). Revista Boliviana de Ecología y Conservación Ambiental 19: 23-46.

Estrada-Pareja, M.M., S.M. Márquez-Girón, and L.F. Restrepo-Betancur. 2007. Caracterización de las propiedades del aire húmedo (sincrometría) del microclima de la hacienda Vegas de la Clara (nordeste antioqueño, Colombia). Revista Colombiana de Ciencias Pecuarias 20: 339-342.

Fairchild, G.B., and C.O. Handley, Jr. 1966. Gazetteer of collecting localities in Panama. In R.L. Wenzel, and V.J. Tipton (editors), Ectoparasites of Panama: 9-22 + folding map. Chicago: Field Museum of Natural History.

García, F.J., J. Sánchez-Hernández, and T. Semedo. 2014. Descripción de una nueva especie de comadrejita ratona del género Marmosops Matschie, 1916 (Didelphimorphia, Didelphidae). Theyra 5: 701-723.

Gardner, A.L. 1993. Order Didelphimorphia. In D.E. Wilson and D.M. Reeder (editors), Mammal species of the world, 2nd ed.: 15-23. Washington, DC: Smithsonian Institution Press.

Gardner, A.L. (editor). 2008 (“2007”). Mammals of South America. Vol. 1: Marsupials, xenarthrans, shrews, and bats. Chicago: University of Chicago Press.

Gardner, A.L., and G.K. Creighton. 1989. A new generic name for Tate's (1933) microtarsus group of South American mouse opossums (Marsupialia: Didelphidae). Proceedings of the Biological Society of Washington 102: 3-7.

Gardner, A.L., and G.K. Creighton. 2008 (“2007”). Genus Marmosops Matschie, 1916. In A.L. Gardner (editor), Mammals of South America, vol. 1: marsupials, xenarthrans, shrews, and bats: 61-74. Chicago: University of Chicago Press.

Goldman, E.A. 1912. New mammals from eastern Panama. Smithsonian Miscellaneous Collections 60: $1-18$.

Goldman, E.A. 1920. Mammals of Panama. Smithsonian Miscellaneous Collections 69 (5): 1-309, folding map.

Goodwin, G.G., and A.M. Greenhall. 1961. A review of the bats of Trinidad and Tobago. Bulletin of the American Museum of Natural History 122 (3): 187 $302+40$ pls

Gregory, W.K. 1910. The orders of mammals. Bulletin of the American Museum of Natural History 27: $1-524$.

Gutiérrez-Pinto, N., A.M. Cuervo, J. Miranda, J.L. Pérez-Emán, R.T. Brumfield, and C.D. Cadena. 2012. Non-monophyly and deep genetic differentiation across low-elevation barriers in a Neotropical montane bird (Basileuterus tristriatus; Aves: Parulidae). Molecular Phylogenetics and Evolution 64: 156-165.

Handley, C.O., Jr. 1966. Checklist of the mammals of Panama. In R.L. Wenzel and V.J. Tipton (editors), Ectoparasites of Panama: 753-795. Chicago: Field Museum of Natural History.

Handley, C.O., Jr. 1976. Mammals of the Smithsonian Venezuelan project. Brigham Young University Science Bulletin (Biological Series) 20 (5): [i-iv], 1-91.

Handley, C.O., Jr., and L.K Gordon. 1979. New species of mammals from northern South America: mouse opossums, genus Marmosa Gray. In J.F. Eisenberg (editor), Vertebrate ecology in the northern Neotropics: 65-72. Washington, DC: Smithsonian Institution Press.

Hershkovitz, P. 1977. Living New World monkeys (Platyrrhini), with an introduction to Primates, vol. 1. Chicago: University of Chicago Press.

Hershkovitz, P. 1997. Composition of the family Didelphidae Gray, 1821 (Didelphoidea: Marsupialia), with a review of the morphology and behavior of the included four-eyed pouched opossums of the genus Philander Tiedemann, 1808. Fieldiana Zoology (new ser.) 86: 1-103.

Hice, C.L., and P.M. Velazco. 2012. The non-volant mammals of the Reserva Nacional Allpahuayo-Mishana, Loreto, Peru. Special Publications of the Museum of Texas Tech University 60: [i, ii], 1-135.

Hurtado, N., E. Arias, and V. Pacheco. 2014. Redescription of Mimon koepckeae (Chiroptera: Phyllostomidae). Zoología 31: 377-388. 
Instituto Geográfico Agustín Codazzi. 2015. Cartografía básica. Internet resource (http://www.igac. gov.co/geoportal), accessed November, 2015.

Kirsch, J.A.W., and R.E. Palma. 1995. DNA/DNA hybridization studies of carnivorous marsupials. V. A further estimate of relationships among opossums (Marsupialia: Didelphidae). Mammalia 59: 403-425.

Kirsch, J.A.W., F.-J. Lapointe, and M.S. Springer. 1997. DNA-hybridization studies of marsupials and their implications for metatherian classification. Australian Journal of Zoology 45: 211-280.

Leiner, N.O., and W.R. Silva. 2007. Seasonal variation in the diet of the Brazilian slender opossum (Marmosops paulensis) in a montane Atlantic Forest area, southeastern Brazil. Journal of Mammalogy 88: 158-164.

Leiner, N.O., E.Z.F. Setz, and W.R. Silva. 2008. Semelparity and factors affecting the reproductive activity of the Brazilian slender opossumm (Marmosops paulensis) in southeastern Brazil. Journal of Mammalogy 89: 153-158.

Lessa, L.G., and F.N. da Costa. 2010. Diet and seed dispersal by five marsupials (Didelphimorphia: Didelphidae) in a Brazilian cerrado reserve. Mammalian Biology 75: 10-16.

Linares, O.J. 1998. Mamíferos de Venezuela. Caracas: Sociedad Conservacionista Audubon de Venezuela.

Lim, B.K. 2012. Preliminary assessment of Neotropical mammal DNA barcodes: an underestimation of biodiversity. Open Zoology Journal 5 (suppl. 1-M3): 10-17.

Lim, B.K., M.D. Engstrom, J.C. Patton, and J.W. Bickham. 2008. Systematic review of small fruit-eating bats (Artibeus) from the Guianas, and a re-evaluation of A. glaucus bogotensis. Acta Chiropterologica 10: 243-256.

Lim, B.K., M.D. Engstrom, J.C. Patton, and J.W. Bickham. 2010. Molecular phylogenetics of Reig's shorttailed opossum (Monodelphis reigi) and its distributional range expansion into Guyana. Mammalian Biology 75: 287-293.

Loretto, D., and M.V. Vieira. 2008. Use of space by the marsupial Marmosops incanus (Didelphimorphia, Didelphidae) in the Atlantic Forest, Brazil. Mammalian Biology 73: 255-261.

Lorini, M.L., J.A. de Oliveira, and V.G. Persson. 1994. Annual age structure and reproductive patterns in Marmosa incana (Lund, 1840) (Didelphidae, Marsupialia). Zeitschrift für Säugetierkunde 59: 65-73.

Lund, P.W. 1840. [Preprint of] Blik paa Brasiliens Dyreverden för sidste Jordomvaeltning. Tredie
Afhandling: Fortsaettelse af Pattedyrene. Kongelige Danske Videnskabernes Selskabs Naturvidenskabelige og Matematiske Afhandlinger 8: 219-272 + pls. xiv-xxiv. [Preprint 56 pp., repaginated; not seen. Journal issue paginated as above published 1841]

Lunde, D.P., and W.A. Schutt, Jr. 1999. The peculiar carpal tubercles of male Marmosops parvidens and Marmosa robinsoni (Didelphidae: Didelphinae). Mammalia 63: 495-504.

Malcolm, J.R. 1991. Comparative abundances of Neotropical small mammals by trap height. Journal of Mammalogy 72: 188-192.

Mangan, S.A., and G.H. Adler. 2000. Consumption of arbuscular mycorrhizal fungi by terrestrial and arboreal small mammals in a Panamanian cloud forest. Journal of Mammalogy 81: 563-570.

Matschie, P. 1916. Bemerkungen über die Gattung Didelphis L. Sitzungsberichte der Gesellschaft Naturforschender Freunde, Berlin 1916: 259-272.

McDiarmid, R.W., and M.A. Donnelly. 2005. The herpetofauna of the Guayana Highlands: amphibians and reptiles of the lost world. In M.A. Donnelly, B.I. Crother, C. Guyer, M.H. Wake, and M.E. White (editors), Ecology and evolution in the tropics: a herpetological perspective: 461-560. Chicago: University of Chicago Press.

Moreno, P., and L.Albuja-V. 2005. Nuevos registros de Akodon orophilus (Rodentia: Muridae) en el Ecuador. Revista Politécnica (Serie Biología 6) 26: 28-44.

Mustrangi, M.A., and J.L. Patton. 1997. Phylogeography and systematics of the slender mouse opossum Marmosops (Marsupialia, Didelphidae). University of California Publications in Zoology 130: i-x, 1-86.

Myers, C.W. 1969. The ecological geography of cloud forest in Panama. American Museum Novitates 2396: 1-52.

Nascimento, D.C., A.P.M. Olímpo, E. Conceição, B.A.T.P. Campos, E.C. Fraga, and M.C. Barros. 2015. Phylogeny of Marmosops and the occurrence of Marmosops pinheiroi (Pine, 1981) (Didelphimorphia, Didelphidae) in the Cerrado savanna of Maranhão, Brazil. Genetics and Molecular Research 14: 304-313.

O'Connell, M.A. 1979. Ecology of didelphid marsupials from northern Venezuela. In J.F. Eisenberg (editor), Vertebrate ecology in the northern Neotropics: 73-87. Washington, DC: The Smithsonian Institution Press.

Otálora-Ardila, A. 2003. Mamíferos de los bosques de roble. Acta Biológica Colombiana 8: 57-71. 
Passamani, M. 1995. Vertical stratification of small mammals in Atlantic Hill Forest. Mammalia 59: $276-279$

Patterson, B.D., D.F. Stotz, and S. Solari. 2006. Biological surveys and inventories in Manu. Fieldiana Zoology (new series) 110: 3-12.

Patton, J.L., M.N.F. da Silva, and J.R. Malcolm. 2000. Mammals of the Rio Juruá and the evolutionary and ecological diversification of Amazonia. Bulletin of the American Museum of Natural History 244: $1-306$.

Pavan, S.E. 2015. A new species of Monodelphis (Didelphimorphia: Didelphidae) from the Brazilian Atlantic Forest. American Museum Novitates 3832: 1-15.

Pavan, S.E., S.A. Jansa, and R.S. Voss. 2014. Molecular phylogeny of short-tailed opossums (Didelphidae: Monodelphis): taxonomic implications and tests of evolutionary hypotheses. Molecular Phylogenetics and Evolution 79: 199-214.

Paynter, R.A., Jr. 1982. Ornithological gazetteer of Venezuela. Cambridge, MA: Museum of Comparative Zoology (Harvard University).

Paynter, R.A., Jr. 1997. Ornithological gazetteer of Colombia, 2nd ed. Cambridge, MA: Museum of Comparative Zoology (Harvard University).

Paynter, R.A., Jr., and M.L. Traylor, Jr. 1991. Ornithological gazetteer of Brazil [2 vols.]. Cambridge, MA: Museum of Comparative Zoology (Harvard University).

Peralta, M.C., and V. Pacheco. 2014. Rediscovery of Marmosops juninensis Tate, 1931 (Didelphimorphia: Didelphidae) in the Yungas of Peru. Check List 10: 436-440.

Pérez-Hernández, R. 1989. Distribution of the family Didelphidae (Mammalia-Marsupialia) in Venezuela. In K.H. Redford, and J.F. Eisenberg (editors), Advances in Neotropical mammalogy: 363-410. Gainesville: Sandhill Crane Press.

Pérez-Hernández, R., P. Soriano, and D. Lew. 1994. Marsupiales de Venezuela. Caracas: Cuadernos Lagoven.

Pine, R.H. 1981. Reviews of the mouse opossums Marmosa parvidens Tate and Marmosa invicta Goldman (Mammalia: Marsupialia: Didelphidae) with description of a new species. Mammalia 45: 55-70.

Ratter, J.A., P.W. Richards, G. Argent, and D.R. Gifford. 1973. Observations on the woody vegetation of northeastern Mato Grosso. I. The woody vegetation types of the Xavantina-Cachimbo Expedition area. Proceedings of the Royal Society of London B 266: 449-492.
Reig, O.A., J.A.W. Kirsch, and L.G. Marshall. 1985. New conclusions on the relationships of the opossumlike marsupials, with an annotated classification of the Didelphimorphia. Ameghiniana 21: 335-343.

Ribeiro-Júnior, M.A., R.V. Rossi, C.L. Miranda, and T.C.S. Ávila-Pires. 2011. Influence of pitfall trap size and design on herpetofauna and small mammal studies in a Neotropical Forest. Zoologia 28: 80-91.

Ridgway, R. 1912. Color standards and color nomenclature. Washington, DC: Published by the author.

Rossi, R.V., R.S. Voss, and D.P. Lunde. 2010. A revision of the didelphid marsupial genus Marmosa. Part 1. The species in Tate's "Mexicana" and "Mitis" sections and other closely related forms. Bulletin of the American Museum of Natural History 334: 1-83.

Ruelas, D., and V. Pacheco. 2015. Taxonomía y distribución de Vampyriscus brocki (Peterson 1968; Phyllostomidae: Chiroptera) en Perú y primer registro para Ucayali. Therya 6: 625-642.

Sánchez-Giraldo, C., and J.F. Díaz-Nieto. 2015. Dynamics of species composition of small non-volant mammals from the northern Cordillera Central of Colombia. Mammalis 79: 385-397.

Silva, C.R. da, et al. [10 authors]. 2013. Mammals of Amapá state, eastern Brazilian Amazonia: a revised taxonomic list with comments on species distributions. Mammalia 77: 409-424.

Simmons, N.B., and R.S. Voss. 1998. The mammals of Paracou, French Guiana: a Neotropical lowland rainforest fauna. Part 1. Bats. Bulletin of the American Museum of Natural History 237: 1-219.

Stephens, L., and M.L. Traylor, Jr. 1983. Ornithological gazetteer of Peru. Cambridge, MA: Museum of Comparative Zoology (Harvard University).

Stephens, L., and M.L. Traylor, Jr. 1985. Ornithological gazetteer of the Guianas. Cambridge, MA: Museum of Comparative Zoology (Harvard University).

Tate, G.H.H. 1931. Brief diagnoses of 26 apparently new forms of Marmosa (Marsupialia) from South America. American Museum Novitates 493: 1-14.

Tate, G.H.H. 1933. A systematic revision of the marsupial genus Marmosa with a discussion of the adaptive radiation of the murine opossums (Marmosa). Bulletin of the American Museum of Natural History 66: 1-250 + 26 pls.

Thomas, O. 1896. On new small mammals from the Neotropical region. Annals and Magazine of Natural History (ser. 6) 18: 301-314.

Thomas, O. 1900. Descriptions of new Neotropical mammals. Annals and Magazine of Natural History (ser. 7) 5: 217-222. 
Thomas, O. 1924. New South American mammals. Annals and Magazine of Natural History (ser. 9) 13: 234-237.

Tirira, D. 2012. Presencia confirmada de Lonchophylla cadenai Woodman y Timm, 2006 (Chiroptera, Phyllostomidae) para el noroccidente de Ecuador. In D.G. Tirira and S.F. Burneo (editors), Investigación y conservación sobre murciélagos en el Ecuador (Fundación Mamíferos y Conservación y Asociación Ecuatoriana de Mastozoología Publicación Especial sobre los Mamíferos del Ecuador 9): 185194. Quito: Pontificia Universidad Católica del Ecuador.

Trouessart, E.-L. 1898. Catalogus mammalium tam viventium quam fossilium. Fasiculus V. Sirenia, Cetacea, Edentata, Marsupialia, Allotheria, Monotremata. Berolini: R. Friedländer \& Sohn.

Trouessart, E.-L. 1905. Catalogus mammalium tam viventium quam fossilium. Quinquennale supplementium (1899-1904). Cetacea, Edentata, Marsupialia, Allotheria, Monotremata. Berolini: R. Friedländer \& Sohn.

Umetsu, F., L. Naxara, and R. Pardini. 2006. Evaluating the efficiency of pitfall traps for sampling small mammals in the Neotropics. Journal of Mammalogy 87: 757-765.

USBGN. 1955. [Gazetteer prepared by U.S. Board on Geographic Names] British West Indies and Bermuda. Washington, DC: U.S. Government Printing Office.

Valqui, M. 2001. Mammal diversity and ecology of terrestrial small rodents in western Amazonia [Ph.D. dissertation, Department of Wildlife Ecology and Conservation, University of Florida, Gainesville]. Ann Arbor: UMI Dissertation Services.

Velazco, P.M., and N.B. Simmons. 2011. Systematics and taxonomy of great striped-faced bats of the genus Vampyrodes Thomas, 1900 (Chiroptera: Phyllostomidae). American Museum Novitates 3710: $1-35$.

Vieira, E.M., and E.L.A. Monteiro-Filho. 2003. Vertical stratification of small mammals in the Atlantic rainforest of south-eastern Brazil. Journal of Tropical Ecology 19: 501-507.

Voss, R.S. 1991. An introduction to the Neotropical muroid rodent genus Zygodontomys. Bulletin of the American Museum of Natural History 210: 1-113.

Voss, R.S., and L.H. Emmons. 1996. Mammalian diversity in Neotropical lowland rainforests: a preliminary assessment. Bulletin of the American Museum of Natural History 230: 1-115.
Voss, R.S., and S.A. Jansa. 2003. Phylogenetic studies on didelphid marsupials II. Nonmolecular data and new IRBP sequences: separate and combined analyses of didelphine relationships with denser taxon sampling. Bulletin of the American Museum of Natural History 276: 1-82.

Voss, R.S., and S.A. Jansa. 2009. Phylogenetic relationships and classification of didelphid marsupials, an extant radiation of New World metatherian mammals. Bulletin of the American Museum of Natural History 322: 1-177.

Voss, R.S., and D.W. Fleck. 2011. Mammalian diversity and Matses ethnomammalogy in Amazonian Peru. Part 1: Primates. Bulletin of the American Museum of Natural History 351: 1-81.

Voss, R.S., D.P. Lunde, and N.B. Simmons. 2001. The mammals of Paracou, French Guiana: a Neotropical rainforest fauna. Part 2. Nonvolant species. Bulletin of the American Museum of Natural History 263: $1-236$.

Voss, R.S., T. Tarifa, and E. Yensen. 2004. An introduction to Marmosops (Marsupialia: Didelphidae), with the description of a new species from Bolivia and notes on the taxonomy and distribution of other Bolivian forms. American Museum Novitates 3466: $1-40$.

Voss, R.S., B.K. Lim, J.F. Díaz-Nieto, and S.A. Jansa. 2013. A new species of Marmosops (Marsupialia: Didelphidae) from the Pakaraima Highlands of Guyana, with remarks on the origin of the endemic Pantepui mammal fauna. American Museum Novitates 3778: 1-27.

Voss, R.S., E.E. Gutiérrez, S. Solari, R.V. Rossi, and S.A. Jansa. 2014. Phylogenetic relationships of mouse opossums (Didelphidae: Marmosa) with a revised subgeneric classification and notes on sympatric diversity. American Museum Novitates 3817: 1-27.

Watsa, M., G.A. Erkenswick, J.A. Rehg, R. Leite Pitman. 2012. Distribution and new sightings of Goeldi's monkey (Callimico goeldii) in Amazonian Peru. International Journal of Primatology 33: 1477-1502.

Wible, J.R. 2003. On the cranial osteology of the shorttailed opossum Monodelphis brevicaudata (Didelphidae, Marsupialia). Annals of the Carnegie Museum 72: 137-202.

Woodman, N., et al. [7 authors]. 1991. Annotated checklist of the mammals of Cuzco Amazonico, Peru. Occasional Papers of the Museum of Natural History University of Kansas 145: 1-12. 


\section{APPENDIX 1}

\section{GAZETTEer}

This gazetteer includes all localities from which we personally examined specimens of Marmosops (Sciophanes) for this report. Numbers correspond to specimen records plotted on maps in the text. Italicized place names are those of the largest political divisions (state, department, province, etc.) within each country. Boldface identifies collection localities as they appear in the text of this report. For each entry we provide geographic coordinates and elevation above sea level (in parentheses if recorded by the collector, otherwise in square brackets), name(s) of the species collected there, name(s) of the collector(s), and date(s) of collection. Units of distance (kilometers [km] or miles [mi]) are those recorded by the collector(s), as are units of elevation (meters $[\mathrm{m}]$ or feet $[\mathrm{ft}]$ above sea level).

\section{BOLIVIA}

1. Beni, 1 km E La Emboscada [= La Embocada at $15^{\circ} 03^{\prime} \mathrm{S}, 66^{\circ} 58^{\prime} \mathrm{W}, 600 \mathrm{~m}$; Anderson, 1997], Estancia La Cabaña: Marmosops bishopi (G.K. Creighton, 13 November 1979).

2. Cochabamba, Serranía Mosetenes $\left(16^{\circ} 14^{\prime} \mathrm{S}\right.$, $66^{\circ} 25^{\prime} \mathrm{W}, 1300 \mathrm{~m}$ ): Marmosops bishopi (E. Yensen, 3 September 2003).

3. La Paz, Iturraldi, Alto Río Madidi $\left[13^{\circ} 35^{\prime} \mathrm{S}, 68^{\circ} 46^{\prime} \mathrm{W}\right.$, 270 m; Anderson, 1997]: Marmosops bishopi (L.H. Emmons, 27 May 1990).

4. La Paz, La Reserva $\left(15^{\circ} 44^{\prime} \mathrm{S}, 67^{\circ} 31^{\prime} \mathrm{W}, 840 \mathrm{~m}\right)$ : Marmosops bishopi (T. Tiurina, 22 July 1992).

5. Santa Cruz, El Refugio $\left(14^{\circ} 46^{\prime} \mathrm{S}, 61^{\circ} 02^{\prime} \mathrm{W}\right.$, ca. 200 $\mathrm{m}$ ): Marmosops bishopi (L.H. Emmons, 6-15 November 1998).

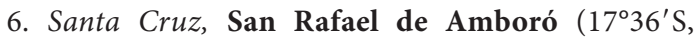
633' W, 400 m): Marmosops bishopi (B.R. Riddle, 31 July 1985).

\section{BRAZIL}

7. Amapá, Serra do Navio (including sublocalities "Rio Amapari” and "Km 190 EFA") [ca. 059'N, 5203'W, 100 m; Paynter and Traylor, 1991]: Marmosops pinheiroi (F. de P. Pinheiro, 16 September 1969-8 May 1970).

8. Amazonas, Barro Vermelho, left bank Rio Juruá ( $\left.6^{\circ} 28^{\prime} \mathrm{S}, 68^{\circ} 46^{\prime} \mathrm{W}\right)$ : Marmosops bishopi (J.L. Patton, 25 October 1991).

9. Amazonas, Faro, Boca Rio Paratucu [= Rio Piratucu, mouth at $1^{\circ} 59^{\prime} \mathrm{N}, 56^{\circ} 58^{\prime} \mathrm{W}$; Paynter and Traylor,
1991]: Marmosops parvidens (A.M. Olalla, 21 December 1930).

10. Amazonas, MCSE Reserves, $80 \mathbf{~ k m ~} \mathbf{N}$ Manaus $\left(2^{\circ} 25^{\prime} \mathrm{S}, 59^{\circ} 50^{\prime} \mathrm{W}\right)$ : Marmosops parvidens (J.R. Malcolm, 7 October 1983-4 September 1985).

11. Amazonas, Vai-Quem-Quer, right bank Rio Juruá [3 $3^{\circ} 19^{\prime} \mathrm{S}, 66^{\circ} 01^{\prime} \mathrm{W}$; Patton et al., 2000]: Marmosops bishopi (J.R. Malcolm, 14 May 1992).

12. Mato Grosso, 264 km N (by road) Xavantina, Serra do Roncador $\left[12^{\circ} 51^{\prime} \mathrm{S}, 51^{\circ} 46^{\prime} \mathrm{W}, 1750 \mathrm{ft}\right.$; Pine, 1981]: Marmosops bishopi (R.H. Pine, 5 July 1968).

13. Pará, 52 km SSW Altamira $\left(3^{\circ} 39^{\prime} \mathrm{S}, 52^{\circ} 22^{\prime} \mathrm{W}\right)$, east bank Rio Xingu: Marmosops pinheiroi (M.D. Carleton, 15 September 1986).

14. Pará, Belém [ $1^{\circ} 27^{\prime}$ S, $48^{\circ} 29^{\prime} \mathrm{W}$; Paynter and Traylor, 1991]: Marmosops pinheiroi (collector unknown, 25 May 1970).

15. Pará, Rio Tocantins, Ilha do Taiuna [ca. $2^{\circ} 15^{\prime} \mathrm{S}$, 49³0'W]: Marmosa parvidens (A.M. Olalla, 2 November 1931).

16. Pará, Utinga [near Belém, ca. $1^{\circ} 27^{\prime} \mathrm{S}, 48^{\circ} 29^{\prime} \mathrm{W}$ (see above); including sublocalities "Agua Preta," "Nova Area Experimental," and "Trapping Area 1"]: Marmosops pinheiroi (R.H. Pine, 10-14 June 1968; A.P. Souza, 18 February-25 June 1965 and 3 August 1967).

\section{COLOMBIA}

17. Amazonas, Leticia, Vereda Peña Roja $\left[0^{\circ} 41^{\prime} \mathrm{S}\right.$, $72^{\circ} 08^{\prime}$ W, 300m; Díaz-N., 2012]: Marmosops bishopi (P. Rivas P., 31 March 2004).

18. Antioquia, Gómez Plata, Hacienda Vegas de la Clara $\left(6^{\circ} 35^{\prime} 22^{\prime \prime} \mathrm{N}, 75^{\circ} 11^{\prime} 49^{\prime \prime} \mathrm{W}, 1120 \mathrm{~m}\right)$ : Marmos ops chucha (C.A. Calderón-Acevedo, 16 July 2014).

19. Antioquia, Municipio Amalfi, Porce Tres $\left[6^{\circ} 56^{\prime} \mathrm{N}\right.$, $75^{\circ} 08^{\prime} \mathrm{W}, 660 \mathrm{~m}$; Google Earth at the crest of the wall of the dam]: Marmosops chucha (M. Bernal, 6 September 2004).

20. Antioquia, Municipio Amalfi, Vereda Guayabito, Finca Costa Rica, Bosque Caracolí $\left(6^{\circ} 52^{\prime} \mathrm{N}\right.$, $75^{\circ} 06^{\prime} \mathrm{W}, 1840 \mathrm{~m}$ ): Marmosops handleyi (C. Sánchez-Giraldo, J.F. Díaz-Nieto, D. Marín-C., November 2004-February 2008).

21. Antioquia, Municipio Yarumal, Corregimiento El Cedro, Vereda Corcovado, Finca El Bosque, Bosque San Andrés $\left(7^{\circ} 04^{\prime} \mathrm{N}, 75^{\circ} 25^{\prime} \mathrm{W}, 1760 \mathrm{~m}\right)$ : Marmosops handleyi (C. Sánchez-Giraldo, J.F. Díaz-Nieto, 1-2 October 2005).

22. Antioquia, Municipio Yarumal, Corregimiento El Cedro, Vereda El Rosario, sitio Alto de Ventanas, Finca Villa Nueva $\left(7^{\circ} 05^{\prime} \mathrm{N}, 75^{\circ} 27^{\prime} \mathrm{W}, 1950 \mathrm{~m}\right)$ : 
Marmosops handleyi (C. Sánchez-Giraldo, J.F. DíazNieto, 9-11 January 2006).

23. Antioquia, Urabá, Villa Arteaga ([ $7^{\circ} 20^{\prime} \mathrm{N}, 76^{\circ} 26^{\prime} \mathrm{W}$; Hershkovitz, 1977], $130 \mathrm{~m}$ ): Marmosops chucha (P. Hershkovitz, 28 January 1950).

24. Antioquia, Valdivia, 9 km S Valdivia $\left(\left[7^{\circ} 06^{\prime} \mathrm{N}\right.\right.$, 752' W; Anderson, 1999], $1400 \mathrm{~m}$ ): Marmosops handleyi (P. Hershkovitz, 16-18 June 1950), M. chucha (P. Hershkovitz, 17 June 1950).

25. Antioquia, Valdivia, La Cabaña [ca. $7^{\circ} 10^{\prime} \mathrm{N}$, $75^{\circ} 25^{\prime} \mathrm{W}$; based on P. Hershkovitz field notes]: Marmosops chucha (P. Hershkovitz, 22 June 1950).

26. Antioquia, Valdivia, Quebrada Valdivia $\left(\left[7^{\circ} 10^{\prime} \mathrm{N}\right.\right.$, 75²6'W; Anderson, 1999], 900 m): Marmosops chucha (P. Hershkovitz, 30 June 1950).

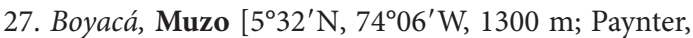
1997]: Marmosops magdalenae (P. Hershkovitz, 15 August 1952).

28. Caldas, Norcasia, Vereda Montebello, entre las fincas El Horizonte y La Albania, quebrada La Albania $\left(5^{\circ} 34^{\prime} 48^{\prime \prime} \mathrm{N}, 74^{\circ} 55^{\prime} 46^{\prime \prime} \mathrm{W}, 817 \mathrm{~m}\right)$ : Marmosops chucha (J.H. Castaño, 6 April 2014).

29. Caldas, Norcasia, Vereda San Roque, Reserva Natural Río Manso $\left(05^{\circ} 40^{\prime} 08^{\prime \prime} \mathrm{N}, 74^{\circ} 47^{\prime} 17^{\prime \prime} \mathrm{W}, 200 \mathrm{~m}\right)$ : Marmosops chucha (J.H. Castaño, 26 November 2009).

30. Caldas, Samaná, Corregimiento San Diego, Vereda La Sonrisa $\left[5^{\circ} 37^{\prime} \mathrm{N}, 74^{\circ} 57^{\prime} \mathrm{W}, 900 \mathrm{~m}\right.$; Google Earth at "Vereda La Sonrisa"], Finca La Sonrisa: Marmosops chucha (D.C. Villanueva-C., 1 April 2014).

31. Caldas, Samaná, Río Honda $\left(\left[5^{\circ} 42^{\prime} \mathrm{N}, 75^{\circ} 01^{\prime} \mathrm{W}\right.\right.$; Hershkovitz, 1997], 1200 m): Marmosops chucha (P. Hershkovitz, 26 February 1951).

32. Huila, Acevedo, Río Aguas Claras, near San Adolfo ([ca. $1^{\circ} 37^{\prime} \mathrm{N}, 75^{\circ} 59^{\prime} \mathrm{W}$; Paynter, 1997], 1400-1700 $\mathrm{m})$ : Marmosops magdalenae. (P. Hershkovitz, 21-28 June 1951).

33. Santander, Encino, Vereda Rionegro, Reserva Biológica Cachalú, Bosque de Roble Cerca de Torre $\left(6^{\circ} 6^{\prime} 50^{\prime \prime} \mathrm{N}, 73^{\circ} 8^{\prime} 10^{\prime \prime} \mathrm{W}, 1940 \mathrm{~m}\right)$ : Marmosops magdalenae (M.E. Rodríguez-Posada, 18 July 2002).

34. Santander, Puerto Parra, Vereda India Baja, Corregimiento Campo Capote $\left[6^{\circ} 40^{\prime} \mathrm{N}, 73^{\circ} 53^{\prime} \mathrm{W}\right.$, ca. 104 m; Instituto Geográfico Agustín Codazzi, 2015]: Marmosops magdalenae (Y. Muñoz-Saba, 11 March 2012).

\section{ECUADOR}

35. Morona Santiago, Parroquia Macuma, Wisui [ $2^{\circ} 07^{\prime} \mathrm{N}, 77^{\circ} 44^{\prime} \mathrm{W}, 650 \mathrm{~m}$; Arguero et al., 2012]: Marmosops bishopi (A. Arguero, and F. Sánchez, 21 July 2013).
36. Napo, Huamaní $\left[0^{\circ} 43^{\prime} \mathrm{S}, 77^{\circ} 37^{\prime} \mathrm{W}, 1250 \mathrm{~m}\right.$; Gardner, 2008]: Marmosops bishopi (R. Mena, 27 August 1992).

37. Napo, parroquia Cotundo, Río Hollín [ $\left[0^{\circ} 41^{\prime} \mathrm{S}\right.$, $77^{\circ} 44^{\prime} \mathrm{W}, 1105 \mathrm{~m}$; Moreno and Albuja, 2005]: Marmosops bishopi (R. Mena, 23 February 1993).

38. Orellana, Aguarico, Campamento Chiruisla, Área de Amortiguamiento del Parque Nacional Yasuní $\left(0^{\circ} 37^{\prime} \mathrm{S}, 75^{\circ} 53^{\prime} \mathrm{W}\right)$ : Marmosops bishopi (A. Molina, G. Toscano, A. Camacho, 10 November 2009).

39. Orellana, Aguarico, Parque Nacional Yasuní, Río Tiputini, Comunidad Guiyero, Bosque de Nambay [0³6'35" S, 76 27'52" W, $237 \mathrm{~m}$; Albuja and Arguero, 2011]: Marmosops bishopi (L. Albuja, and A. Arguero, 19 May 2012). This locality was originally reported in the UTM coordinate system by Albuja and Arguero (2011: 30).

40. Orellana, Parque Nacional Yasuní, Estación Científica Yasuní $\left(0^{\circ} 40^{\prime} 38^{\prime \prime} \mathrm{S}, 76^{\circ} 24^{\prime} 05^{\prime \prime} \mathrm{W}\right)$ : Marmosops bishopi (A. Pérez, 4 May 2011).

41. Pastaza, Arajuno, área operación AGIP, Bloque 10 Comunidad de Paparahua. Cercanías Río Villano ( $\left.1^{\circ} 29^{\prime} \mathrm{S}, 77^{\circ} 25^{\prime} \mathrm{W}\right)$ : Marmosops bishopi (C. Boada, 26 June 2012).

42. Pastaza, Arajuno, Curaray, área operación AGIP, Bloque 10, cercanías Río Lliquino (including "Helipuerto K4" at $1^{\circ} 28^{\prime} \mathrm{S}, 77^{\circ} 29^{\prime} \mathrm{W}$; and "Helipuerto $\mathrm{K} 10^{\prime}$ at $1^{\circ} 28^{\prime}, 77^{\circ} 31^{\prime} \mathrm{W}$ ): Marmosops bishopi (C. Boada, 2-18 February 2012 and 11 October 2012).

43. Pastaza, Arajuno, Curaray, área operación AGIP, Bloque 10. Comunidad de Tarangaro, Cercanías Río Manderocayu ( $\left.1^{\circ} 24^{\prime} 02^{\prime \prime} \mathrm{S}, 77^{\circ} 22^{\prime} 59^{\prime \prime} \mathrm{W}\right)$ : Marmosops bishopi (C. Boada, 22-24 August 2012, and 5 November 2012).

44. Sucumbíos, Cantón Shushufindi, Parroquia Pañacocha, Río Pañayaku $\left[0^{\circ} 21^{\prime} \mathrm{S}, 76^{\circ} 25^{\prime} \mathrm{W}, 230 \mathrm{~m}\right.$; Tirira, 2012]: Marmosops bishopi (collector not recorded, 28 February 2014).

45. Sucumbíos, El Reventador $\left[0^{\circ} 02^{\prime} \mathrm{S}, 77^{\circ} 31^{\prime} \mathrm{W}\right.$, Google Earth at "El Reventador"]: Marmosops bishopi (collector and date not recorded).

\section{FRENCH GUIANA (FRANCE)}

46. Les Nouragues $\left[4^{\circ} 05^{\prime} \mathrm{N}, 52^{\circ} 40^{\prime} \mathrm{W}, 210 \mathrm{~m}\right.$; Voss and Emmons, 1996]: Marmosops parvidens (F. Catzeflis, 3 August 2002) and M. pinheiroi (J.-F. Mauffrey, 15 May 1999).

47. Paracou $\left[5^{\circ} 17^{\prime} \mathrm{N}, 52^{\circ} 55^{\prime} \mathrm{W}\right.$, ca. $45 \mathrm{~m}$; Simmons and Voss, 1998], near Sinnamary: Marmosops parvidens and M. pinheiroi (L.H. Emmons, R.W. Kays, D.P. Lunde, and R.S. Voss, 1991-1994). 
48. River Arataye $\left(4^{\circ} 00^{\prime} \mathrm{N}, 52^{\circ} 40^{\prime} \mathrm{W}, 30 \mathrm{~m}\right)$ : Marmosops parvidens (L.H. Emmons, 2 October 1984).

\section{GUYANA}

49. Cuyuni-Mazaruni, Mount Roraima (including "Second Camp" at $5^{\circ} 17^{\prime} \mathrm{N}, 60^{\circ} 45^{\prime} \mathrm{W}, 800 \mathrm{~m}$; and "Third Camp" at $\left.5^{\circ} 16^{\prime} \mathrm{N}, 60^{\circ} 44^{\prime} \mathrm{W}, 1000 \mathrm{~m}\right):$ Marmosops pakaraimae (B.K. Lim and D.M. Jafferally, 26 February-8 March 2003).

50. Demerara-Mahaica, Hyde Park, $30 \mathrm{mi}$ [up the] Demerara R[iver] [ $6^{\circ} 30^{\prime} \mathrm{N}, 58^{\circ} 16^{\prime} \mathrm{W}$, ca. $100 \mathrm{~m}$; Stephens and Traylor, 1985]: Marmosops parvidens (S.B. Warren, 8 September 1906).

51. Potaro-Siparuni, Iwokrama Forest, Canopy Walkway $\left(4^{\circ} 15^{\prime} \mathrm{N}, 58^{\circ} 55^{\prime} \mathrm{W}, 70 \mathrm{~m}\right)$ : Marmosops pinheiroi (B.K. Lim et al., 19 August 2008).

52. Potaro-Siparuni, Iwokrama Forest, Kabukalli Landing $\left(4^{\circ} 17^{\prime} \mathrm{N}, 58^{\circ} 31^{\prime} \mathrm{W}\right)$ : Marmosops pinheiroi (B.K. Lim et al., 13-18 October 1999).

53. Potaro-Siparuni, Iwokrama Forest, Turtle Mountain, 10 km NW Kurupukari $\left(4^{\circ} 44^{\prime} \mathrm{N}, 58^{\circ} 43^{\prime} \mathrm{W}, 50 \mathrm{~m}\right)$ : Marmosops pinheiroi (B.K. Lim et al., 31 October 1997).

54. Potaro-Siparuni, Mount Ayanganna, First Plateau Camp $\left(5^{\circ} 20^{\prime} \mathrm{N}, 59^{\circ} 57^{\prime} \mathrm{W}, 1100 \mathrm{~m}\right.$; Lim et al., 2010): Marmosops pakaraimae (B.K. Lim, 27 October 2002).

55. Potaro-Siparuni, Mount Wokomung, First Plateau Camp $\left(5^{\circ} 07^{\prime} \mathrm{N}, 59^{\circ} 49^{\prime} \mathrm{W}, 1130 \mathrm{~m}\right)$ : Marmosops pakaraimae (B.K. Lim and W.P. Kilburn, 19-20 February 2003).

56. Upper Takutu-Upper Essequibo, Karanambo [3 $3^{\circ} 45^{\prime} \mathrm{N}, 59^{\circ} 18^{\prime} \mathrm{W}$; Lim et al., 2008]: Marmosops parvidens (M.D. Engstrom et al., 1 October 1990).

\section{PANAMA}

57. Darién, Cana (= Santa Cruz de Cana $\left[7^{\circ} 47^{\prime} \mathrm{N}\right.$, $77^{\circ} 42^{\prime} \mathrm{W}$; Fairchild and Handley, 1966], $2000 \mathrm{ft}$ ): Marmosops invictus (E.A. Goldman, 14-20 March 1912).

58. Darién, Cerro Tacarcuna $\left(\left[8^{\circ} 10^{\prime} \mathrm{N}, 77^{\circ} 18^{\prime} \mathrm{W}\right.\right.$; Fairchild and Handley, 1966], $4800 \mathrm{ft}$ ): Marmosops invictus (C.O. Handley, Jr., 5-11 March 1964).

59. Darién, Tacarcuna Casita Camp $\left(\left[8^{\circ} 01^{\prime} \mathrm{N}\right.\right.$, $77^{\circ} 22^{\prime} \mathrm{W}$; Fairchild and Handley, 1966], $2700 \mathrm{ft}$ ): Marmosops invictus (C.O. Handley, Jr., 21 January 1959).

60. Darién, Tacarcuna Laguna Camp $\left(\left[8^{\circ} 04^{\prime} \mathrm{N}\right.\right.$, $77^{\circ} 19^{\prime} \mathrm{W}$; Fairchild and Handley, 1966], $4000 \mathrm{ft}$ ): Marmosops invictus (C.O. Handley, Jr., 9-11 March 1959).
61. Panamá, Cerro Azul [ $9^{\circ} 14^{\prime} \mathrm{N}, 79^{\circ} 21^{\prime} \mathrm{W}, 850-3200$ $\mathrm{ft}$; Fairchild and Handley, 1966]: Marmosops invictus (C.O. Handley, Jr., 3 February 1958).

\section{PERU}

62. Amazonas, Condorcanqui, Nieva, Puerto Tunduza [4 ${ }^{\circ} 46^{\prime} 55^{\prime \prime} \mathrm{S}, 77^{\circ} 52^{\prime} 32^{\prime \prime} \mathrm{W}$; Ruelas and Pacheco, 2015]: Marmosops bishopi (L. Luna, 8 November 1997; E. Vivar, 9-16 November 1997).

63. Cusco, Cosñipata, Hacienda Villa Carmen [ca. $12^{\circ} 50^{\prime} \mathrm{S}, 71^{\circ} 15^{\prime} \mathrm{W}, 600 \mathrm{~m}$; Stephens and Traylor, 1983]: Marmosops bishopi (C. Kalinowski, 20 September 1954).

64. Cusco, Distrito Echarate, La Convención, Camisea,

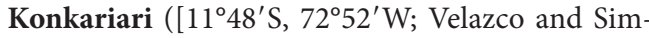
mons, 2011], 450 m): Marmosops bishopi (J.L. Mena, 27 October 1997)

65. Huánuco, Montealegre, Puerto Márquez [= San Márquez at $9^{\circ} 32^{\prime} \mathrm{S}, 74^{\circ} 56^{\prime} \mathrm{W}$, ca. $100 \mathrm{~m}$; Stephens and Traylor, 1983], Río Pachitea: Marmosops bishopi (G. Tessman, 16 November 1923).

66. Junín, 22 mi E Tarma ([ca. $11^{\circ} 25^{\prime} \mathrm{S}, 75^{\circ} 23^{\prime} \mathrm{W}$ ], 7000-7600 ft): Marmosops juninensis (A.L. Tuttle, 21-24 June 1964; E.L. Bush, 19 June 1964).

67. Junín, Provincia Satipo, Distrito Pampa Hermosa, San Antonio, near to Río Pampa Hermosa $\left[11^{\circ} 24^{\prime}\right.$ S, 74 46 ' W, 1387-1406 m; Peralta and Pacheco, 2014]: Marmosops juninensis (M.C. Peralta, 5-8 July 2011).

68. Junín, Utcuyacu $\left(\left[\mathrm{ca} .11^{\circ} 12^{\prime} \mathrm{S}, 75^{\circ} 28^{\prime} \mathrm{W}\right.\right.$; Stephens and Traylor, 1983], $1463 \mathrm{~m}$ ): Marmosops juninensis (H. Watkins, 25 November 1929).

69. Loreto, $25 \mathrm{~km} \mathrm{~S} \mathrm{Iquitos,} \mathrm{Estación} \mathrm{Biológica} \mathrm{Allpa-}$ huayo [ $3^{\circ} 58^{\prime} \mathrm{S}, 73^{\circ} 25^{\prime} \mathrm{W}$; Hice and Velazco, 2012]: Marmosops bishopi (C.L. Hice, 11 October 1997-10 November 1998). This locality is equivalent to the "Reserva Nacional Allpahuayo-Mishana," which is said to be located $28 \mathrm{~km} \mathrm{SW}$ of Iquitos on the Iquitos-Nauta highway (Hice and Velazco, 2012: 3).

70. Loreto, Jenaro Herrera $\left[4^{\circ} 55^{\prime} \mathrm{S}, 73^{\circ} 40^{\prime} \mathrm{W}\right.$; Voss and Fleck, 2011]: Marmosops bishopi (D.P. Lunde, 6 June 2003; J.A. Amanzo, 14-20 March 1997, 13 June-3 July 2003; M. Villalobos, 9 June-27 July 2003).

71. Loreto, Maynas, Alto Nanay, Quebrada Agua Negra

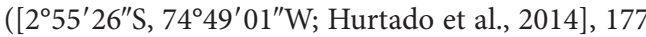
$\mathrm{m}$ ): Marmosops bishopi (L. Huamaní, 25 October 2008).

72. Loreto, Maynas, San Juan Bautista, Trece de Febrero, km 31.5 carretera Iquitos-Nauta, Estación de Campo UNAP ([ $3^{\circ} 59^{\prime} 59^{\prime \prime} \mathrm{S}, 73^{\circ} 26^{\prime} 31^{\prime \prime} \mathrm{W}$; Hurtado et al., 2014], $120 \mathrm{~m}$ ): Marmosops bishopi (W. Sánchez, 22 April 2004). 
73. Loreto, Nuevo San Juan $\left[5^{\circ} 15^{\prime} \mathrm{S}, 73^{\circ} 10^{\prime} \mathrm{W}\right.$; Voss and Fleck, 2011]: Marmosops bishopi (R.S. Voss, 28 May 1998).

74. Loreto, San Jacinto $\left[2^{\circ} 19^{\prime} \mathrm{S}, 75^{\circ} 52^{\prime} \mathrm{W}, 180 \mathrm{~m}\right.$; Duellman and Mendelson, 1995]: Marmosops bishopi (R.M. Timm, 4 July 1993).

75. Loreto, San Juan Bautista, El Triunfo, km 48 (including $\mathrm{km} \mathrm{49)}$ carretera Iquitos-Nauta ([ $4^{\circ} 09^{\prime} 02^{\prime \prime} \mathrm{S}, 73^{\circ} 28^{\prime} 03^{\prime \prime} \mathrm{W}$; Hurtado et al., 2014], 120 $\mathrm{m})$ : Marmosops bishopi (W. Sánchez, 24 February 2004, 01 April 2005).

76. Loreto, San Juan Bautista, La Habana, km 52 carretera Iquitos-Nauta ([4 $4^{\circ} 10^{\prime} 52^{\prime \prime} \mathrm{S} 73^{\circ} 28^{\prime} 52^{\prime \prime} \mathrm{W}$; Hurtado et al., 2014], $120 \mathrm{~m}$ ): Marmosops bishopi (W. Sánchez, 28 June 2004).

77. Loreto, San Juan Bautista, San Lucas, km 44 carretera Iquitos-Nauta, $1 \mathrm{~km} \mathrm{E}$ del camino ([ca. $4^{\circ} 06^{\prime} 15^{\prime \prime} \mathrm{S}, 73^{\circ} 27^{\prime} 48^{\prime \prime} \mathrm{W}$; Hurtado et al., 2014], 120 $\mathrm{m})$ : Marmosops bishopi (W. Sánchez, 4 February 2005). Coordinates here provided (obtained from Hurtado et al., 2014) were taken at "San Lucas km 43 carretera Iquitos-Nauta."

78. Loreto, San Pedro ("hills 0.5 to $1 \mathrm{~km} \mathrm{E}$ and NE of

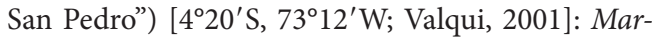
mosops bishopi (M. Valqui, 20 May 1994).

79. Loreto, Teniente López (including " $1 \frac{1 / 2}{2 m ~ N}$ of Teniente López”) [2³6'S, 7607’ W, 200 m; Duellman and Mendelson, 1995]: Marmosops bishopi (N. Woodman, 25 July 1993; R.M. Timm, 26 July 1991).

80. Loreto, Tigre, margen izquierda del río Pucacuro, Collpa Salvador $\left[2^{\circ} 37^{\prime} 55^{\prime \prime} \mathrm{S}, 75^{\circ} 08^{\prime} 39^{\prime \prime} \mathrm{W}\right.$; Watsa et al., 2012]: Marmosops bishopi (L. Arias, 10 July 2001).

81. Loreto, Tigre, Río Pucacuro (including "margen derecha" and "margen izquierda"), Cocha Coconilla [2 $42^{\prime} 17^{\prime \prime} \mathrm{S}, 75^{\circ} 05^{\prime} 50^{\prime \prime} \mathrm{W}$; Watsa et al., 2012]: Marmosops bishopi (L. Arias; 19 July-5 August 2001).

82. Madre de Dios, Albergue Lodge, Cuzco Amazónico [12³3'S, 6903' W, $200 \mathrm{~m}$; Woodman et al., 1991] (including "ca. $12 \mathrm{~km}$ E Puerto Maldonado, Río Madre de Dios"): Marmosops bishopi (J.E. Cadle, 8 March 1984; V. Pacheco, 18 June 1989; R. Arana, 21 January 1990).

83. Madre de Dios, Manu, Blanquillo [12 $25^{\prime} 37^{\prime \prime}$, $70^{\circ} 42^{\prime} 17^{\prime \prime} \mathrm{W}, 273 \mathrm{~m}$; S. Solari personal commun.]: Marmosops bishopi (S. Solari, 11 March 1993).

84. Madre de Dios, Quebrada Aguas Calientes, 2.75 km E Shintuya ( $\left[12^{\circ} 41^{\prime} \mathrm{S}, 71^{\circ} 15^{\prime} \mathrm{W}\right.$; Patterson et al., 2006], 450-520 m): Marmosops bishopi (B.D. Patterson, 10 September 1999; S. Solari, 30 August 1999 and 11 September 1999).
85. Madre de Dios, Tambopata, Río La Torre [coordinates not located]: Marmosops bishopi (C. Ascorra, 11 December 1995).

86. Madre de Dios, Tambopata, S.N. Pampas del Heath, P.C. Enahuipa $\left(12^{\circ} 39^{\prime} 45^{\prime \prime} \mathrm{S}, 68^{\circ} 57^{\prime} 30^{\prime \prime} \mathrm{W}\right)$ : Marmosops bishopi (A. Cornejo, 19 June 1996).

87. Pasco, Santa Cruz [10 $37^{\prime} \mathrm{S}, 75^{\circ} 22^{\prime} \mathrm{W}, 2050 \mathrm{~m}$ Cadena et al., 2007], ca. 9 km SSE Oxapampa: Marmosops juninensis (T. Schulenberg, S. Allen, D. Stotz; 24 February 1982).

88. San Martín, Rioja, Pardo Miguel, Naranjos, Caserio El Diamante $\left(5^{\circ} 45^{\prime} 12^{\prime \prime} \mathrm{S}, 77^{\circ} 31^{\prime} 34^{\prime \prime} \mathrm{W}, 1078 \mathrm{~m}\right)$ Marmosops bishopi (P.M. Velazco, 16-17 May 2011).

89. Ucayali, Contamana, Sierra de Contamana, Cerros de Canchaguaya, Aguas Calientes ([07 $11^{\prime} 20^{\prime \prime} \mathrm{S}, 74^{\circ} 56^{\prime} 54^{\prime \prime} \mathrm{W}$; Hurtado et al., 2014] $320 \mathrm{~m}$ ): Marmosops bishopi (U. Paredes, 15-20 November 2000).

\section{SURINAM}

90. Brokopondo, Brownsberg Nature Park, Jeep Trail $\left(4^{\circ} 56^{\prime} \mathrm{N}, 55^{\circ} 12^{\prime} \mathrm{W}, 500 \mathrm{~m}\right)$ : Marmosops parvidens (M.D. Engstrom et al., 13-19 April 2002).

91. Brokopondo, Finisanti $\left[5^{\circ} 08^{\prime} \mathrm{N}, 55^{\circ} 29^{\prime} \mathrm{W}\right.$; Voss, 1991], Saramacca River: Marmosops pinheiroi (P. Hershkovitz, 31 December 1961).

92. Nickerie, Kayser Gebergte Airstrip, E of Zuid River [ca. $3^{\circ} 07^{\prime} \mathrm{N}, 56^{\circ} 27^{\prime} \mathrm{W}$, ca. $278 \mathrm{~m}$; Stephens and Traylor, 1985]: Marmosops parvidens (H.A. Beatty, 30 December 1960).

93. Nickerie, Sipaliwini Airstrip $\left(2^{\circ} 02^{\prime} \mathrm{N}, 56^{\circ} 08^{\prime} \mathrm{W}\right)$ : Marmosops pinheiroi (S.L. Williams, 20 August 1979).

94. Sipaliwini, Bakhuis Transect $9\left(4^{\circ} 29^{\prime} \mathrm{N}, 57^{\circ} 02^{\prime} \mathrm{W}\right.$, $170 \mathrm{~m}$ ): Marmosops pinheiroi (B.K. Lim and S.L. Peters, 3 November 2005).

95. Sipaliwini, Bakhuis Transect $13\left(4^{\circ} 33^{\prime} \mathrm{N}, 57^{\circ} 04^{\prime} \mathrm{W}\right.$, $175 \mathrm{~m}$ ): Marmosops parvidens (B.K. Lim and A.V. Borisenko, 19 January 2006).

\section{TRINIDAD AND TOBAGO}

96. Tobago, near Charlotteville $\left[11^{\circ} 19^{\prime} \mathrm{N}, 60^{\circ} 33^{\prime} \mathrm{W}\right.$; Voss, 1991]: Marmosops carri (M.E. Holden, 18-22 January 1989).

97. Trinidad, Caparo $\left[10^{\circ} 27^{\prime} \mathrm{N}, 61^{\circ} 20^{\prime} \mathrm{W}\right.$; USBGN, 1955]: Marmosops carri (F.M. Chapman, 19 March17 April 1894).

98. Trinidad, Cedros [ca. $10^{\circ} 06^{\prime} \mathrm{N}, 61^{\circ} 48^{\prime} \mathrm{W}$; Goodwin and Greenhall, 1961]: Marmosops carri (Trinidad Regional Virus Laboratory [TRVL] collectors, 7 March 1972). 
99. Trinidad, Cumaca $\left[10^{\circ} 42^{\prime} \mathrm{N}, 61^{\circ} 09^{\prime} \mathrm{W}\right.$; USBGN, 1955]: Marmosops carri (W.G. Downs, 20 July 1954).

100. Trinidad, Sangre Grande, Rio Grande Forest [ca. $10^{\circ} 41^{\prime} \mathrm{N}, 61^{\circ} 01^{\prime} \mathrm{W}, 200 \mathrm{ft}$; see note]: Marmosops carri (W.G. Downs, 21 June-19 July 1956). Note: coordinates estimated from those of Sangre Grande (USBGN, 1955) based on Goodwin and Greenhall's (1961: 296) statement that Rio Grande Forest is ca. 10 airline miles NE Sangre Grande.

101. Trinidad, St. Augustine $\left[10^{\circ} 39^{\prime} \mathrm{N}, 61^{\circ} 24^{\prime} \mathrm{W}\right.$; USBGN, 1955]: Marmosops carri (E. Friend, 2 October 1936).

102. Trinidad, Turure Forest $\left[\mathrm{ca} .10^{\circ} 32^{\prime} \mathrm{N}, 61^{\circ} 07^{\prime} \mathrm{W}\right.$; Goodwin and Greenhall, 1961]: Marmosops carri (TRVL collectors, 1966-1969).

\section{VENEZUELA}

103. Aragua, Rancho Grande $\left[10^{\circ} 21^{\prime} \mathrm{N}, 67^{\circ} 40^{\prime} \mathrm{W}\right.$, ca 1000 m; Handley, 1976]: Marmosops carri (W. Beebe, 29 June 1946; C.O. Handley and D.J. Rhymer, 27-31 March 1960). According to García et al. (2014: 721), Marmosops ojastii has also been taken at this locality.

104. Bolívar, 85 km SSE El Dorado, Km 121 [= "Km $125^{\prime \prime}$ at $6^{\circ} 02^{\prime} \mathrm{N}, 61^{\circ} 22^{\prime} \mathrm{W}, 1032 \mathrm{~m}$; Gardner, 2008]: Marmosops pakaraimae (M.D. Tuttle, 9 May 1966).

105. Bolívar, Auyán-tepui [ca. $5^{\circ} 55^{\prime} \mathrm{N}, 62^{\circ} 32^{\prime} \mathrm{W}$; Paynter, 1982], 460 m: Marmosops pinheiroi (G.H.H. Tate, 9 March 1938). See Voss et al. (2013) for additional information about this locality.

106. Bolivar, Churi-tepui [ca. $5^{\circ} 13^{\prime} \mathrm{N}, 61^{\circ} 54^{\prime} \mathrm{W}$; McDiarmid and Donnelly, 2005], Camp 5 (4900 ft): Marmosops pakaraimae (E. McGuire, 13 January 1953).

107. Carabobo, Cumbre de Valencia [ca. $10^{\circ} 20^{\prime} \mathrm{N}$, $68^{\circ} 00^{\prime} \mathrm{W}, 1700 \mathrm{~m}$; Paynter, 1982]: Marmosops carri (M.A. Carriker, Jr., 20 October 1910).

108. Carabobo, La Copa, 4 km NW Montalbán ([ca. $10^{\circ} 09^{\prime} \mathrm{N}, 68^{\circ} 21^{\prime} \mathrm{W}$; Handley, 1976], $1513 \mathrm{~m}$ ): Marmosops carri (A.L. Tuttle, 2-8 August 1968).

109. Carabobo/Falcón/Yaracuy, 19 km NW Urama [ca. $10^{\circ} 37^{\prime} \mathrm{N}, 68^{\circ} 24^{\prime} \mathrm{W}, 25-60 \mathrm{~m}$; Handley, 1976]: Marmosops ojastii (M.D. Tuttle, 19 October 1965).

110. Distrito Federal, $4 \mathrm{~km} \mathrm{~N}$. Caracas, Los Venados (including locality $5 \mathrm{~km} \mathrm{~N}$. Caracas $\left[10^{\circ} 32^{\prime} \mathrm{N}\right.$, 6654'W; Handley, 1976], 1443-1500 m): Marmosops carri (M.D. Tuttle, 10-11 August 1965).

111. Falcón, near La Pastora (including sublocalities 5 $\mathrm{km} \mathrm{N}$ and $13 \mathrm{~km}$ E Mirimire, and $14 \mathrm{~km}$ ENE Mirimire; $\left.11^{\circ} 12^{\prime} \mathrm{N}, 68^{\circ} 37^{\prime} \mathrm{W}, 122-125 \mathrm{~m}\right)$ : Marmosops fuscatus (Smithsonian Venezuelan Project [SVP] team, 11-16 November 1967).
112. Falcón, Serranía de San Luís, Parque Nacional J.C. Falcón (including sublocalities in Sector Cerro Galícia, $10 \mathrm{~km} \mathrm{~W}$ and $4 \mathrm{~km} \mathrm{~N}$ Cabure $\left[11^{\circ} 11^{\prime} \mathrm{N}\right.$, $69^{\circ} 42^{\prime} \mathrm{W}$, ca. $1300 \mathrm{~m}$; Anderson et al., 2012]; and in Sector Cumbres de Uria, ca. $9 \mathrm{~km} \mathrm{~N}$ Cabure $\left[11^{\circ} 14^{\prime} \mathrm{N}, 6^{\circ} 37^{\prime} \mathrm{W}, 1320-1370 \mathrm{~m}\right.$; Anderson et al., 2012]): Marmosops fuscatus (J. Ochoa-G., 25 April 2006; R.P. Anderson, 12 August 2006).

113. Mérida, La Azulita $\left[8^{\circ} 43^{\prime} \mathrm{N}, 71^{\circ} 27^{\prime} \mathrm{S}, 1135 \mathrm{~m}\right.$ Paynter, 1982]: Marmosops fuscatus (W.H. Osgood and H.B. Conover, 21 April 1920).

114. Mérida, Mérida (including sublocality "Rio Abbaregas" [ca. $8^{\circ} 36^{\prime} \mathrm{N}, 71^{\circ} 08^{\prime} \mathrm{W}$; Paynter, 1982], 1600-1630 m): Marmosops fuscatus (S. Briceño, 1896-1902).

115. Miranda/Vargas, $9.4 \mathrm{~km}$ N Caracas, Hotel Hum-

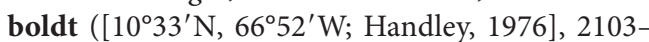
2230 m): Marmosops carri (M.D. Tuttle, 7 August-4 September 1965). Anderson and Gutiérrez (2009: 85) noted that SVP collections labeled "Hotel Humboldt" could have been collected either in the states of Miranda or Vargas contra Handley (1976: 79), who placed this locality on the border between the Distrito Federal and Miranda. One specimen from this locality (USNM 370035) has a recorded elevation of $1281 \mathrm{~m}$, which we assume to be a lapsus for $2181 \mathrm{~m}$.

116. Monagas, San Augustín (including sublocalities "2 $\mathrm{km} \mathrm{N}$ and $4 \mathrm{~km}$ W Caripe" and " $5 \mathrm{~km}$ NW Caripe"; $\left.10^{\circ} 12^{\prime} \mathrm{N}, 63^{\circ} 32^{\prime} \mathrm{W}, 1150-1338 \mathrm{~m}\right)$ : Marmosops carri (Smithsonian Venezuelan Project, 6 July 1967).

117. Trujillo, Hacienda Misisí, 13-14 km E Trujillo ([921' N, 70² $18^{\prime} \mathrm{W}$; Handley, 1976], 2000-2210 m): Marmosops carri (SVP team, 28 January 1966; J.A.W. Kirsch, 21 June 1969).

118. Zulia, Pueblo Nuevo, La Fría $\left[8^{\circ} 55^{\prime} \mathrm{N}, 71^{\circ} 25^{\prime} \mathrm{W}\right.$; DMA, 1993]: Marmosops sp. (H.B. Baker, 13 August 1914). 

